Florida International University

FIU Digital Commons

FIU Electronic Theses and Dissertations

University Graduate School

6-10-2013

\title{
The Relationship between Job Structure, Burnout, and Coping Methods among Public School county Bus Drivers, Bus Aides, Mechanics, and Clerical Workers
}

Monica Restrepo

carasima@hotmail.com

DOI: $10.25148 /$ etd.FI13080507

Follow this and additional works at: https://digitalcommons.fiu.edu/etd

Part of the Cognition and Perception Commons, Educational Leadership Commons, Health $\underline{\text { Psychology Commons, Industrial and Organizational Psychology Commons, and the Other }}$ Education Commons

\section{Recommended Citation}

Restrepo, Monica, "The Relationship between Job Structure, Burnout, and Coping Methods among Public School county Bus Drivers, Bus Aides, Mechanics, and Clerical Workers" (2013). FIU Electronic Theses and Dissertations. 898.

https://digitalcommons.fiu.edu/etd/898 


\title{
FLORIDA INTERNATIONAL UNIVERSITY
}

\author{
Miami, Florida
}

THE RELATIONSHIP BETWEEN JOB STRUCTURE, BURNOUT, AND COPING METHODS AMONG PUBLIC SCHOOL COUNTY BUS DRIVERS, BUS AIDES, MECHANICS, AND CLERICAL WORKERS

A dissertation submitted in partial fulfillment of the requirements for the degree of DOCTOR OF EDUCATION

in

ADULT EDUCATION

AND

HUMAN RESOURCE DEVELOPMENT

by

Monica Restrepo 


\section{To: Dean Delia C. Garcia \\ College of Education}

This dissertation, written by Monica Restrepo, and entitled, The Relationship between Job Structure, Burnout, and Coping Methods among Public School county Bus Drivers, Bus Aides, Mechanics, and Clerical Workers, having been approved in respect to style and intellectual content, is referred to you for judgment.

We have read this dissertation and recommend that it be approved.

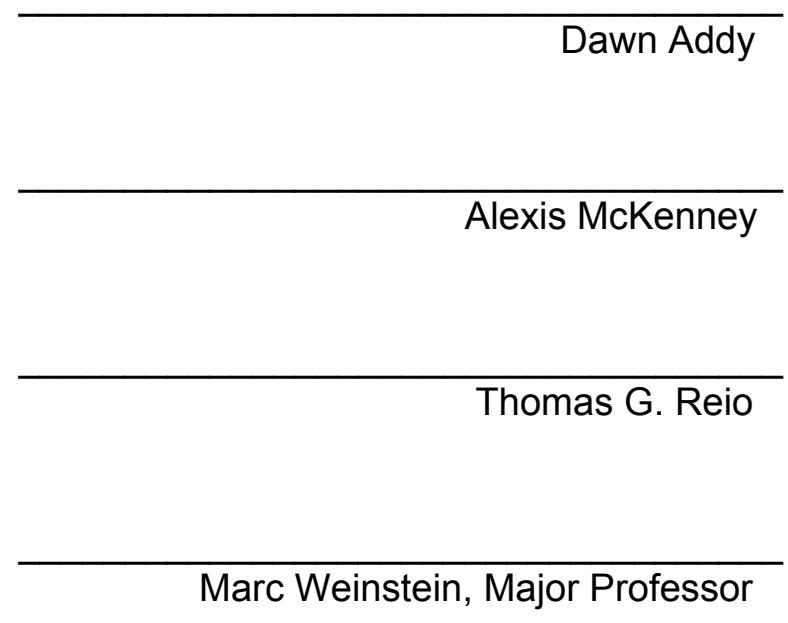

Date of Defense: June 10, 2013

The dissertation of Monica Restrepo is approved.

Dean Delia C. Garcia College of Education

Dean Lakshimi N. Reddi University Graduate School

Florida International University, 2013 
(C) Copyright 2013 by Monica Restrepo

All rights reserved. 


\section{DEDICATION}

To my two daughters, Cara and Sima.

May your roots always be deep and your wingspan infinite. 


\section{ACKNOWLEDGMENTS}

First I would like to thank the county administrators for allowing this study, and the participants for taking the time to fill out the survey. Likewise, I owe gratitude to my assistants and friends who helped me throughout the data collection.

The steadfast support of my dissertation committee made the completion of this project possible. I would like to express deep gratitude to Dr. Marc Weinstein, my major professor and dissertation chair. Your generous, unwavering support and eagerness to provide guidance were invaluable. I am most thankful for your mentorship and sincere wish to see this project to fruition.

I would like to thank Dr. Thomas G. Reio wholeheartedly for the many discussions and guidance you provided without hesitation, not only during this dissertation process, but throughout my graduate studies. You helped me take the next big steps.

To Dr. Dawn Addy and Dr. Alexis McKenney, I extend my humble and sincere appreciation for serving on my committee, giving of your time, and sharing of your intellect. I am profoundly grateful to Dr. Linda Bliss for your genuine sense of service and scholarship. This dissertation has truly been a collaborative effort.

To Oliver, my godson, thank you- unknowingly you have constantly countered my doubts with "because you can".

I am grateful to my two daughters, Cara and Sima for sharing endless study nights, partnering with me throughout this process, and sharing a passion 
for learning. And to my tireless husband, thank you for your endless support and love-- and for walking along beside me all the way to the end. 


\section{ABSTRACT OF THE DISSERTATION \\ THE RELATIONSHIP BETWEEN JOB STRUCTURE, BURNOUT, AND COPING METHODS AMONG PUBLIC SCHOOL COUNTY BUS DRIVERS, BUS AIDES, MECHANICS, AND CLERICAL WORKERS}

\section{by}

Monica Restrepo

Florida International University, 2013

Miami, Florida

Professor Marc Weinstein, Major Professor

The purpose of this study was to examine the relationship between the structure of jobs and burnout, and to assess to what extent, if any this relationship was moderated by individual coping methods. This study was supported by the Karasek's (1998) Job Demand-Control-Support theory of work stress as well as Maslach and Leiter's (1993) theory of burnout. Coping was examined as a moderator based on the conceptualization of Lazarus and Folkman (1984).

Two overall overarching questions framed this study: (a) what is the relationship between job structure, as operationalized by job title, and burnout across different occupations in support services in a large municipal school district? and (b) To what extent do individual differences in coping methods moderate this relationship?

This study was a cross-sectional study of county public school bus drivers, bus aides, mechanics, and clerical workers $(N=253)$ at three bus depot 
locations within the same district using validated survey instruments for data collection. Hypotheses were tested using simultaneous regression analyses.

Findings indicated that there were statistically significant and relevant relationships among the variables of interest; job demands, job control, burnout, and ways of coping. There was a relationship between job title and physical job demands. There was no evidence to support a relationship between job title and psychological demands. Furthermore, there was a relationship between physical demands, emotional exhaustion and personal accomplishment; key indicators of burnout.

Results showed significant correlations between individual ways of coping as a moderator between job structure, operationalized by job title, and individual employee burnout adding empirical evidence to the occupational stress literature. Based on the findings, there are implications for theory, research, and practice. For theory and research, the findings suggest the importance of incorporating transactional models in the study of occupational stress. In the area of practice, the findings highlight the importance of enriching jobs, increasing job control, and providing individual-level training related to stress reduction. 


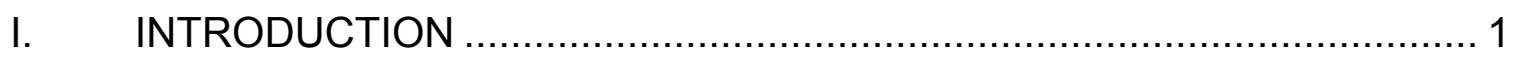

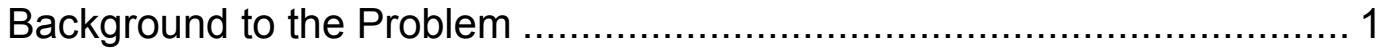

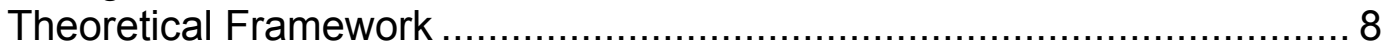

Purpose of the Study ................................................................. 11

Research Questions and Hypotheses................................................. 11

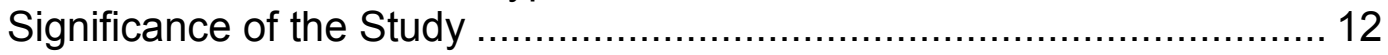

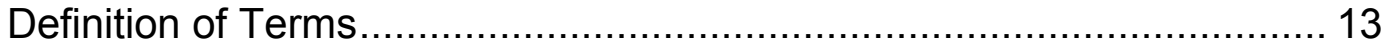

Delimitations

Organization of Study .............................................................. 15

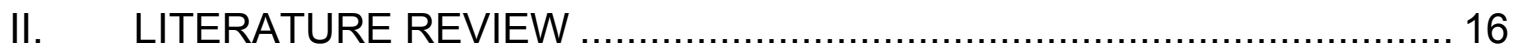

Conceptualizations of Stress ...................................................... 16

Models of Occupational Stress Review.............................................. 18

Person -Environment Fit Model 18

Effort-Reward Imbalance Model ................................................. 22

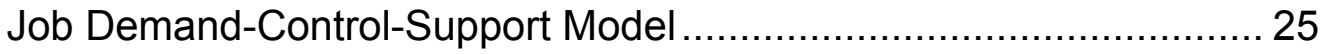

Transactional Model ............................................................. 30

Gender Effects and Occupational Stress....................................... 33

Cultural Background and Occupational Stress ................................... 35

Coping and Occupational Stress ................................................... 38

Conceptualization of Coping ........................................................ 39

Ways of Coping ..................................................................... 40

Outcomes of Occupational Stress .................................................. 43

Cardiovascular and Other Diseases ............................................. 43

High Blood Pressure .................................................................. 45

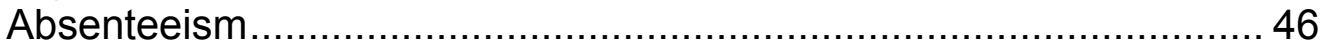

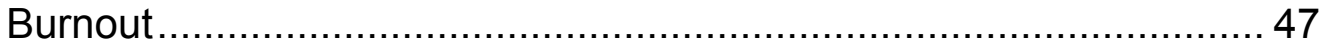

Burnout and Turnover............................................................ 52

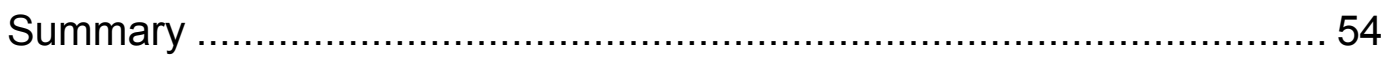

Integrated Proposed Model........................................................... 54

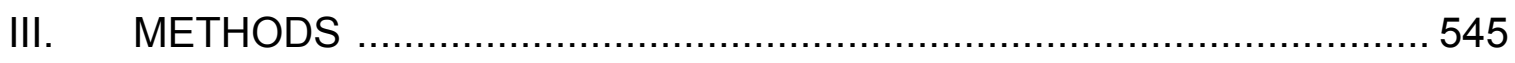

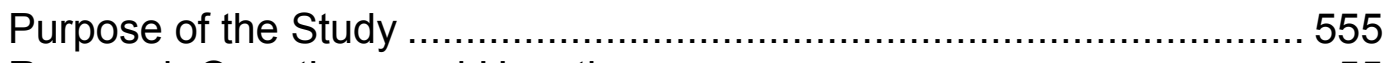

Research Questions and Hypotheses.................................................. 55

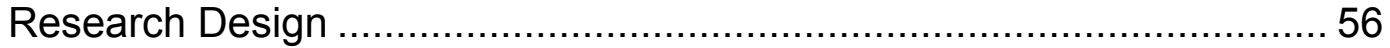

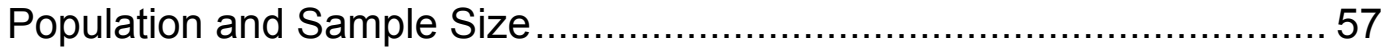

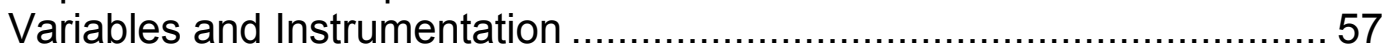

Independent Variables and Measurement Instruments .................... 57

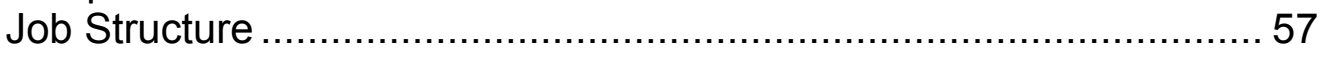

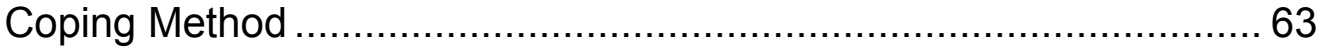




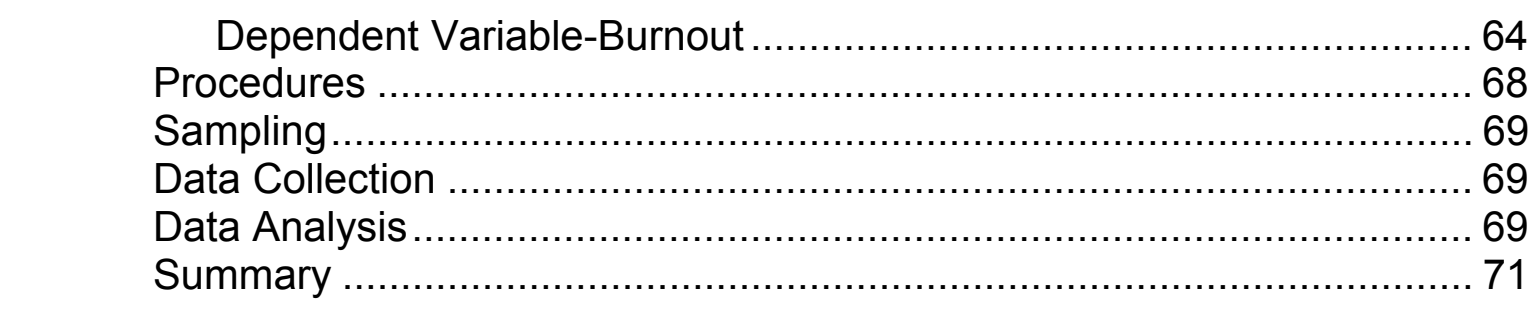

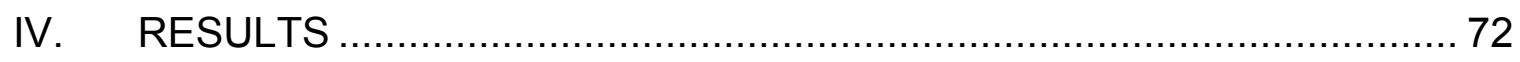

Background of the Sample........................................................... 72

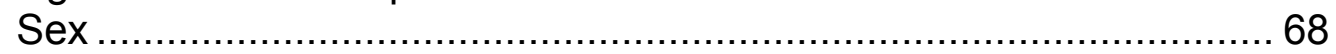

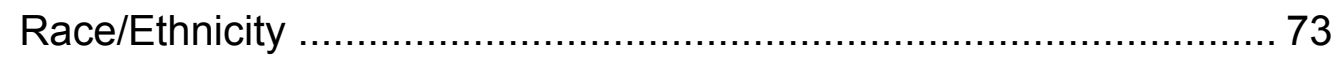

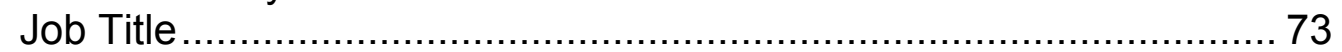

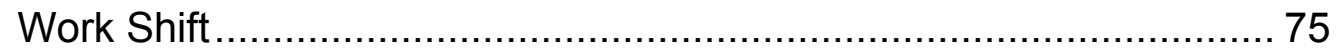

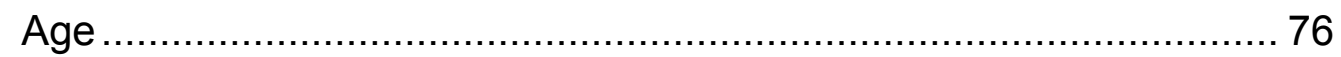

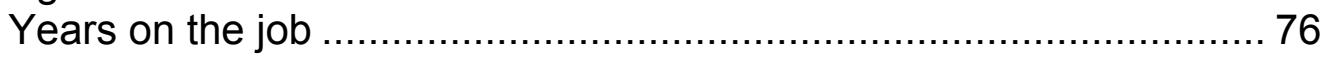

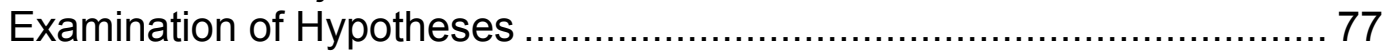

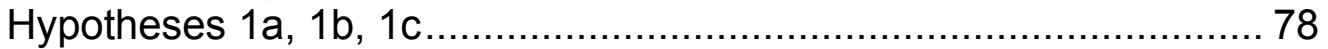

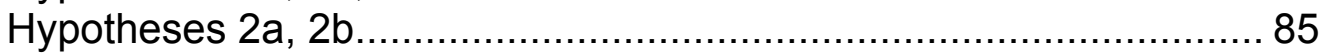

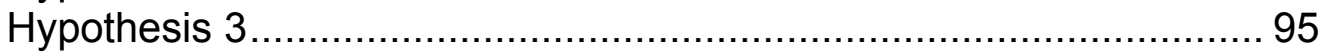

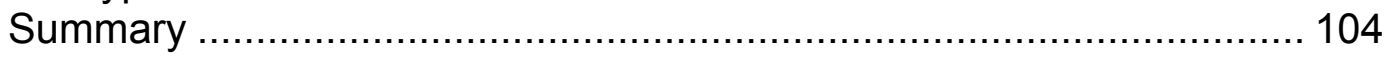

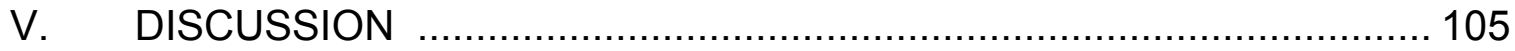

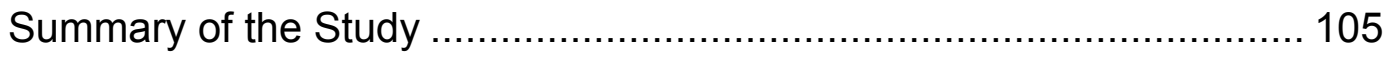

Discussion of the Results................................................................. 106

Hypotheses 1a, 1b, 1c - Job Structure, Demands and Control ........ 107

Hypotheses 2a and 2b - Job Structure and Burnout ...................... 108

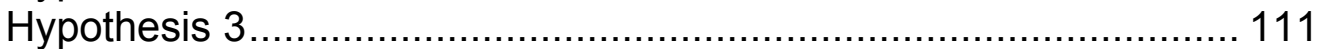

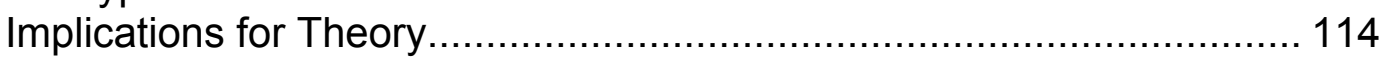

Job Control and Demands ........................................................ 115

Job Structure and Burnout.......................................................... 116

Role of Individual Differences through Coping .............................. 117

Implications for Research ........................................................... 118

Implications for Practice ................................................................. 121

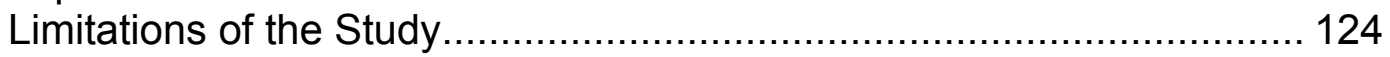

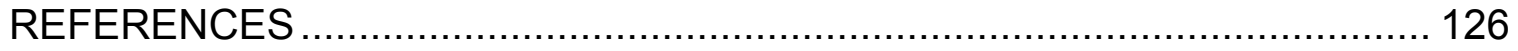

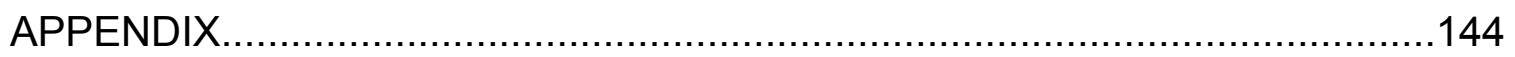

VITA 


\section{LIST OF TABLES}

TABLE

PAGE

1. Frequency Table of Demographic Values..................................................

2. Cross Tabulation of Sex and Race/Ethnicity by Job Title............................74

3. Cross Tabulation of Bus Depot Location by Job Title .................................75

4. Summary of Means of Age and Years on the Job ..................................76

5. Cross Tabulation of Means and Standard Deviations of Job Title by Age and Years on the Job

6. Summary of Means and Standard Deviations of Job Content Questionnaire (JCQ) Scale Scores by Job Title .79

7. Summary of Simultaneous Regression Analysis of Physical Job Demands ..81

8. Summary of Simultanoues Regression Analysis of Psychological Job Demands

9. Summary of Simultaneous Regression Analysis of Decision Latitiude .85

10. Summary of Means and Standard Deviations of Maslach Burnout Inventory (MBI) Scale Scores by Job Title

11. Summary of Simultaneous Regression Analysis of Emotional Exhaustion ..89

12. Summary of Simultaneous Regression Analysis of Depersonalization .90

13. Summary of Simultaneous Regression Analysis of Personal Accomplsihment

14. Summary of Simultaneous Regression Analysis of Relationship between Maslach Burnout Inventory (MBI) Sclaes, Job Content Questionnaire (JCQ)

Scales and Job Title, Bus Depot Location, Gender, and Marital Status

15. Cronbach's Alpha Reliability for Brief COPE Inventory Scales 96

16. Results of Princiapl Component Analysis with Varimax Rotation of Brief COPE Scale 
17. Summary of Linear Regression Analysis of Relationship between Maslach Burnout Inventory Scales (MBI) and New Coping Factors (Problem-solving Coping, Support-Seeking, Escape Coping 


\section{CHAPTER I \\ INTRODUCTION}

This study explores the relationship between job structure, burnout and whether ways of coping have any moderating effect on a sample of public school county transportation workers. This chapter begins with a discussion of the background of the study, theoretical framework, problem statement, and purpose of the study. Next, research questions and hypotheses, significance of the study, and definition of terms are presented. This chapter concludes with limitations and organization of the study.

\section{Background to the Problem}

The nature of work has undergone profound changes in recent decades. Economic factors, technological advances, demographic developments, and economic rationalization have created conditions for an increase in work stress related to work overload, job insecurity, and more competitive demands (Dollard, 2003; Murphy, 2002; Tetrick \& Quick, 2011). Additionally, increase of retirement age (Farrow \& Reynolds, 2012), longer working hours, shift work (Landsbergis et al., 2011), temporary and part-time work, and outsourcing have also placed new levels of stress within organizations and among employees (Koukoulaki, 2010; Papadopoulos, Georgiadou, Papazoglou, \& Michaliou, 2010; Pasca \& Wagner, 2011). Today fewer jobs are defined by physical demands and more are defined by mental and emotional demands (Siegrist et al., 2004). All of these have contributed to more research in the fields of occupational health psychology and occupational safety and health as occupational stress has been linked to 
behavioral, psychological, and physiological outcomes (Landsbergis et al., 2011; Maslach \& Leiter, 1997) such as absenteeism, burnout, and cardiovascular disease.

The Occupational Safety and Health Act of 1970 created both the Occupational Safety and Health Administration (OSHA) and the National Institute for Occupational Safety and Health (NIOSH). OSHA develops and enforces workplace safety and health regulations. $\mathrm{NIOSH}$ focuses on securing safe and healthy working conditions for employees through research, information, education, and training in the field of occupational safety and health. Initially, $\mathrm{NIOSH}$ dealt with exposure to physical or chemical agents in organizations, but job stress issues gradually became more prevalent (Campbell, Nelson, \& Quick, 2001) as information and service jobs replaced manufacturing jobs (Maslach \& Leiter, 1997; Murphy, 2002).

It has been estimated that work related strains like job anxiety and emotional exhaustion have an annual cost of $\$ 300$ billion to organizations (Chapman, 2005). NIOSH (2012) has recently initiated the new Total Worker Health Program, acknowledging that health, safety and general well-being of employees are directly related to the work environment. Although the program is comprehensive, encompassing many issues relevant to total worker health, obesity, cardiovascular disease, high blood pressure and stress are recognized as significant (NIOSH, 2012). Additionally, $\mathrm{NIOSH}$ has emphasized absenteeism as an area of concern for employers because it negatively impacts costs and 
productivity. Thus, work stress affects both the employee and the work organization.

Initially, work stress was described in terms of executive and management positions (Karasek, 1979). At the same time, epidemiologists were studying the distribution and causes of health conditions in populations (Susser, 1973). As researchers probed into job structure, and epidemiologists probed into causes of group health conditions, control emerged as a common factor in work stress analysis. Epidemiologists began to place an emphasis on social patterns and social conditions and the relationship to health in individuals and populations giving rise to the term social epidemiology (Berkman \& Kawachi, 2000). Issues such as social class and worker control became important areas of inquiry. Similarly, work stress theorists began incorporating worker control into their models (Karasek \& Theorell, 1990; Siegrist, 1996). It became evident that workers with less control experienced more job stress (Melchior et al., 2005; Schaufeli \& Bakker, 2004).

Thus, work stress has been shown to be more prevalent in service occupations (Dollard, 2003; Lonne, 2003; Melchior et al., 2005). Although an abundance of occupational stress literature has focused on health related professions or emergency personnel work (Dollard, 2003; Landsbergis, 1988; Wu, Chi, Chen, Wang, \& Jin, 2010), this dissertation focuses on public school transportation workers, a population that has been neglected in the occupational stress literature. Transportation workers have "substantially higher rates of mortality and morbidity in comparison to many other occupational groups" (Evans 
\& Carrère, 1991, p. 658). Public transit drivers need to abide by strict time frames regardless of traffic congestion, having little control over their job. Moreover, urban public bus drivers have shown greater risk for cardiovascular disease (Albright, Winkleby, Ragland, Fisher, \& Syme, 1992).

In a meta-analysis of 27 studies published since the 1950s of occupational health of urban bus drivers (none included public school bus drivers), researchers found important relationships between bus drivers and cardiovascular disease (Tse et al., 2006). One study, which controlled for socioeconomic factors, found double the rate of cardiovascular disease for bus and tram drivers as compared to other occupations (Rosengren, Anderson, \& Wilhelmsen, 1991). Research findings showed that high blood pressure rates were significantly greater for bus drivers in a large urban transit system $(n=$ $1,500)$ even after adjusting for age and race in a comparison to other occupational groups (Ragland et al., 1987). Contradicting these findings, results of a study of 1,396 American bus drivers failed to support a correlation between subjective reports of occupational stress and incidence of high blood pressure (Albright et al., 1992). These inconsistent findings led to exploration of other factors in the stress process. Little was known initially about the specific work stressors because most research regarded transit workers as a homogenous occupational group (Greiner, Krause, Ragland, \& Fisher, 1998).

A demands control perspective, in which high demands and low control predict job strain, was used in the early 1990 s to evaluate bus driver stress (Evans \& Carrère, 1991; Kompier \& di Martino, 1995). In this approach, 
environmental stressors such as traffic congestion, organizational factors such as lack of supervisory support (Greiner et al., 1998) or unrealistic demands such as unviable time schedules to get from one stop to another (Albright et al., 1992) were now being considered. Thus, the occupational stress framework, based on an imbalance of job demands and job control, began to serve as a basis to help define work stressors for bus drivers. For example, an intervention study found that when drivers expressed a greater sense of control, systolic blood pressure, heart rate and self-reported stress all significantly declined (Rydstedt, Johansson, \& Evans, 1988).

Apart from physiological diseases, occupational stress has also been linked to behavioral outcomes, such as absenteeism. Bus drivers have shown remarkably high rates of absenteeism (Evans \& Carrère, 1991). Referring back to NIOSH's new Total Worker Health program, absenteeism was stated to be a major outcome to be considered. Absenteeism rates are usually very high in transit organizations (Kompier \& di Martino, 1995); in the 50 year review of bus driver stress, the authors pointed out that in the U.S., nearly one-fourth of total public transportation operating costs are related to absenteeism (Evans \& Carrère, 1991). In several transit operator studies, absenteeism has been associated with self-reported job stress (Kompier \& di Martino, 1995; Tse et al., 2006). In the U.S., employee absenteeism is estimated to cost US $\$ 225.8$ billion a year in lost productivity (Biron \& Bamberger, 2012; Stewart, Ricci, Chee, Hahn, \& Morganstein, 2003). 
Researchers have also investigated possible mediators and moderators of work stress. Even though the importance of control and specific coping strategies have been established with regards to health outcomes as potential mediators of stress (Evans \& Carrère, 1991; Folkman \& Moskowitz, 2000; Greiner et al., 2004; Kuhlmann, 1990), coping in transit workers has received comparatively less consideration (Chen \& Cunradi, 2008).

Although few in number, studies have shown bus drivers under high stress who got sick more often used more avoidance coping strategies than those who got sick less often (Bartone, 1989). Another study including male public bus drivers $(n=99)$ found that emotional coping strategies were positively correlated to work stress and somatic complaints (Kuhlmann, 1990). In their meta-analysis of bus driver stress research, the authors Tse et al. (2006) concluded that:

Research needs to also concentrate on practical interventions that are systematically implemented and evaluated, to improve the well-being of bus drivers. By improving the "human side" of the role it is expected that the efficiency of transport will be enhanced for bus drivers, operators and passengers alike. (p. 89)

Occupational stress has also been strongly linked to burnout. Burnout is characterized as the feeling of exhaustion, cynicism, and ineffectiveness (Maslach \& Schaufeli, 1993). A study of 1,231 transit operators participated in the San Francisco MUNI Health and Safety Study with results demonstrating a direct association between transit operators' daily work stress and symptoms of burnout even after controlling for coping behaviors (Chen \& Cunradi, 2008). 
Although burnout has not been studied extensively in terms of public transit workers, there can be a strong indirect assumption that bus drivers, who are a stressed population, are at higher risk for developing symptoms of burnout (Tse et al., 2006).

The costs and effects of burnout are considerable for both employees and organizations. Halbesleben and Buckley (2004) reviewed the burnout literature from 1993-2004 and found consistency among outcomes correlated to burnout such as: reduction of job performance, turnover and intent to turnover, and negative physiological symptoms. Employees with a diminished quality of life hinder their potential for a productive, growing career and therefore, become a workforce that can no longer provide efficient dedication, creativity, and productivity (Maslach \& Leiter, 1997).

Burnout leads to turnover, which in effect places a greater burden on the current employees who now have less staff and higher demands- setting the ground for greater stress and burnout and more turnover (Lonne, 2003). Findings of a longitudinal study of 3,985 participants showed a significant association between burnout and future sick leave (Toppinen-Tanner, Ojajarvi, Vaananen, Kalimo, \& Jappinen, 2005). After an analysis of 25 research studies, Barak, Nissly, and Levin (2001) concluded the high turnover rate of professional workers causes a serious challenge to human services organizations. Burnout underscores the relationship between human service workers' self-assessed role stress and the intent to leave their jobs (Kim \& Stoner, 2008). Results of that 
study supported the theory that higher levels burnout contribute to higher likelihood of turnover.

\section{Theoretical Framework}

There have been many theoretical approaches to identifying occupational stress. It has been categorized as a misfit between a worker and the worker's environment, as well as the worker's perceptions of the work environment (House, 1981). Work stressors are typically correlated to work overload (Barak et al., 2001), role ambiguity and perception of low control (Leiter \& Maslach, 1999), and job conditions (Schaufeli \& Bakker, 2004). Occupational stress models deal with job demands that although not necessarily negative, may turn into job stressors when meeting those demands requires high effort and is associated with high costs that trigger negative responses such as depression, anxiety, or burnout (Schaufeli \& Bakker, 2004). Occupational stress models mainly focus on placing the burden on the employer and the structure of jobs, however, this study proposes that a further integration of individual differences, such as coping methods, can actually have an impact on occupational stress and its outcome.

Situationalist models, arguing that environmental characteristics influence job attitudes more than individual differences (Nelson \& Simmons, 2011) have been put forth to identify occupational stress that leads to strain such as encumbering organizations' job designs, demands and workers' perceptions of job control (Karasek, 1979; Maslach, 2001), and imbalanced efforts and rewards (Siegrist, 2002). 
Behaviorist models have targeted distinct worker behaviors, rather than environmental factors, in an effort to bring about beneficial change such as behavior-based safety in industrial jobs (Geller, 2001). Dispositionalists have emphasized a strong relationship between work attitudes and behaviors, and individual attributes (Gerhart, 1987; Nelson \& Sutton, 1990). Interactional models have accentuated the continuous interaction between individual differences and situational characteristics (Schneider, 1987).

As researchers were developing occupational stress models, Leiter and Maslach (1988) were developing theories on job burnout and defining workplace stressors related to burnout (Leiter \& Maslach, 1999; Maslach, 2001), a significant burden on both individuals and organizations. Burnout is an expression created by Freudenberger (1977) to describe physical and psychological distress. Burnout is defined as the feeling of exhaustion, cynicism, and ineffectiveness (Maslach \& Leiter, 1997), characterized as a threedimensional pattern of emotional exhaustion, depersonalization, and reduced personal accomplishment, mostly prevalent in "people-oriented" professions human services, health care, and education (Maslach \&Leiter, 1997, p. 20). The Maslach Burnout Inventory (MBI) is the most widely used measure of burnout utilized by researchers and organizations which evaluates three central dimensions of an individual's experience with the work environment: exhaustionenergy; depersonalization-involvement and inefficacy-accomplishment (Maslach \& Leiter, 1997). Research studies have shown relatively high levels of burnout with a significant correlation with scores on the three MBI subscales, 
depersonalization, emotional exhaustion, and personal accomplishment (Losa Iglesias, Vallejo, \& Fuentes, 2010).

As much as occupational stress models can help define particular work stressors and impacting consequences of work stress, there also needs to be an emphasis on the role of individual differences. Variation in people's capabilities to cognitively process their emotions distinguishes how some handle their emotions in response to stressful situations (Mayer, Salovey, \& Caruso, 2000). Although Lazarus' interactive transactional model has not been extensively researched in the work place context (Folkman, Lazarus, Gruen, \& DeLongis, 1986; Ganster \& Perrewé, 2011), it has illustrated the role individual differences play "as mediators of stress appraisal and moderators of the stress-outcome relationship" (Cox \& Ferguson, 1991, p. 11) in providing a valuable framework for the evaluation of appraisal and coping.

Schneider (1987) believed that people's traits, not the environment or organizational structure, were the primary determinants of organizational behavior. Personality theorists have a propensity to analyze individual characteristics as mediators that predict when the stress reaction will occur (Wofford \& Daly, 1997, p. 135). Cognitive theorists use experience as a modifier of the cognition process and its consequent impact on stress (Wofford \& Daly, 1997). Lazarus (1993) provided a foundation for coping theory by defining the process as "ongoing cognitive and behavioral efforts to manage specific external and/or internal demands that are appraised as taxing or exceeding the resources of the person" (p. 237). Problem and emotion-focused coping emerged as two 
major functions of coping (Lazarus, 1993) which have since been researched extensively.

\section{Purpose of the Study}

The purpose of this study is to examine the relationship between the structure of jobs and burnout and to assess to what extent, if any, this relationship is moderated by individual coping methods.

\section{Research Questions and Hypotheses}

This study is framed by two overarching questions: (a) what is the relationship between job structure, as operationalized by job title, and burnout across different occupations in support services in a large municipal school district? and (b) to what extent do individual coping methods moderate this relationship? Specifically, the following hypotheses will be tested:

$H_{1 a:}$ Different occupational categories of employees in the same workplace have different levels of physical demands.

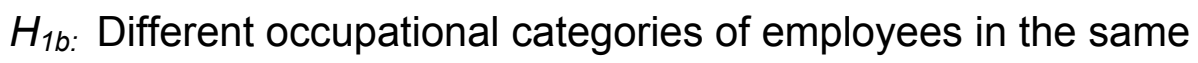
workplace have different levels of psychological demands.

$H_{1 c:}$ Different occupational categories of employees in the same workplace employees have different levels of job control.

$H_{2 a:}$ Occupations characterized by greater levels of physical demands and lower levels of job control have greater levels of individual employee burnout.

$H_{2 b \text { : }}$ Occupations characterized by greater levels of psychological demands and lower levels of job control have greater levels of individual employee burnout. 
$H_{3}$ : Individual differences in coping act as a moderator between job structure, operationalized by job title, and individual employee burnout.

\section{Significance of the Study}

The Occupational Health and Safety Act, along with NIOSH's new Total Worker Health program, have given the field of occupational health a new perspective for exploring ways to deal more effectively with work stress in order to help alleviate the negative outcomes. Empirical evidence has shown that job stress is strongly correlated with physical health diseases, such as cardiovascular disease, high blood pressure, (Landsbergis et al., 2011; Schnall \& Landsbergis, 1994) and even obesity (Rosengren et al., 1991). Similarly, there is strong empirical support for the idea that work stress is positively related to behavioral outcomes such as absenteeism, which has grave economic impact on organizations. Job strain, as measured by demands and control has proven to be directly related to burnout. Effects of burnout, apart from financial costs to the organization, also have impacted costs on insurance companies as well as the individual.

The Affordable Care Act (ACA) passed in 2010, symbolizes the most significant changes to the United States' health care system since the 1965 formation of the Medicare and Medicaid programs and is to provide insurance coverage for an added 32 million previously uninsured Americans (The National Academis Press, 2011). A change of this magnitude impacts health care recipients, as well as health care providers, namely employers. Findings from this research may well serve large and small employers in maximizing training 
initiatives in an effort to not only to promote employee health, but also to help lower medical costs.

This study was conducted to explore whether ways of coping may help to moderate the effects of job strain, thus alleviating or even preventing negative outcomes. More specifically, this study examined this relationship among municipal public school county bus drivers, bus aides, mechanics and clerical workers. Findings provided new information for interventions to enable ways of coping that may help reduce risks for this occupational group (Chen \& Cunradi, 2008) and help to ensure children are transported safely. Human resource departments could include such interventions as coaching in coping methods.

Although research in job stress has been prominent, there is a lack of operationalization of results into concrete action programs (Chen \& Cunradi, 2008; Tse et al., 2006). In addition, by using theoretical elements from the JDCS model, the transactional model and ways of coping, this study provided additional empirical evidence on the subject.

\section{Definition of Terms}

Absenteeism. This term is defined as an employee absence from scheduled work (Johns, 2008). Common measures of absenteeism are recordsbased or self-report indicators of number or rate of single day absences, frequency, and time lost (Chadwick-Jones, Nicholson, \& Brown, 1982).

Burnout. Freudenberger (1977) used this phrase to describe physical and psychological distress. Burnout is defined as the feeling of exhaustion, cynicism, and ineffectiveness (Maslach \& Leiter, 1997). Characterization includes 
a three-dimensional pattern of emotional exhaustion, depersonalization, and reduced personal accomplishment, mostly prevalent in "people-oriented" professions - human services, health care, and education (Maslach \& Leiter, 1997, p. 20). It is most commonly measured using the Maslach Burnout Inventory (MBI) (Maslach \& Jackson, 1981).

Coping. This described the process of cognitive and behavioral efforts used to react or respond to a given stimulation where demands are regarded as exceeding individual resources (Lazarus (1993).

Coping strategies. Although there is no consensus on coping strategies in the literature, for purposes of this study, coping strategies are based on Carver's (1997) Brief COPE scale.

Job strain. This describes a negative affective state when job demand is high and job latitude is low (Karasek, 1979).

Job structure. This term was used in this dissertation to describe the characteristics of a job title based on the job demands and control model by Karasek et al. (1998). Job structure was operationalized by job title in this study.

Occupational stress. This phrase described work stress when there is an imbalance between demands, control and support within a work environment (Karasek et al., 1998).

Stress. This term referred to the non-specific reaction to any demand (Seyle, 1975). Seyle delineated the phases of the stress process to go from an alarmed response to the situation, to resistance to the stressor, to exhaustion. 


\section{Delimitations}

This study was conducted at three bus depots in a large municipal county. Participation in this study is delimited to currently employed Bus Drivers, Bus Aides, Mechanics, and Clerical Workers. Results of this study are generalizable to currently employed Bus Drivers, Bus Aides, Mechanics, and Clerical Workers at all eight bus depots in this large municipal county as the sample is similar to the population of current transportation employees in these four job titles at the county bus depots.

\section{Organization of Study}

This chapter presented the background of the study, theoretical framework, problem statement, and purpose of the study. The research questions and hypotheses, significance of the study, and definition of terms were also discussed. Chapter 2 provides a comprehensive literature review that supports this dissertation study. Chapter 3 illustrates the methods to be used in this study. Chapter 4 presents the results of the data collection and analysis. Chapter 5 discusses these results and provides implications for further research, theory, and practice. 


\section{CHAPTER II}

\section{LITERATURE REVIEW}

As noted in the introduction, NIOSH's new Total Worker Health program acknowledges the role of stress in total worker health. This initiative resonates with researchers and practitioners because "stress" is part of the human condition and nearly everyone can relate at one time to how stress in their own life may have contributed to unhealthy habits or the onset of a common cold or illness. For researchers, however, the universality of stress poses a specific challenge since the common understanding of stress among the general population varies widely. Moreover, in the academic literature the term stress has been conceptualized as the independent variable, the dependent variable, and even as a process itself (Cooper, Dewe, \& O'Driscoll, 2001) and researchers have put forth varying conceptualizations of stress.

This chapter reviews the definition of stress in the academic literature and then reviews the theoretical bases of occupational stress using empirical studies of the outcomes of occupational stress and coping. In addition, a brief review of the effects of gender and culture is also presented. The chapter concludes with a presentation of an approach to occupational stress that integrates psychological, behavioral and environmental perspectives of occupational stress that have often been treated independently of one another.

\section{Conceptualizations of Stress}

Seyle (1975) delineated stress as the non-specific reaction to any demand. According to Seyle, the phases of the stress process develop from an alarmed 
response to the situation, to resistance to the stressor, and to exhaustion.

Psychological stress represents a particular relationship between the person and the environment that is considered by the person as "taxing or exceeding his or her resources and endangering his or her well-being" (Lazarus \& Folkman, 1984, p. 19). Stressors can be characterized as the distinctiveness of the tasks, relationships with co-workers, the organization as a whole, or the nature of the demands that the organization or other people lay on the person (Beehr, Glaser, Canali, \& Wallwey, 2001).

Initial stress research proposed homeostasis as the explanation of how the body responds to environmental demands (Cannon, 1932). Homeostasis is defined as the process by which the body maintains stability through physical means (Ganster \& Perrewé, 2011). However, the concept of allostasis filled the gap between how the body responds to environmental triggers and how a person will respond to perceived and anticipated demands (Ganster \& Perrewé, 2011). Allostasis can thus be defined as "the process of adjustment of various effector systems (cardiovascular, neuroendocrine, and others) to cope with real or imagined challenges to homeostatic systems (Ganster \& Perrewé, 2011, p. 39).

Cannon (1932) proposed that low levels of stressors could be tolerated but cautioned that prolonged stressors resulted in biological break-down. Strain refers to the response to the stress condition that can have long term outcomes (Sauter, Murphy, \& Jurrell, 1990). Responses may be psychological and expressed as negative emotions, or physiological which trigger the autonomic nervous system and immune reactions (Siegrist, 2001). Strains describe the 
worker's psychological and physiological reactions to demands (Hurrell et al., 1998). Although not all stress is detrimental, the academic literature has focused on the negative effects. Furthermore, within the realm of occupational stress, theories have also focused predominantly on the negative effects of stressors (Meurs \& Perrewé, 2011). Characteristics of the work setting that cause strains and poor individual psychological health are defined as occupational stressors for the individual (Beehr et al., 2001; Seyle, 1975). Definitions of stress, although within varied frameworks, do have an underlying commonality that it involves a string of events that includes: (a) the existence of a demand, (b) an individual perception after initial appraisal that the stressor exceeds individual resources, and; (c) an individual response that usually affects the well-being of the individual (Cooper et al., 2001, p. 16).

\section{Models of Occupational Stress Review}

Although an abundance of occupational stress models and frameworks have evolved since the 1960's, four models have been most prevalent in the literature: (a) the person-environment (P-E) fit theory ; (b) the effort-reward imbalance model; (c) the job demand-control-support (JDCS) model, and; (d) the transactional model (Ganster \& Perrewé, 2011; Karasek, 1979; Vandenberg, Kyoung-Ok, DeJoy, Wilson, \& Griffin-Blake, 2002).

\section{Person-Environment Fit Model}

The P-E fit model approach refers to stress as an outcome of a mismatch between the worker's needs and the worker's job environment (Caplan, 1987; Vandenberg et al., 2002). Although the mismatch is based on the gap between 
environmental objective demands and supplies, and the worker's objective needs and abilities, stress results from the worker's perceptions of his/her actual abilities and needs as compared to the worker's perceptions of environmental demand (Vandenberg et al., 2002). Additionally, value incongruence between the worker values and organizational values leads to cognitive dissonance and frustration (Cable \& Edwards, 2004; O'Reilly III, Chatman, \& Caldwell, 1991). The reaction to the perceived discrepancy, as well as the extent of the discrepancy can lead to strain. There are two distinct versions of P-E fit. One involves the fit between the environmental supplies and personal values (S-V), and the other between a worker's demands and abilities (D-A) (Caplan, 1987). A key element, the "assessment of the $\mathrm{P}$ and $\mathrm{E}$ components along commensurate dimensions" (Caplan, 1987, p. 249) is also the most criticized (Ahmad, 2010; Edwards \& Cooper, 1990; Kristof-Brown, Zimmerman, \& Johnson, 2005).

To provide better indicators to describe the mismatch, Muchinsky and Monahan (1987) suggested further conceptualization of the model recommending supplementary and complementary congruence. Supplementary congruence describes the match between a person and the environment using variables such as individual satisfaction and performance as indicators of fit and can occur when there is a value congruence between the employee and the environment or organization (Muchinsky \& Monahan, 1987). Supplementary fit is based upon the theoretical framework of human values that postulate 10 separate kinds of values that diverse cultures and societies can relate to power, 
achievement, hedonism, stimulation, self-direction, universalism, benevolence, tradition, conformity, and security (Schwartz, 1992). Although there are 10 distinct values, it is the interaction and dynamic between them that is key, forming a circumplex value model. This circumplex model places the 10 distinct values on the circumference of a circle where the strength of the relationship between variables decreases as the distance between variables on the circle increases (Schwartz \& Boehnke, 2004). To test this value model, Schwartz and Boehnke (2004) used a confirmatory factor analysis to analyze data from two sets of 23 samples from 27 countries $(N=10,857)$. Results showed a significant continuum based on a "quasi-circumplex structure" and confirmed the basic 10 values (Schwartz \& Boehnke, 2004). Complementary congruence describes the match between how a person's abilities complement the needs of the work environments (Muchinsky \& Monahan, 1987), or as Cable and Edwards (2004) stated, it "can mean that an employee has a skill set that an organization requires, or it can mean that an organization offers the rewards that an individual wants" (p. 822). Complementary fit encompasses psychological needs based on need-fulfillment theory.

A study of 963 water treatment employees of diverse job types and backgrounds, evaluated 3 conceptual models of supplementary and complementary person environment fit: employee relationship, social identity and simultaneous effects model (Cable \& Edwards, 2004). The employee relationship model emphasized worker values based on aspirations and organizational rewards as theorized by Kristof (1996). The social identity model 
highlighted how people use social categories to classify themselves (Ashforth \& Mael, 1989). In that study, the social category was the organization. The simultaneous effects model was premised on the assumption that psychological needs fulfillment and value congruence are distinct and each acts as a separate predictor (Cable \& Edwards, 2004).

To evaluate psychological needs-fulfillment and value congruence, Cable and Edwards (2004) drew from Schwartz's (1992) established human basic values and created the 24-item Work Values Survey identifying eight central work values: altruism, relationships, pay, security, authority, prestige, variety, and autonomy (Cable \& Edwards, 2004, p. 825). Participants were asked to assess each item from four different perspectives: 1) psychological needs; 2) organizational supplies; 3 ) individual values, and 4) organizational values. In addition, three outcomes of psychological needs fulfillment and value congruence were examined: intent to stay, job satisfaction, and organizational identification (Cable \& Edwards, 2004). Results showed that psychological needs fulfillment and value congruence are both strong predictors of employee attitudes in a work environment (Cable \& Edwards, 2004), each with equal footing (p. 830).

There are significant limitations found in the literature of the P-E fit model. After a meta-analysis of 46 studies of various conceptualizations on the P-E fit literature, Kristof-Brown et al. (2005) described a lack of research on validating multidimensional approaches" (p. 320) of P-E fit, as well as a need to include personal and situational attributes. Moreover, Edwards and Cooper (1990) criticized the use of the two types of fit as interchangeable predictors to the 
identical psychological, physiological, and behavioral set of outcomes. In addition, researchers have noted the lack of measuring for control in the P-E fit model (Landsbergis, 1988) as a limitation because control is an important characteristic in psychosocial and physiological stress research (Caplan, 1987; Landsbergis, 1988; Vandenberg et al., 2002).

\section{Effort-Reward Imbalance Model}

While the P-E model is focused on the mismatch between a person's needs and the environment, as well as value congruence, Siegrist, Siegrist, and Weber (1986) developed an occupational stress model based on the mismatch of efforts and rewards within a psychosocial framework to help predict physiological outcomes. The effort-reward model is principally correlated with stressful physiological conditions (Bakker, Killmer, Siegrist, \& Schaufeli, 2000) resulting from the imbalance between efforts and rewards. The psychosocial framework is founded on the cognitive theory of emotion (Lazarus \& Folkman, 1984; Schachter \& Singer, 1962). A review of Schacter's cognitive theory of emotion concurred that an interaction between physiological stimulation and cognition, or emotional appraisal, of the stimulation situation needs to be present for an emotional state to occur (Reisenzein, 1983). One component cannot exist without the other; without cognition, the individual cannot process which emotion will be felt in response to the arousal. And although critics have cited a deficiency in clarification about appraisal and cognition (Reisenzein, 1983; Zajonc, 1980), one common accepted definition has been found in the review of the literature: 
Cognitive activity is a necessary precondition of emotion because to experience an emotion, people must comprehend-whether in the form of a primitive evaluative perception or a highly differentiated symbolic process-that their well-being is implicated in a transaction, for better or worse. (R. S. Lazarus, 1984, p. 124)

Tailored to the work environment specifically, the ERI model proposes that workers expect certain rewards for certain efforts and that when the expectation is not met, inequity produces strain that leads to poor health outcomes (Ganster \& Perrewé, 2011). The effort-reward imbalance (ERI) asserts a "lack of reciprocity" between high costs (efforts) and low gains (rewards) in the work environment, which generates prolonged strain responses at the psychosocial level (Siegrist, 2001, p. 54). Continued high costs or efforts arise from circumstances related to a lack of additional employment choices within the labor market, the notion of accepting a current unreasonable work environment in exchange for a promotion in the future, and the constant striving to cope with higher demands to obtain greater rewards (Siegrist, 2001). Rewards are classified by money, esteem and recognition, and career opportunities including job security (Siegrist et al., 2010).

An important distinction of the ERI model has been the emphasis between extrinsic and intrinsic components (De Jonge, Bosma, Peter, \& Siegrist, 2000). Extrinsic components refer to situational efforts such as job demands (both psychological and physical) as well as situational rewards such as money, esteem and job security (De Jonge et al., 2000). The intrinsic component is 
specified as overcommitment, a personality trait where excessive goals exist along with the need for approval (van Vegchel, de Jonge, Bosma, \& Schaufeli, 2005). Overcommitted individuals amplify efforts which most likely lead to a diminished sense of reward (van Vegchel et al., 2005). Therefore, the ERI model can be used to predict that high efforts with low rewards or high overcommitment with low rewards leads to poor health (Siegrist, 2002; van Vegchel et al., 2005). In addition, the combination of high efforts, low rewards and high overcommitment may predict the greatest threat to health (Siegrist, 2002; van Vegchel et al., 2005).

The most commonly used measurement of the ERI model has been the ERI Questionnaire (ERI-Q; Siegrist \& Peter, 1996) which contains three separate scales to measure effort, rewards, and overcommitment using 23 Likert-scaled items. The effort scale consists of six items rated on a 5-point scale, the reward scale contains 11 items also rated on a 5-point Likert scale, and overcommitment contains six items rated on a 4-point Likert scale. "I have constant time pressure due to a heavy work load" is an example of an effort scale item; "My job promotion prospects are poor", an example of rewards scale; and "'Work rarely lets me go, it is still on my mind when I go to bed", an example of overcommitment item (Siegrist \& Peter, 1996).

Limitations of the effort-reward imbalance model refer to a lack of clarification of the three reward dimensions (Siegrist, 2001) and how each relates to specific efforts. In addition, moderators such as overcommitment have not been clearly defined (van Vegchel et al., 2005). Van Vegchel et al. (2005) 
suggested that more longitudinal studies are needed to show "time lags" between effort and rewards, since most studies have been cross-sectional ( $p$. 1128). This would allow a better determination of causal relationships between efforts, rewards and overcommitment. Ganster and Perrewé (2011) pointed out the need for more objective emphasis on the work environment of the ERI model in order to better determine whether the work environment or the individuals' perceptions of the work environment is the cause for imbalance. Finally, although worker control has been shown in numerous studies to have a significant effect on occupational stress (Karasek, 1979; Landsbergis, 1988; Schaufeli \& Bakker, 2004), the ERI model does not include control as a variable.

\section{Job Demand-Control-Support Model}

Stressors and strain are features of both physiological and psychological aspects. Workers' influence or control over the environment is an issue of critical importance in psychological and physiological research on stress (Vandenberg et al., 2002). Karasek (1979) created a two-dimensional approach to occupational stress including demand and control. High levels of demand combined with very low control can lead to great levels of occupational stress, and in turn to high levels of occupational strain. Building upon research on social support effects in worker environments (House, 1981; Johnson \& Hall, 1988; Vandenberg et al., 2002), Karasek included a third dimension, social support. The job demandcontrol-support model (JDCS) proposes high demands, low control, and low social support are conducive to worker strain. The emphasis of this model lies upon structural, organizational facets of the work setting (Karasek, 1979). Job 
demands refer to workers' perceptions of the tasks needed to perform the job (Karasek, 1979) and the mental preparedness to perform the task (Beehr et al., 2001). Three types of job demands are described as time demands, monitoring demands, and problem-solving demands (Beehr et al., 2001). Job control refers to the decision latitude, or workers' perceptions of the amount of power they have over job demands. Decision latitude entails the possible control workers have over their tasks as far as their decision-making authority and intellectual abilities or skill discretion to perform the tasks (Karasek \& Theorell, 1990). Social support is identified by workers' perceptions of amount of managerial and co-worker support. Social support functions as a buffer against the different levels of high demands and low decision latitude (Theorell, 1999).

The JDCS model measures levels of stressors, not stress itself. Stress is seen as a catalyst, many times a positive one, which triggers higher states of arousal in order to comply with demands (Karasek, 1979). Karasek and Theorell (1990) identified four quadrants within the model: high strain, low strain, active, and passive jobs. High strain professions, such as nurses, social workers, waiters, or assemblers, experience high demands, low control, and low social support (Dollard, 2003). In turn, low strain jobs have low demands, but high decision latitude. High-level executives and professionals, who have high demands but also high decision latitude, are classified as having active jobs. Passive jobs have low demands and low control. Johnson et al. (1989) stated the combination of high demands, low decision latitude and low support is most detrimental and may lead to the most severe health problems. Social support 
has also been examined within occupational stress research (Karasek \& Theorell, 1990; Leiter \& Maslach, 1999; Winnubst, 1993). In a study of 13,779 participants, Johnson and Hall (1988) provided empirical evidence where workrelated social support emerged to deepen the impact of job strain. Workers with the lowest levels of social support had higher incidence of job strain.

Van der Doef and Maes (1999) performed a comprehensive literature review of 20 years (1979-1997) of demand-control-support empirical research. Findings from the meta-analysis of 63 studies showed strong support for the strain hypothesis, which states that the most negative psychological well being is found in employees working in high demands and low control jobs. The majority of the studies showed employees working in high demands, low control, and low support jobs experienced the highest strain levels (Van der Doef \& Maes, 1999). Extending this review, Hausser, Mojzischa, Niesela, and Schulz-Hardta (2010) examined 83 studies of the JDCS model published between 1998-2007 and concluded that additive effects of the three major components were supported when the sample size was adequate. Using the data from the Whitewall II studies, phases 1-3, Stansfeld, Fuhrer, Shipley, and Marmot (1999) showed that lack of support from co-workers and supervisors, and lack of clear direction from supervisors, were associated with increased risk of psychiatric disorders. Conversely, Stansfeld et al. (1999) suggested that because employees in the Whitehall II study were civil servants and higher demands are often found in higher levels of employment, there was no significant job strain based on the interaction of job demands and decision authority (p. 306). Hierarchical 
regression analyses demonstrated that high job demands, low skill discretion, and low social support from superiors were the most constant predictors of occupational strain across samples in a study of 609 Italian and 873 Dutch nurses (Pisanti et al., 2011). Results indicated the best predicted effects were job satisfaction $\left(R^{2}=.38\right)$, emotional exhaustion $\left(R^{2}=.39\right)$, and psychosomatic symptoms $\left(R^{2}=.45\right)$.

Only a small number of longitudinal studies included in the meta-analysis by Van der Doef and Maes (1999) supported the demand/control interaction (Van der Doef \& Maes, 1999). Further, Hausser et al. (2010) pointed out that although there was strong evidence for additive effects in cross-sectional studies, the findings of longitudinal studies were less conclusive. However, there have been by far many more empirical cross-sectional studies than longitudinal studies using the JDCS model (De Jonge, van Vegchel, Shimazu, Schaufeli, \& Dormann, 2010). A meta-analysis of longitudinal studies revealed that 8 of the 19 (42\%) high-quality studies supported the strain hypothesis of the JDCS model (de Lange, Taris, Kompier, Houtman, \& Bongers, 2003). In conclusion, 16 studies (84\%) confirmed normal causal effects of job demands, job control, and/or social support on different sorts of outcomes (de Lange et al., 2003).

The Job Content Questionnaire (JCQ) has been noted to be the most widely used job-stress assessment measure to predict job strain that can lead to burnout and physiological and psychological disorders (Hurrell et al., 1998; Karasek et al., 1998). The JCQ is a 49-item, self-administered questionnaire that measures social and psychological characteristics of jobs. Theoretically, the JCQ 
acknowledges that employee behavior is, to a considerable degree, caused by the social work setting (Karasek et al., 1998). The five scales (a) decision latitude, (b) psychological demands, and (c) social support (d) physical demands, and (e) job insecurity are used to assess the effects of high demand, low control and, low support on predicting job strain in workers (Karasek et al., 1998).

The decision latitude scale is comprised of subscales with questions assessing skill discretion, decision authority, skill underutilization, employee influence on organizational issues, union and work-group participation (Karasek et al., 1998, p. 324). Examining skill discretion allows a comparison of job skills required and an employee's permissible ability to decide which skills to use to perform the job. Decision authority refers to the liberty an employee has in making decisions about work (Pelfrene et al., 2001). An individual's perception of work load or role ambiguity represents psychological demands. The outcome of the decision latitude and psychological demands scales places the individual within a quadrant of Karasek's active (high demand, high control), passive (low demand, low control), high strain (high demand, low control), and low strain (low demand, high control) model. An additional indicator of high strain is measured with the social support subscale which evaluates supervisor and co-worker support/non-support. Physical demands and job insecurity incorporate two remaining elements found to be indicative of work stress. Physical overload combined with mental overload has been found to be indicative or work stress. Job insecurity deals with an employee's perception of future career opportunities and job security. 
In Brazil, with a random sample of 1311 formal and informal working residents, de Araujo and Karasek (2008) found a strong consistency between social support, skill discretion, decision authority and physical demand and the JDCS model. A review of 36 studies examining cardiovascular disease or mortality, over two thirds affirmed a positive relationship with job strain (Schnall \& Landsbergis, 1994). While a significant number of studies have supported the contention that high demands and low support, acting independently, are predictors of job strain, critics have posited that there is a lack of strong evidence of the effect of the interaction of job demands and control as adequate predictors (Beehr et al., 2001; De Jonge \& Kompier, 1997; Ganster \& Perrewé, 2011; Taris, 2006). Whereas the strong point of the JDCS Model has been the interactive effect of three characteristics of the work environment (De Jonge et al., 2010), it has also been a weak point in that the concepts of control and demands are too broad (Ganster \& Perrewé, 2011). Finally, there is question as to whether control and demands alone can be isolated as the primary stressors without taking into account the effects of individual differences (De Jonge \& Kompier, 1997; Ganster \& Perrewé, 2011).

\section{Transactional Model}

This chapter has thus far examined occupational stress from environmental, psychosocial, and physiological perspectives operationalized by the P-E fit, ERI and JDCS approaches. However, although the transactional model proposed by Lazarus and Folkman (1984) also depicts the interactive process between the person and the environment, the difference lies in that it is 
based on the cognitive theory of psychological stress (Folkman et al., 1986; Lazarus, 1995). Stress is not solely created by the individual or the environment, but rather by the relationship between the two (Ganster \& Perrewé, 2011; Lazarus, 1999). Furthermore, environmental circumstances, or stressors, are not regarded as the origin for a stress response (Webster, Beehr, \& Love, 2011); it is the appraisal of the stressor that triggers a stress response. Lazarus (1995) stated:

In my opinion, we must get away from solely normative studies that tell us about the work environment or person variables as separate causal antecedents of stress and distress, and apply the principles of transaction, process, appraisal and coping, both in the conduct of research and in stress management. (p.12)

Therefore the key premise of Lazarus and Folkman's transactional model is that primary appraisal, secondary appraisal and coping strategies mediate the relationship between stressor and the individual's stress outcomes (Goh, Sawang, \& Oei, 2012; Lazarus, 1999). The transactional model also proposes that a discrepancy between environmental demands and individual coping with these demands generates strain (Meurs \& Perrewé, 2011).

Interactional descriptions of stress have focused on the structural characteristics of the interaction between person and environment, whereas transactional definitions lean heavily on the "dynamics of the psychological mechanisms of cognitive appraisal and coping that underpin a stressful encounter" (Cooper et al., 2001, p. 12). Furthermore, stress is additionally 
characterized as a dynamic cognitive state (Cooper et al., 2001). Dewe (1997) argued that although stressors and effects of stressors are important, it is imperative to include individual methods of appraisal and coping as well. Within the transactional framework, the process of appraisal is the connection between the individual and environmental processes (Cooper, Dewe, \& O'Driscoll, 2011).

Cooper et al. (2001) highlighted three significant themes of the transactional model as: a) a dynamic cognitive state; b) a dissonance or imbalance in customary functioning; and, c) the management of that dissonance or imbalance (p.12). Moreover, additional features such as environmental factors and individual differences play a role in defining the stress process (Cooper et al., 2001).

Ganster and Perrewé (2011) explained that in the transactional model, there is a process of a first appraisal of a perceived threat or event within the work setting, as well as a classification of the threat. The second appraisal assesses the reaction to the threat or stressor. The coping strategy is either problem-focused or emotion-focused, depending on the individual's sense of control over the stressor (Ganster \& Perrewé, 2011, p. 40). Further discussion on coping and coping methods is found in the following section.

No model is without its critics. Although it is valuable to understand the individual's unique assessment of stressors, reactions and coping strategies, it is also important to gain a better understanding of common stressors in the workplace context. The focus on individual patterns does not help to determine the workplace attributes that may be negatively affecting most employees (Brief 
\& George, 1995) or help delineate workplace conditions the may be construed to be workplace stressors (Ganster \& Perrewé, 2011; Harris, 1995). A study of 150 adults included an analysis of antecedent personality factors and the coping methods (primary and secondary appraisal) described by the same individual in five different personal stressful situations and the appraised characteristics of each (Folkman et al., 1986). The authors of the study acknowledged the "microanalytic level" of the study by focusing on the intraindividual reactions of each participant (Folkman et al., 1986, p. 578) giving critics a basis to emphasize the model's neglect of organizational effects on stress (Harris, 1995). Following this study, Folkman et al. (1986) encouraged researchers to "effectively identify stable aspects of stressful person-environment transactions and the appraisal and coping processes that occur within their context" (p. 578). Despite this recommendation, little subsequent research has been done to apply this model in an organizational context. While it is possible for an individual to appraise a situation as both a challenge and threat (Lazarus \& Folkman, 1984), research has been limited to assuming individuals appraise stressors as either one or the other (Webster et al., 2011).

\section{Gender Effects and Occupational Stress}

According to the Bureau of Labor Statistics (2011) in 2010, an estimated 65 million women had jobs, with 53\% working in education and health services; trade, transportation, and utilities; and local government. Interestingly, these three sectors also proved to have the highest overall "quit" rate (Bureau of Labor Statistics, 2012). During this period, the growth of the education and health 
industry, and the number of women employed in it, has been notable.

Researchers have examined the link between gender and occupational stress (Mazzola, Schonfeld, \& Spector, 2011).

Liu, Spector, and Shi (2008) conducted a mixed methods study of 179 university faculty and university support staff that completed a single questionnaire by mail. Responses described stressful incidents experienced at work within the past 30 days by each participant. Results revealed the women experienced a higher correlation of job strain with depression $(t=-3.14, d f=283$, $p<.001)$, turnover intentions $(t=-3.24, d f=283, p<.001)$, and physical symptoms $(t=-2.62, d f=282, p<.001)$ than did the men (Liu et al., 2008). Compared to men, women reported greater psychological strain, anger and depression when controlling for occupation (Liu et al., 2008).

Methods of coping have also been found to vary between men and women. In a study of coping among professors, Narayanan et al. (1999a) established that compared to their female counterparts, male professors reported to be more likely to take direct action ( $33 \%$ versus $17 \%$ for men and women, respectively) while women were more likely to talk more frequently to co-workers (16\% versus $9 \%$ ) and family (16\% versus $7 \%)$. In a two wave study of 555 high school teachers, $60 \%$ female and $40 \%$ male, women reported a higher use of social support than men (González-Morales, Rodríguez, \& Peiró, 2010).

A cross-sectional study of 208 university employees (non-faculty) examined relationships among gendered work conditions, such as sexism and discrimination, job demands, job satisfaction, and health (Bond, Punnett, Pyle, 
Cazeca, \& Cooperman, 2004). Women demonstrated significantly higher levels of social support and job satisfaction, but reported more frequent gender harassment and discrimination than men. Results also showed an increase in psychological distress was related to gender discrimination and low organizational responsiveness to discrimination, particularly for those in femaledominated jobs (Bond et al., 2004, p. 40).

Although, a study by Morash, Kwak, and Haarr (2006) of police officers found the strongest predictor of stress for both female and male officers was dealing with bias by coworkers (p.549), Iwasaki and colleagues (2004) found that female managers reported experiencing more emotional stress, feeling great duties concerning their liability for others. Studies have also shown that after controlling for gender, occupation can have a significant impact on workers' job strains, therefore job attributes by occupations are also significant (Liu et al., 2008). It is also important to examine the effects of cultural background due to globalization, diversity, and immigration which make organizations more and more multiethnic.

\section{Cultural Background and Occupational Stress}

Culture has been defined as a multifaceted, constantly changing system of meaning that is learned, collective, and passed one from one generation to another (Triandis, 1989). Hofstede (1980) emphasized that culture is not an individualistic attribute, but rather a group characteristic conditioned by similar education and experiences. Hofstede further classified culture into five dimensions: power distance, individualism, masculinity, uncertainty avoidance, 
and long-term orientation. Although explanation of each of these dimensions is beyond the scope of this chapter, it is important to note the second dimension, individualism. The United States ranked high on the individualist dimension (Hofstede, 1980) suggesting a greater tendency for individuals to look only after themselves and their immediate family. Latin American countries ranked as highly collectivist, where individuals acknowledge in-groups and out-groups (Hofstede, 1980), therefore not only looking after themselves, their families, their workplace, but also expecting the same in return from each. Lazarus (1999) expressed:

The concern is that cultural psychologists and anthropologists treat culture as a monolithic concept, as if everyone growing up and living within the same culture subscribes to the same values and beliefs, or shares common emotional and coping processes. The United States- along with many other countries throughout the world is multi-ethnic: it contains diverse ethnic or subcultural groups, which makes it difficult to say authoritatively how Americans as a people think and react emotionally to similar events. (p. 66)

It can be hypothesized that more individualistic cultures need less social support, and collective cultures need or expect greater social support, a key element to consider in large organizations. To what extent can employees be "classified" as belonging to a certain culture typology? In addition, Pasca and Wagner (2011) pointed out that establishing social support for immigrant workers may be more complex, having to take discrimination, stereotypes, and 
acculturation into account. There is a gap in the literature with respect to social support and specific cultural tendencies and attributes within-countries (Chang \& Spector, 2011; Pasca \& Wagner, 2011) as well as between countries (Liu, Spector, \& Shi, 2007).

In a study comparing Canadian-born employees and non-Canadian born employees, Pasca and Wagner (2012) found that non-Canadian born education, health care, and social work professionals showed significantly higher levels of somatic and paranoid ideation distress than their Canadian born counterparts. However, there was no significant difference in occupational stress levels between the two groups. The authors attributed this finding to the commonality in education levels among all of the participants, despite their place of birth. When comparing US university faculty and staff employees to Chinese university faculty and staff, results showed only the US participants perceived a higher level of job autonomy and recurrently described lack of job control as a job stressor (Liu et al., 2007). It is clear that culture does play a role in occupational stress and specific work stressors, however future research needs to be more comparative to better examine the specific cultural elements between organizations in different countries (Chang \& Spector, 2011), within multicultural organizations (Pasca \& Wagner, 2011), and the context of acculturated employees within the host country to "ensure increased accountability to ensure equitable, responsible and inclusive workplaces" (Pasca \& Wagner, 2011, p. 697). 
Present in each of the occupational stress models, taking gender and culture into account, are the demands and reactions that "can now be understood only within the context of the evaluative processes that give significance and meaning to encounters" (Cooper et al., 2001, p. 16). It is not one or the other that acts independently; rather it is through the process that the person and the environment are related. Strain takes place when there is an imbalance between the demands of the encounter and the resources of the individual to manage those demands (Cooper et al., 2001).

\section{Coping and Occupational Stress}

Either directly, such as in the transactional or ERI approaches, or indirectly such as in the JDCS and P-E models, some aspect of coping has played an essential role in helping to better define how individual attributes affect the stress/strain process and outcomes. There does not seem, however, to be a consensus on how coping is defined and used in occupational stress research. For example, while Folkman and Lazarus (1980) initially stated that coping with a stressor could be categorized as either problem-focused or emotion-focused, subsequently, after lack of empirical evidence of mutual exclusivity, argued that although it is important to distinguish between the two, they are not "distinctive types of coping actions" (Lazarus, 1996). Lazarus (2006) declared it best to view emotion and problem-focused coping not as separate typologies of coping, but rather as two complementary functions.

However, many research studies have continued to categorize coping as one or the other and have expressed surprise when the data have shown weak 
results (Ben-Zur \& Michael, 2007). Other such as De Jonge et al. (2000) introduced overcommitment in the ERI model as a "pattern of coping that defines

a set of attitudes, behaviors and emotions reflecting excessive striving in combination with a strong desire of being approved and esteemed" (p. 1318). Therefore, this section will briefly review the conceptualization of coping as a mediator/moderator of stress along with a review of ways of coping.

\section{Conceptualization of Coping}

Lazarus and Folkman (1984) defined coping as "constantly changing cognitive and behavioral efforts to manage specific external and/or internal demands that are appraised as taxing or exceeding the resources of the person" (p. 141). Significant differences in coping behavior have been consistently correlated to worker experiences, thus a clearer understanding of these relationships will help define the moderating role of coping (Schaubroeck, 1999, p. 755). Cognitive efforts include staging, judgment, and enactment (Wofford \& Daly, 1997). In the staging phase the person's social information and cognitive complexity are key, whereas in the judgment phase a person's attribution processes are important (Wofford \& Daly, 1997, p. 135).

Moderators help assess the predisposition of a person's ability to deal with stressors (Baron \& Kenny, 1986). Coping is a process that moderates stress. Primary appraisal is mediated by an individual's psychological constructs and that individual's reaction to the stressor producing "emotional and adaptational" responses (Wofford \& Daly, 1997, p. 135) where cognition and emotion are concurrent (Folkman et al., 1986). Secondary appraisal is moderated by a 
person's personality variables and is considered a decision-making construct in the stress-outcome relationship (Cox \& Ferguson, 1991). Zajonc (1980) disputed that affective responses occur upon conscious appraisal due to the immediacy of a person's reaction, and further stated that reactions were automated and not controlled processes. The secondary appraisal, as Lazarus asserts, is an evaluation process of choosing a coping typology.

The central notion is that the structure of coping spans the conceptual space between instances of coping and adaptive processes. Hence, the critical problem for the field is to construct a complete and coherent set of categories at an intermediate level that organizes innumerable situation-specific highly personal responses with respect to their functions in mediating the effects of stress (Skinner et al., 2003, p. 217).

\section{Ways of Coping}

While the assessment of occupational stress based on objective stressor to strain frameworks have produced significant correlations (de Lange et al., 2003; Schaufeli \& Bakker, 2004; Siegrist, 2002) others argue the interpretation of objective stressors plays a more critical role in predicting employee strain (Lazarus, 2006; Perrewé \& Zellars, 1999). This interpretation has been discussed in terms of coping processes or strategies (Lazarus, 1984). Because of the extensive coping strategies found in the literature, it is important to review these extensively to better understand assessments across occupational research studies (Skinner et al., 2003). 
Ways of coping are described by some as basic descriptive components considered to assess how people react to stressful situations (Skinner \& Zimmer-Gembeck, 2007), or by others as a "series of predicates, each which portrays a coping thought or action that people sometimes engage in when under stress" (Carver, Scheier, \& Weintraub, 1989, p. 267). After reviewing 100 assessments of coping, Skinner et al. (2003) found a total of 400 ways of coping used. However, not each way of coping represented a different category. Therefore, Skinner et al. (2003) recommended a hierarchical system based on descriptions of the structure of coping using a group of hierarchically organized families (p.121). Such families included problem solving, support-seeking, escape, distraction, cognitive restructuring, rumination, helplessness, escape, self-reliance, emotional regulation, information-seeking, negotiation, opposition, and delegation which could then be placed in a higher order category such as an action category or functions of coping category (Skinner et al., 2003, p. 245).

Even though all of these characterizations continue to be widely used, confirmatory factor analyses have revealed that no feature alone effectively describes the structure of coping (Connor-Smith \& Flachsbart, 2007). For example, in the literature, problem-focused and emotion-focused strategies are described as functions of coping. As discussed previously, not being mutually exclusive presents a dilemma for each as a single function category. Skinner et al. (2003) used the case where formulating a plan in response to a stressor exemplifies problem-solving, but at the same time can also calm negative 
emotions (p.227). In essence, problem-focused or emotion-focused reactions constitute ways of coping, not categories of coping (Skinner et al., 2003).

The oversimplification of defining a category as either problem-focused or emotion-focused has been criticized by many researchers because each of these can contain many separate individual activities such as support seeking, planning, and denial (Carver et al., 1989; Connor-Smith \& Flachsbart, 2007; Skinner et al., 2003). The Ways of Coping scale (Folkman \& Lazarus, 1985) is an example of a scale that is based on the problem-focused and emotion focused as distinct categories. While researchers have stated the importance of distinguishing between the two (Carver et al., 1989; Skinner et al., 2003), they should not be recognized as distinct functions of coping, but again as ways of coping.

The most commonly used methods of coping assessment are the Ways of Coping scale (Folkman \& Lazarus, 1988) and the COPE inventory (Carver, 1997). While the Ways of Coping scale is based on two broad types of problem versus emotion -focused coping, the COPE inventory assesses people's actual coping actions (Carver et al., 1989). A total of 14 distinct conceptual scales measure active coping, planning, suppressing competing activities, restraint coping, seeking social support for instrumental reasons, seeking social support for emotional reasons, positive reinterpretation and growth, acceptance, turning to religion, focusing on the venting emotion, denial, behavioral disengagement, mental disengagement, and a single item measure of alcohol-drug disengagement (Carver et al., 1989, p. 272). These concepts can be described 
as fulfilling the action category hierarchy described by Skinner (2003). Coping then is an important construct that can be used to determine how people respond to stressful situations and in turn try to find significant correlations that impact outcomes.

\section{Outcomes of Occupational Stress}

Thus far, various approaches of occupational stress and coping have been reviewed. The following section identifies major physiological, behavioral, and psychosocial outcomes of occupational stress operationalized by cardiovascular disease, high blood pressure, absenteeism, and burnout, respectively.

\section{Cardiovascular and Other Diseases}

Work stressors have been strongly associated with physiological outcomes. Obesity and job strain have proven to be main public health issues in today's world, underlying a range of health-related outcomes, most importantly cardiovascular disease (Kivimäki et al., 2006; Nyberg et al., 2012). A crosssectional analysis of 13 European cohort studies $(n=161,746)$, including the Whitehall II study, examined the relationship between job strain and body mass index (BMI) (Nyberg et al., 2012). Results showed a "U" shaped cross-sectional correlation between job strain and BMI. Increased odds of job strain between underweight [odds ratio 1.12, 95\% confidence interval $(\mathrm{Cl}) 1.00-1.25$ ], obese class I (odds ratio $1.07,95 \% \mathrm{Cl} 1.02-1.12$ ) and obese classes II / III participants (odds ratio $1.14,95 \% \mathrm{Cl} 1.01-1.28$ ) as measured up against normal weight participants (Nyberg et al., 2012, p. 66). Although the authors argued that 
reducing job strain would reduce obesity in the general population, there is an indirect relationship between obesity and heart disease, and between heart disease and job strain.

In a study of 13,779 participants, Johnson and Hall (1988) confirmed an increase in cardiovascular disease (CVD) when workers experienced high demands, low control, and low social support. Using the JDCS model, 18 of 34 studies of job strain and CVD (1981-2002) indicated significant correlations (Landsbergis et al., 2011). The Whitehall II study is an on-going longitudinal study which has completed nine phases including 10,308 participants $(6,895$ men and 3,413 women), aged 35 to 55 years at the time of the first phase, from 20 London-based Civil Service departments (Stansfeld et al., 1999). Stansfeld et al. (1999) analyzed data from phases 1-3, administered a general health questionnaire, and showed for the first time a significant relationship between the effort-reward imbalance and an increased possibility of psychiatric morbidity. The JDCS model was used to examine six cohorts from four European countries with a participant population of 21,111 middle-aged men and showed 185 acute coronary or coronary deaths during a follow up period of 40 months (Kornitzer et al., 2006). A meta-analysis of 14 prospective cohort studies with a total of 83,014 workers, found a work stress to be related to a $50 \%$ increased risk of CVD (Kivimäki et al., 2006).

A meta-analysis of 45 empirical studies of the ERI model from 1986-2003, found significant positive correlations between high efforts and low rewards (van Vegchel et al., 2005). Eight of the studies used CVD as an outcome category 
and $100 \%$ of these showed a signficant and postive correaltion between high efforts, low rewards, and increased CVD (van Vegchel et al., 2005). Results for the inclusion of overcommitment did not yield significant findings as the construct was not similarly defined in the studies (van Vegchel et al., 2005). Studies have shown the sustained cycle of high efforts and low rewards to produce negative health results due to chronic high levels of strain (Peter et al., 1998; Siegrist, 2001; Siegrist et al., 2010; van Vegchel et al., 2005). Health effects were related to moderate risk of coronary heart disease (Kuper, Singh-Manoux, Siegrist, \& Marmot, 2002; Siegrist, 2001) and mild to moderate psychiatric disorders (Stansfeld, Rasul, Head, \& Singleton, 2011). A study of psychophysiological stress among 60 urban bus drivers, showed a significant relationship between job strain and elevations of urinary catecholamines (Evans \& Carrère, 1991) further underscoring the relationship between strain and health outcomes. Catecholamines aid the body in responding to stress and prepare the body for "fight-or-flight" reactions. The adrenal glands produce large amounts of catecholamines as a reaction to stress (WebMD).

\section{High Blood Pressure}

High-blood pressure has been positively linked with an increased risk of CVD (Vasan et al., 2001). A significant correlation between job strain and blood pressure disease in men was shown in a longitudinal study between 1985-1995 of 213 men (Landsbergis et al., 2003). Each participant completed the Job Content Questionnaire (JCQ), a validated assessment measure to predict job strain that can lead to burnout, physiological and psychological disorders (Hurrell 
et al., 1998; Karasek et al., 1998), and wore a blood pressure monitor for 24 hours. Results confirmed higher systolic blood pressure, 10.2-mmHg higher work and 14.6-mmHg higher home for men employed for more than 25 years who reported experienced job strain for $50 \%$ of their work life as opposed to those who did not report job strain (Landsbergis et al., 2003, p. 1003). Another considerable outcome of occupational stress is absenteeism in the workplace.

\section{Absenteeism}

Absenteeism is defined as an employee absence from scheduled work (Johns, 2008). In 2002, the rate of absenteeism was $2.1 \%$ and in 2007 had risen to $2.3 \%$ according to the 17 th Annual Unscheduled Absences Survey by the Commerce Clearing House (2007). The survey also stated that absenteeism due to workplace stress had significantly increased from $6 \%$ in 2006 to $13 \%$ in 2007. Jauregui and Schnall (2009) noted in reviewing the literature that long work hours, high demands, lack of control over work decisions, and poor social support have all been attributed to sickness work absences. But it would be valid to question if the absence was caused by these factors which triggered stress which in turn caused sickness, or if the absence was a coping response. After a meta-analysis of 153 studies, Darr and Johns (2008) concluded that there is an indirect relationship between work stressors that cause illness and in turn absenteeism (p.307). Absenteeism was found to be a possible coping response for acute work strain it; but for chronic work it may actually have the opposite effect of increasing strain from being absent (Johns, 2008). Absenteeism as a work stressor mediator or as a work strain result still impacts the organization in 
terms of productivity loss (Jauregui \& Schnall, 2009), in addition to placing more work demands on the present employees.

Although many models of occupational stress exist, as well as ways to measure occupational stress, there is no doubt the effects of stress at work have been substantial and real, for both the employee and the employer in terms of employee health outcomes, and organizational outcomes. From a physiological view, studies have examined the effects of work characteristics in relation to occupational stress and have shown sustained job strain leads to increased blood pressure (Landsbergis et al., 2003) cardiovascular disease (Johnson \& Hall, 1988; Schnall \& Landsbergis, 1994), and absenteeism. However, at the same time researchers were developing occupational stress models, Leiter and Maslach (1988) were developing theories on job burnout and defining workplace stressors related to burnout (Leiter \& Maslach, 1999; Maslach, 2001), a significant burden on both individuals and organizations.

\section{Burnout}

Freudenberger (1977) identified burnout as an expression describing physical and psychological distress. Originally, the idea of burnout surfaced as a social problem, rather than academic construct (Maslach \& Schaufeli, 1993) putting it at the forefront for practitioners. However, as society became less integrated and human service professionals faced cutbacks leading to higher demands with less resources, researchers began to lead empirical studies on the concept of burnout (Cherniss, 1980; Maslach \& Schaufeli, 1993) to establish theoretical constructs. Various definitions of burnout have been proposed. Pines 
and Aronson (1988) define burnout as a condition of physical, emotional and mental fatigue brought about by lasting participation in emotionally draining situations. According to Maslach and Leiter (1997) burnout describes the feeling of emotional exhaustion, depersonalization (cynicism), and ineffectiveness or feeling a lack of personal accomplishment. In essence, all definitions of the concept of burnout, or work-related strain, relate to a long term process (Maslach \& Schaufeli, 1993), attributable to a build-up of work-related stress (Halbesleben \& Buckley, 2004).

Maslach and Jackson (1981) developed a three-dimensional model of burnout where emotional exhaustion, depersonalization and reduced personal accomplishment take place within a work context where individuals work with other people. Human services professions become vulnerable and unable to manage their work psychologically and emotionally as a result of constant stressors (Barak et al., 2001). Leiter (1993) emphasizes that people lean toward burnout as a result of their personal response to continual aspects of their work environment. Burisch (1993), however, stresses the inclusion of individual response to inner conflict, more so than a response to work environment factors.

The most widely used measure of burnout is the Maslach Burnout Inventory (MBI), which contains three scales: 1) emotional exhaustion; 20 depersonalization; and 3) personal accomplishment (Maslach et al., 1996; Schaufeli et al., 2009). Although there are currently three versions of the MBI for use with human service professionals, educators, and workers in other occupations, each contains the same three scales to measure burnout. 
Emotional exhaustion is exemplified as a feeling of being emotionally overextended and drained. The strongest correlation has been found between emotional exhaustion and burnout (Leiter, 1993; Leiter \& Maslach, 1999; Lonne, 2003). Newell and MacNeil (2011) examined the degree of burnout, compassion fatigue, and compassion satisfaction between clinical mental health providers offering direct patient care, and administrators offering non-direct patient care within a VA hospital in the United States. Both groups showed high levels of emotional exhaustion; although there was no significant difference between the two groups as hypothesized. A significant finding showed a higher sense of personal accomplishment among the direct care participants. Newell and MacNeil (2011) believe this finding was due to the personal sense of gratification of working directly with a patient. Not having support for this finding indicates a lack of adequate research questions regarding social support and/or environmental factors.

Depersonalization is characterized as cynicism; where workers detach and isolate themselves from their colleagues and more importantly, their clients (Maslach \& Leiter, 1997). This detachment in turn creates a negative atmosphere and reduces a worker's ability to work effectively. Decreased personal accomplishment refers to a worker's diminished sense of competence and success in the workplace. Consequently, a worker's self efficacy and confidence are reduced (Maslach \& Leiter, 1997). Leiter and Maslach (1999) delineated six common areas within the work environment that act as frequent work stressors, placing burnout within an organizational context. Role ambiguity and role conflict 
for human service workers have been shown to correlate highly with emotional exhaustion (Barak et al., 2001; Dollard, 2003). Another study showed role conflict, and not role ambiguity significantly impacted burnout and job dissatisfaction (Um \& Harrison, 1998). Critics point out the higher correlation between emotional exhaustion and burnout as compared with depersonalization and diminished personal accomplishment (Demerouti, Nachreiner, Bakker, \& Schaufeli, 2001).

Mismatches in any of the following six areas of work life can lead to burnout: work overload, control, rewards, community, fairness and values. The concept of inequity is consistent with Karasek's JDCS model of occupational stress where an imbalance of high demands, low control and low social support generates high levels of strain. Just as Karasek and Theorell (1990) highlighted the significance of the interaction of each of the components within the JDCS model, Leiter and Maslach (1999) emphasized the importance of the interaction of the six areas of work life; an imbalance of one single area or component does not readily lead to a negative effect.

Work overload included demands that require more time or support than available to the employee. The problem occurred not from the amount or type of work, but rather from the long-term discrepancy between the employee and the work (Dollard, 2003; Leiter \& Maslach, 1999). A study by LeCroy and Rank (1987) did not find a significant correlation between work overload and burnout, but that may be attributed to measurement discrepancies. After reviewing the literature on work overload and job stress, Barak et al. (2001) found excessive 
workloads to be a significant factor. Role conflict occurred when individuals have little effective control over their work. Rigid demands along with specific work policies that are not parallel to the actual expectation of the employees' work created role conflict. Role conflict burdens employee workload and is strongly related to exhaustion where worker expectations are at odds with supervisor expectation (Leiter \& Maslach, 1999).

Rewards can be categorized as extrinsic and intrinsic. Salary, esteem, and job security are examples of extrinsic rewards. Each of these is highlighted even further during hard economic times. Workers tend to stay in inequitable job positions due to fear of not finding another job. Intrinsic rewards describe a person's feelings about a sense of accomplishment, recognition from superiors, and a sense of self efficacy (Leiter \& Maslach, 1999). Maslach et al. (1996) found a strong association between recognition and personal accomplishment and efficacy. Any inequity in terms of efforts and rewards, brings about a feeling of deprivation, unfairness and may contribute to personal detachment.

Lack of fairness occurs when resources are not allocated with regard to organizational objectives (Leiter \& Maslach, 1999). The notion of fairness is closely related to community and value. Leiter and Maslach (1999) emphasize the benefit of an overlap of individual and organizational values in order to minimize value conflict. Value conflict arises when there is a mismatch between employee demand and employee principles. The strain connected with a lasting mismatch of values exhausts personal energy, decreases involvement, and weakens a sense of personal accomplishment (Maslach \& Leiter, 1997). 
Of the six areas of work life, work overload and control have been the most discussed in the literature. However, the interrelationship among the relationships between all of the variables is most important to reveal a common theme (Leiter \& Maslach, 1999). Burnout is not a process simply resulting from a large overload of work, or an unfair supervisor; it is a complex, "gradual process of disillusionment" (Pines, 1993, p. 35). The effects of burnout on individuals, as well as on the organization have proven to be significant.

\section{Burnout and Turnover}

In a meta-analysis of the burnout literature from 1993-2004, Halbesleben and Buckley (2004) found consistency among outcomes correlated to burnout such as: reduction of job performance, turnover and intent to turnover, and negative physiological symptoms. Findings of a longitudinal study of 3,985 participants showed a significant association between burnout and future sick leave (Toppinen-Tanner et al., 2005). After an analysis of 25 research studies, Barak et al. (2001) concluded the high turnover rate of professional workers causes a serious challenge to human services organizations. Burnout underscores the relationship between human service workers' self-assessed role stress and the intent to leave their jobs (Kim \& Stoner, 2008). Results of this study support the theory that higher levels of burnout contribute to higher likelihood of intent to turnover.

High worker intent to turnover and turnover present organizational dilemmas in terms of cost and quality of care. Turnover burdens active employees with unfilled vacancies, causing more work overload, or with newer 
inexperienced staff; therefore affecting the quality of care (Powell and York 1992). Barak et al. (2001) outlined the direct cost of employee turnover as: separation costs, replacement costs, and training costs. Indirect costs were categorized as loss of efficiency (when an employee has the intention to leave), and loss of productivity of the inexperienced new worker.

Waldman, Kelly, Aurora, and Smith (2004) conducted an in-depth cost analysis of intent to turnover and turnover in a healthcare environment. The study included 5,118 employees of an academic medical center including physicians, nurses, allied health personnel, technical staff, support personnel, and administrators and managers. Analysis showed annual turnover rates ranging from $9 \%$ for physicians to $49 \%$ for allied health personnel. Nurse replacement represented the largest costs. The annual cost calculated based on the turnover rates corresponded to $3.4-5.8 \%$ of the annual budget, or $\$ 17-29$ million dollars. Loss of productivity of inexperienced new employees as compared to employees who have attained job mastery was labeled as Costs of Reduced Productivity (CoRP). The CoRP for nurses ranged from $\$ 5,245$ to $\$ 16,102$. In the United States, over the past 10 years, the proportion of voluntary separation a job exceeded the number of layoffs (Bureau of Labor Statistics, 2012).

Work stressors, strain and their outcomes been described and examined in many studies, with the majority of samples coming from social services, nursing, police, teaching and health care (Schaufeli \& Greenglass, 2001). 


\section{Summary}

Thus far, this chapter has shown that there is a significant connection between job structure, work environment, and personal perceptions of control, demands, rewards and interactions at work within the work environment. Prolonged imbalance in any of these interactions can cause job strain leading to a many negative outcomes in terms of employee health and impacting the work organization. This chapter has presented a conceptual review of stress and prominent theoretical models of occupational stress. Coping methods and how they may act as mediators or moderators in this complex relationship of interaction between employees and their work environments was described. A specific review of outcomes was presented, including cardiovascular disease, high blood pressure, absenteeism and burnout. Ways of coping was reviewed within the framework of work stress.

\section{Integrated Proposed Model}

Although most occupational stress models focus on placing the burden on the employer and the work structure, this study proposed that a further integration of individual differences, such as coping methods, can actually have an impact on occupational stress and its outcomes. This study aimed to show how a combination of worker and work environment is what is substantial in occupational stress theory, not solely the work structure, or solely the employee; rather a synergetic model based on the relationship between job structure, burnout, and ways of coping as a moderator. 


\section{CHAPTER III}

\section{METHODS}

This chapter first relates the purpose of the study. Second, research questions and hypotheses are presented. The next section delineates the research design and methods used with a description of the population, variables and instruments. Procedures will be detailed along with data management, collection and analysis.

\section{Purpose of the Study}

The purpose of this study was to examine the relationship between the structure of jobs and burnout and to assess to what extent, if any, this relationship is moderated by individual coping methods (see Figure 1).

\section{Research Questions and Hypotheses}

This study was framed by two overall overarching questions: (a) what is the relationship between job structure, as operationalized by job title, and burnout across different occupations in support services in a large municipal school district? and (b) To what extent do individual differences in coping methods moderate this relationship? Specifically, the following hypotheses are tested:

$H_{1 a:}$ Different occupational categories of employees in the same workplace have different levels of physical demands.

$H_{1 b \text { : }}$ Different occupational categories of employees in the same workplace have different levels of psychological demands.

$H_{1 c \text { : }}$ Different occupational categories of employees in the same employees have different levels of job control. 
$H_{2 a:}$ Occupations characterized by greater levels of physical demands and lower levels of job control have greater levels of individual employee burnout.

$H_{2 b:}$ Occupations characterized by greater levels of psychological demands and lower levels of job control have greater levels of individual employee burnout.

$H_{3:}$ Individual differences in coping act as a moderator between job structure, operationalized by job title, and individual employee burnout.

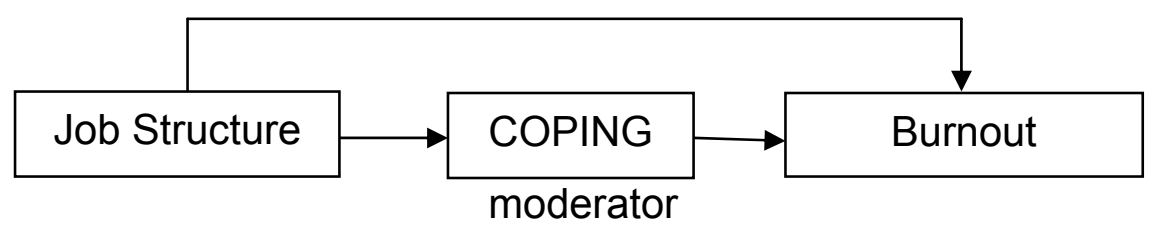

Figure 1. Coping as a moderator between job structure and burnout.

\section{Research Design}

This study was a cross-sectional study that examined the relationship between variables (Trochim \& Donnelly, 2008) based on established theories of workplace stress. The purpose of this research was to find correlations between two or more variables through self-report questionnaires. Although experimental research design looks to establish a cause-effect relationship (Field, 2009), for purposes of this study, it was important to observe the actual perceptions of the population; therefore, a non-experimental, cross-sectional design was used to establish correlations. Gay and Airasian (2000) describe the purpose of correlational research as a method "to determine whether, and to what degree, a relationship exists between two or more quantifiable variables" (p.321). A 
common method in correlational research is the use of surveys to gather selfreport data representative of a population in order to generalize the findings (Bartlett II, Kotrlik, \& Higgins, 2001).

\section{Population and Sample Size}

The sample population for this study was county public school transportation bus drivers, bus driver aides, mechanics, and clerical workers at three bus depots wtihin the same municipal county. All participants were actively employed by the county. The total population consisted of 859 public school county transportation workers, including bus drivers, bus aides, mechanics, and clerical workers, at three different bus depots located in a large metropolitan area. The population consisted of approximately 525 bus drivers, 223 bus driver aides, 51 mechanics, and 60 clerical workers. Therefore, the total population size was 849 . For a power analysis of .80 with an effect size of .15 and an alpha of .05, the recommended minimum sample size is 120 (Hinkle, Wiersma, \& Jurs, 2003).

\section{Variables and Instrumentation}

Each of the variables in this study, burnout, and coping method was assessed using a validated instrument. Each variable and its instrument are described in the sections that follow.

\section{Independent Variables and Measurement Instruments}

\section{Job Structure}

Job structure was used in this study as term to describe the characterization of a job based on Karasek's (1998) model which includes job 
demands and control. Occupational categories, delineated by job title, were used as a proxy for job structure in this study. Based on Karasek's (1998) occupation-based job characteristics, each of the four occupational groups in this study, Bus Drivers, Bus Aides, Mechanics, and Clerical Workers were hypothetically categorized into one of the four quadrants of the model: active, passive, low strain and high strain.

Karasek described each of the quadrants as follows. The active quadrant includes jobs with characteristically high demands and high control, such as executives, physicians, and engineers. The passive quadrant incorporates jobs with low demands and low control such as clerical workers and janitors. Occupations that are self-paced and usually require considerable training such as mechanics and repairmen are included in the low strain quadrant. The high strain quadrant includes jobs with high demands and low control which include lower-status service occupations such as nurse's aides and waiters.

In this study, school bus drivers had little control over many aspects of their job. For example, there they select their bus routes through a bidding process based on seniority. Being in a large urban setting, traffic patterns were also constantly changing due to road construction and detours posing a challenge to time constraints on scheduled stops and arrival time. In addition, in this study, county bus drivers had little control over who rides the buses. According to the county transportation handbook, problems with disruptive riders required a minimum of three referrals to the school counselor/principal before 
being able to take action on the disruptive student's riding privileges. Current cutbacks in the transportation budget also affected the availability of bus aides, placing even greater demand on the driver. School bus drivers were not only responsible for making sure the children arrived on time, but were also responsible for ensuring safety on board the bus. Therefore, bus drivers were anticipated to be in the high strain quadrant with high demands and low control. The level of responsibility seemed high relative to the control over the job.

Bus Aides had the primary responsibility of maintaining order on the bus. Bus Aides physically helped load and unload handicapped students and needed to be familiar with any necessary restraining devices necessary to ensure the safety of these students. Additionally, Bus Aides were responsible for properly securing wheelchairs on the bus. A final check behind and underneath all seats had to be conducted by the Bus Aide at the end of every run and again once the bus has returned to the bus transportation depot. In addition, Bus Aides were not allowed to break up disruptive fights on the buses; the guidelines indicated to have the Bus Driver call dispatch. Bus Aides were expected to be in the high strain quadrant based on high demands and low control.

Mechanics worked mostly autonomously. It is an occupation that requires significant training and is self-paced. According to Karasek's job characterization mechanics should fall in the low strain quadrant. However, the mechanics in this study worked for a county and had to wait for approval of parts and processing time to complete their tasks. In addition, because of budget cuts, mechanics that have retired have not been replaced, placing a greater burden on the remaining 
workers. Therefore, it was expected that the mechanics would be in the high strain quadrant.

According to Karasek, clerical workers are described as having low job demands as well as low job control and consequently placed in the passive job quadrant. The clerical workers in this study were responsible for ensuring bus drivers and bus aides start their routes on time. Other clerical workers were in charge of dispatch, the line of communication between the bus drivers, the central station, and the schools. For this study, it was expected that clerical workers would fall into the passive job quadrant.

However, to confirm these occupations have been assessed appropriately, the Job Content Questionnaire was administered to the participants. The Job Content Questionnaire (JCQ) has been the most widely used job-stress assessment measure to predict job strain that can lead to burnout, physiological and psychological disorders. (Hurrell et al., 1998; Karasek et al., 1998). The JCQ is a 49-item, self-administered questionnaire that measures social and psychological characteristics of jobs using a 4 point Likert scale. Theoretically, the JCQ acknowledges that employee behavior is, to a considerable degree, caused by the social work setting (Karasek et al., 1998). The five scales (a) decision latitude, (b) psychological demands, and (c) social support (d) physical demands, and (e) job insecurity assess the effects of high demand, low control and, low support on predicting job strain in workers (Karasek et al., 1998). 
The decision latitude scale is comprised of subscales with questions assessing skill discretion, decision authority, skill underutilization, employee influence on organizational issues, union and work-group participation (Karasek et al., 1998, p. 324). Examining skill discretion allows a comparison of job skills required and an employee's permissible ability to decide which skills to use to perform the job. Decision authority refers to the liberty an employee has in making decisions about work (Pelfrene et al., 2001). An individual's perception of work load or role ambiguity represents psychological demands.

The outcome of the decision latitude and psychological demands scales places the individual within a quadrant of Karasek's active (high demand, high control), passive (low demand, low control), high strain (high demand, low control), and low strain (low demand, high control) model. An additional indicator of high strain is measured with the social support subscale which evaluates supervisor and co-worker support/non-support.

Physical demands and job insecurity incorporate two remaining elements found to be indicative of work stress. Physical overload combined with mental overload has been found to be indicative of work stress. Job insecurity deals with an employee's perception of future career opportunities and job security.

The factorial, discriminant and external validity and reliability of the JCQ scales have been tested numerous times in various countries. Karasek et al. (1998) reviewed six studies in four different countries (United States, Canada, Japan, and the Netherlands) with a sample size of 16,601 participants, to assess the cross-national validity of the scales. Results showed factor confirmation for 
decision authority, skill discretion, and psychological demands. The Canadian study demonstrated a strong factor outline including the social support scales. Confirmation for nearly all of the scales was found in the Dutch study. Findings from the Japanese study also showed confirmation of all factors with the exception of skill discretion and psychological demands (Karasek et al., 1998; Kawakami, Kobayashi, Araki, Haratini, \& Furui, 1995).

In the "Beltress" study in Belgium of 21,419 non-random, working participants, Pelfrene et al. (2001) evaluated the scale reliability and the validity of the JCQ scales. Factor analyses were comparable to Karasek et al. (1998) review supporting Karasek's JDCS model. Pelfrene et al. (2001) demonstrated discriminant validity by showing a strong correlation between high strain and low social support. In addition, gender -specific and age-standardized means for psychological demands and decision latitude illustrated an almost perfect slope when compared to International Standard Classification of occupational groups delineating high/low strain jobs (p.306).

External validity has been consistent throughout the many studies using the JCQ (de Araujo \& Karasek, 2008; Kawakami et al., 1995; Pelfrene et al., 2001). High strain results have been consistently linked with low social support. A decrease in decision latitude was uniquely observed in relation to high feeling of stress (Pelfrene et al., 2001). Most recently, in an evaluation of the JCQ in the developing country of Brazil with a random sample of 1311 formal and informal working residents, de Araujo and Karasek (2008) found a strong consistency between social support, skill discretion, decision authority and physical demand 
and the JDCS model. A review of 36 studies examining cardiovascular disease or mortality, over two thirds affirmed positive a positive relationship with job strain. (Schnall \& Landsbergis, 1994).

\section{Coping Method}

To assess coping strategies, the Brief COPE scale (Carver, 1997), a 28item instrument based on14 scales with two items each was used. The Brief COPE scale is founded on the original COPE scale which consisted of 60 items (Carver et al., 1989) intended to measure "conceptually differentiable coping reactions" (Carver et al., 1989, p. 98). Because of participant impatience and redundancy within the original COPE scale, Carver (1997) created the Brief COPE scale. The response format for this scale ranges from 0-3 (not doing this at all to doing this a lot) (Carver, 1997).

To assess the reliability of the scales, the Brief COPE was administered three times to same sample, $(n=168, n=124, n=126$ that was linked to a study of recovery after Hurricane Andrew over a 2-year period (Carver, 1997; David et al., 1996; Ironson et al., 1997). Reliability estimates of the Brief COPE scales were: active coping $=.68$, planning $=.73$, positive reframing $=.64$, acceptance .57 , humor $=.73$, religion $=.82$, using emotional support $=.71$, using instrumental support $=.64$, self-distraction $=.71$, denial $=.54$, venting $=.50$, substance use $=$ .90 , behavioral disengagement $=.65$, and self-blame $=.69$. An acceptable value of reliability of .50 or above, taking into account that there are only 2 items per scale, was achieved for all of the scales (Carver, 1997). Furthermore, all but three, Venting, Denial and Acceptance were above .60 (Carver, 1997). In a 
study by Ben-Zur and Michael (2007), a factor analysis reported two factors and therefore, two new scales, problem-focused $(\alpha=.70)$ and emotion-focused $(\alpha=$ .67). Two scales, restraint and religion that loaded less than .40 were excluded from the study. In this study, a principal component analysis with varimax rotation was performed on the Brief COPE scale.

\section{Dependent Variable- Burnout}

The Maslach Burnout Inventory (MBI), used in more than $90 \%$ of journal articles and dissertations that have examined burnout, is the most widely utilized scale measuring burnout (Maslach et al., 1996; Maslach \& Leiter, 1997;

Schaufeli, Bakker, Hoogduin, Schaap, \& Kladler, 2001). Occupational stress is defined as an imbalance between job demands and control leading to burnout as an outcome. Burnout is more specifically related to workers' feelings of exhaustion combined with their sense of accomplishment within the social work environment (Maslach et al., 1996). Burnout is a condition of emotional exhaustion, depersonalization, and diminished personal accomplishment between employees who do "people work", or work with people in some manner (Maslach \& Leiter, 1997).

The MBI is a questionnaire that "provides a concise perspective on the energy, involvement, and effectiveness of staff members on the job" (Maslach \& Leiter, 1997, p. 155). Currently, there are three versions of the MBI: (a) the original version, the MBI-Human Services Survey (MBI-HSS), intended for professionals in the human services; (b) another version, the MBI-Educators Survey (MBI-ES), designed for educators, and; (c) the newest version, the MBI- 
General Survey, designed for employees in other occupations (Maslach et al., 1996). The survey used for this study was the MBI-Human Services Survey.

The MBI surveys include three scales, to measure emotional exhaustion, depersonalization, and personal accomplishment. Emotional exhaustion, an indicator of the burnout syndrome, refers to workers' feelings that emotional resources are worn out and in turn prevents the workers from giving of themselves at a psychological level (Maslach et al., 1996). The Emotional Exhaustion subscale is made up of 9 items, each relating feelings of being emotionally exhausted by work. Each statement is rated using a response scale, ranging from 0-Never and escalating to 6- Every day. An additional aspect of burnout syndrome is cynical attitudes of workers towards clients. The 5 -item Depersonalization Scale illustrates an insensitive and impersonal reaction towards workers' clients with responses ranging from 0-Never to 6-Every day (Maslach \& Jackson, 1981). Higher mean scores on The Emotional Exhaustion and Depersonalization scales correlate to higher degrees of burnout. In essence, both elements of burnout are related.

The third scale, Personal Accomplishment, measures another symptom of burnout; the feeling of reduced personal accomplishment. Contrary to the other two MBI scales, a higher score negatively correlates with reduced personal accomplishment where lower mean scores indicate higher degrees of burnout (Maslach \& Jackson, 1981). Maslach and Jackson (1981) stipulated that the Personal Accomplishment scale is independent of the other two scales with correlations for the Emotional Exhaustion scale of -0.17 (frequency) and -0.05 
(intensity), and for the Depersonalization scale -0.28 (frequency) and -0.22 (intensity). The original MBI provides each respondent with three individual scores for each scale. Initially, within each subscale, ratings applied to both frequency and intensity. However, the newest version of the questionnaire assesses only frequency (Lee \& Ashforth, 1996; Maslach et al., 1996).

The convergent validity of the MBI-HSS was tested through three different methods. Firstly, a respondent's MBI-HSS assessment was compared to an independent observer's (co-workers, family members) anonymous assessment of the respondent. Respondents with high scores on the Emotional Exhaustion and Depersonalization scales were rated as being emotionally weak by the observer (Maslach et al., 1996). Secondly, data were collected to substantiate hypotheses between certain job characteristics and burnout. In a study by Maslach and Jackson (1984b), the greater number of clients an individual dealt with, the higher the MBI-HSS burnout scores. The study included 845 public contact employees and found that when workloads were high, scores on the Emotional Exhaustion and Depersonalization scales were high and scores on Personal Accomplishment were low. Thirdly, scores on the MBI-HSS correlated with assessments of several outcomes that have been hypothesized to be associated to burnout. Sample questions from MBI-HHS (Maslach et al., 1996): 
How often:

\begin{tabular}{|c|c|c|c|c|c|c|}
\hline 0 & 1 & 2 & 3 & 4 & 5 & 6 \\
\hline Never & $\begin{array}{l}\text { A few } \\
\text { times a } \\
\text { year or } \\
\text { less }\end{array}$ & $\begin{array}{l}\text { Once a } \\
\text { month or } \\
\text { less }\end{array}$ & $\begin{array}{l}\text { A few } \\
\text { times a } \\
\text { month }\end{array}$ & $\begin{array}{l}\text { Once a } \\
\text { week }\end{array}$ & $\begin{array}{l}\text { A few } \\
\text { times a } \\
\text { week }\end{array}$ & $\begin{array}{l}\text { Every } \\
\text { day }\end{array}$ \\
\hline
\end{tabular}

\section{Emotional exhaustion}

I feel emotionally drained from my work.

I feel used up at the end of the day.

\section{Depersonalization}

I don't really care what happens to some recipients.

I've become more callous toward people since I took this job.

Feeling of personal accomplishment:

I feel very energetic.

I can easily create a relaxed atmosphere with my recipients.

The discriminant validity of the MBI-HSS was demonstrated by differentiating it from other assessments of psychological constructs that may be confused with burnout, such as, job dissatisfaction, depression, and occupational stress (Maslach et al., 1996). Several studies have shown low correlation between the Job Diagnostic Survey (JDS), a measure of general job satisfaction and the MBI-HSS. Leiter and Durup (1994) study of 307 hospital workers' scores on the $\mathrm{MBI}$ and on measures of depression validated that burnout is a complex 
"three-factor" syndrome with each component more strongly related to one another than to any characteristic of depression.

The instruments used in this study are all based on self-report responses which can be tainted by common method variance (CMV). Reio (2010) listed eight items that can be used to help reduce the effects of CMV, such as acquiring predictor and criterion variables from several sources, spreading out the measurement, counterbalancing the question sequence, providing clear instructions, and ensuring anonymity (p. 408). Participants in this study will be given clear instructions and ensured anonymity to help minimize the likelihood of CMV.

\section{Procedures}

Approval was obtained from Florida International University's Human Subjects Review Board. Several meetings took place between the researcher and the gatekeeper prior to data collection in order to observe sites and prepare for data collection. A gatekeeper is someone who is useful in accessing the sample population (Bogdan \& Biklen, 2007). In this study, the gatekeeper was a union official who provided initial guidance and access to the bus depot locations. The researcher visited each of the three bus depot locations one time before data collection to observe common areas and population sample. Approval was then obtained from the county transportation Research and Review Committee and permission to start data collection was obtained from the county's administrative director. The following section outlines the procedures used for sampling, data collection, and data analysis. 


\section{Sampling}

Three bus depots, at different locations within the same county, were selected to conduct this study. All employed bus drivers, bus aides, mechanics and clerical workers at selected depots were asked to voluntarily participate in the study.

\section{Data Collection}

A flyer was posted at each of the bus depots one week prior to the data collection data to announce the specifics of the study. Data was collected by the researcher and two research assistants on three different weekdays from 9am to $4 \mathrm{pm}$ at each of the bus depots to allow for all employees to participate. Each participant was given a stapled packet that included a consent form, 14 demographic questions, and the JCQ, COPE and MBI instruments (Appendix A), a pen and a clipboard. Each participant was offered help in reading the questions or if any clarification of any question was needed. At the end of each day, each completed survey was labeled with the depot identifier and numbered consecutively. Each packet was then placed in a secure box.

\section{Data Analysis}

Demographic information was analyzed using descriptive statistics including frequency, mean, and standard deviation. All quantitative data were analyzed using SPSS database (version 20.0 for Windows) and examined for significant relationships of stated hypotheses using correlational and regression analysis (Field, 2009; Trochim \& Donnelly, 2008). 
$H_{1 a}$ : Different occupational categories of employees in the same workplace have different levels of physical demands.

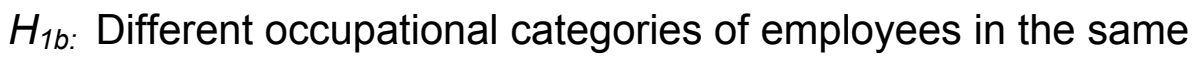
workplace have different levels of psychological demands.

$H_{1 c:}$ Different occupational categories of employees in the same employees have different levels of job control.

To test $\mathrm{H}_{1 \mathrm{a}}, \mathrm{H}_{1 \mathrm{~b} \text {, and }} \mathrm{H}_{1 \mathrm{c}}$, a means analysis was conducted to provide an overall summary of scores on each of the dependent variables. A simultaneous linear regression analysis was then performed to test for statistical significance. The resulting standardized regression coefficients indicated the number of standard deviations that the outcome will change as a result of one standard deviation change in the variable of interest, providing the importance and strength of a model (Field, 2009).

$H_{2 a:}$ Occupations characterized by greater levels of physical demands and lower levels of job control have high greater levels of individual employee burnout.

$H_{2 b \text { : }}$ Occupations characterized by greater levels of psychological demands and lower levels of job control have greater levels of individual employee burnout.

To test $\mathrm{H}_{2 a}$ and $\mathrm{H}_{2 \mathrm{~b}}$, first a means analysis was conducted based on each of the MBI subscales to provide an overall summary of the scores. A simultaneous regression analysis was performed on each of the MBI subscale 
scores. Lastly, these results, along with a means analysis of each of the MBI subscales, and results from the first set of hypotheses were interpreted.

$H_{3:}$ Individual differences in coping act as a moderator between job structure and individual employee burnout.

To test $\mathrm{H}_{3}$, a simultaneous regression analysis of ways of coping (using three new factors that emerged after a principal component analysis with varimax rotation) by Job Title, and the MBI subscales was conducted.

\section{Summary}

This chapter delineated the research design, population and sample, variables and instrumentation and procedures employed for data collection and analysis. 


\section{CHAPTER IV}

\section{RESULTS}

The results of this study are presented in this chapter. The background of the sample is presented using descriptive statistics including frequency and mean. Next, each hypothesis is examined using correlational and regression analyses (Field, 2009; Trochim \& Donnelly, 2008). A summary of the results concludes this chapter.

\section{Background of the Sample}

A total of 859 public school county transportation workers, including bus drivers, bus aides, mechanics, and clerical workers were employed at the three bus depots located in a large metropolitan area from which the sample was drawn. Of these, 525 were bus drivers, 223 were bus aides, 51 were mechanics, and 60 were clerical workers. A total of 253 individuals completed surveys (25.9\% response rate). Demographic variables such as sex, race, job title, age, years in job, and work shift are analyzed in the following subsections.

Participation by bus depot is also displayed.

\section{Sex}

A frequency analysis of gender indicates that 68 participants were men (26.9\%) and 184 were women (72.7\%); one respondent (.40\%) did not report his/her gender. 


\section{Race/Ethnicity}

A frequency analysis of race/ethnicity indicated that of the participants, 200 (79.1\%) were Black, 15 (5.9\%) were White, 30 (11.9\%) were Hispanic, 6 $(2.4 \%)$ chose Other, and $2(.79 \%)$ did not select a race/ethnicity.

\section{Job Title}

The four job titles surveyed in this study were: Bus Driver, Bus Aide, Mechanic, and Clerical Worker. A frequency analysis illustrated that 133 (52.6\%) of participants were Bus Drivers, 51 (20.2\%) were Bus Aides, 33 (13\%) were Mechanics, and $36(14.2 \%)$ were Clerical Workers. These data are shown in Table 1.

Table 1

Frequency Table of Demographic Variables

\begin{tabular}{llcc}
\hline Category & Variable & Frequency & Percent \\
\hline \multirow{3}{*}{ Sex } & Male & 68 & $26.9 \%$ \\
& Female & 184 & $72.7 \%$ \\
& Not reported & 1 & $.40 \%$ \\
& $N$ & 253 & $100 \%$ \\
\hline \multirow{3}{*}{ Race } & Black & 200 & \\
& White & 15 & $79.1 \%$ \\
& Hispanic & 30 & $5.9 \%$ \\
& Other & 6 & $11.9 \%$ \\
& Not reported & 2 & $2.4 \%$ \\
& $N$ & 253 & $100 \%$ \\
\hline \multirow{3}{*}{ Job Title } & & 133 & \\
& Bus Driver & 51 & $52.6 \%$ \\
& Bus Aide & 33 & $13 \%$ \\
& Mechanic & 35 & $14.2 \%$ \\
& Clerical Worker & 1 & $100 \%$ \\
\hline
\end{tabular}


A cross tabulation of sex and race/ethnicity by job title showed that a great majority of Bus Drivers (81.2\%), Bus Aides (92.2\%) and Clerical Workers $(82.9 \%)$ were female. The Mechanics, however, were $100 \%$ male. All four job titles were comprised of predominantly Black participants (see Table 2).

Table 2

Cross Tabulation of Sex and Race/Ethnicity by Job Title

\begin{tabular}{|c|c|c|c|c|c|c|c|c|}
\hline \multirow[t]{2}{*}{ Job Title } & \multicolumn{3}{|c|}{ Sex } & \multicolumn{5}{|c|}{ Race/Ethnicity } \\
\hline & $\begin{array}{c}\text { Male } \\
(\%)\end{array}$ & $\begin{array}{c}\text { Female } \\
(\%)\end{array}$ & $\begin{array}{r}\text { Total } \\
100 \% \\
\end{array}$ & $\begin{array}{c}\text { Black } \\
(\%)\end{array}$ & $\begin{array}{c}\text { White } \\
(\%)\end{array}$ & $\begin{array}{c}\text { Hispanic } \\
(\%)\end{array}$ & $\begin{array}{c}\text { Other } \\
(\%)\end{array}$ & $\begin{array}{l}\text { Total } \\
100 \% \\
\end{array}$ \\
\hline Bus Driver & $\begin{array}{c}25 \\
(18.7 \%)\end{array}$ & $\begin{array}{c}108 \\
(81.2 \%)\end{array}$ & 133 & $\begin{array}{c}115 \\
(86.5 \%)\end{array}$ & $\begin{array}{c}4 \\
(3 \%)\end{array}$ & $\begin{array}{c}11 \\
(8.27 \%)\end{array}$ & $\begin{array}{c}3 \\
(2.2 \%)\end{array}$ & 133 \\
\hline Bus Aide & $\begin{array}{c}4 \\
(7.8 \%)\end{array}$ & $\begin{array}{c}47 \\
(92.2 \%)\end{array}$ & 51 & $\begin{array}{c}49 \\
(96 \%)\end{array}$ & 0 & $\begin{array}{c}2 \\
(3.92 \%)\end{array}$ & 0 & 51 \\
\hline Mechanic & $\begin{array}{c}33 \\
(100 \%)\end{array}$ & 0 & 33 & $\begin{array}{c}12 \\
(38.7 \%)\end{array}$ & $\begin{array}{c}5 \\
(16.1 \%)\end{array}$ & $\begin{array}{c}13 \\
(41.9 \%)\end{array}$ & $\begin{array}{c}1 \\
(3.2 \%)\end{array}$ & 31 \\
\hline $\begin{array}{l}\text { Clerical } \\
\text { Worker }\end{array}$ & $\begin{array}{c}6 \\
(17.1 \%)\end{array}$ & $\begin{array}{c}29 \\
(82.9 \%)\end{array}$ & 35 & $\begin{array}{c}24 \\
(66.7 \%)\end{array}$ & $\begin{array}{c}6 \\
(16.7 \%)\end{array}$ & $\begin{array}{c}4 \\
(11.1 \%)\end{array}$ & $\begin{array}{c}2 \\
(5.6 \%)\end{array}$ & 36 \\
\hline$N$ & $\begin{array}{c}68 \\
(26.9 \%)\end{array}$ & $\begin{array}{c}184 \\
(72.7 \%)\end{array}$ & 252 & $\begin{array}{c}200 \\
(79.7 \%)\end{array}$ & $\begin{array}{c}15 \\
(5.9 \%)\end{array}$ & $\begin{array}{c}30 \\
(11.9 \%)\end{array}$ & $\begin{array}{c}6 \\
(2.4 \%)\end{array}$ & 251 \\
\hline
\end{tabular}

A cross tabulation of bus depot location by job title revealed that Bus Drivers were more willing to participate at the North (39\%) and South (40.6\%) locations than at the Southwest location (20.4\%). There were more Bus Aide participants at the North (41.2\%) and South (35.3\%) locations than the Southwest location 
(23.5\%). Half of the Clerical Worker participants were from the Southwest location. Table 3 shows a summary of these data.

Table 3

Cross Tabulation of Bus Depot Location by Job Title

Job Title

Bus Depot Location

\begin{tabular}{cccc}
\hline $\begin{array}{c}\text { North } \\
(\%)\end{array}$ & $\begin{array}{c}\text { South } \\
(\%)\end{array}$ & $\begin{array}{c}\text { Southwest } \\
(\%)\end{array}$ & $\begin{array}{c}\text { Total } \\
100 \%\end{array}$ \\
\hline 52 & 54 & 27 & 133 \\
$(39 \%)$ & $(40.6 \%)$ & $(20.4 \%)$ &
\end{tabular}

Bus Aide

21

18

$(41.2 \%) \quad(35.3 \%) \quad(23.5 \%)$

12

51

Mechanic

13

(39.4\%)

9

11

33

(27.3\%)

(33.3\%)

Clerical

8

$(22.2 \%)$

10

$(27.8 \%)$

18

36

Worker

$\quad(50 \%)$

$N$

\begin{tabular}{ccc}
94 & 91 & 68 \\
$(37 \%)$ & $(36 \%)$ & $(27 \%)$ \\
\hline
\end{tabular}

\section{Work Shift}

Participants were asked to provide information about their work shift. A cross tabulation analysis indicated that among Bus Drivers, 93\% $(n=124)$ worked a split shift, $3 \%(n=4)$ a midday shift, $2.2 \%(n=3)$ a morning shift, and $1.5 \%(n=2)$ a stand-by shift; $96 \%(n=48)$ of Bus Aides reported working a split shift, and $4 \%(n=2)$ a morning shift and one not reporting a shift. Among the Mechanics, 93.9\% $(n=31)$ indicated they worked an 8-hour shift, with 6\% $(n=2)$ 
not reporting a shift. Among the Clerical Workers, $100 \%(n=36)$ reported working an eight hour shift.

\section{Age}

A mean analysis of age showed the average age of participants $(n=246)$ was 49.6 years with a standard deviation of 9.25 . Approximately $2.7 \%(n=7)$ of participants did not report their age.

\section{Years on the Job}

A mean analysis revealed the average years on the job of participants $(n=247)$ was 15.32 with a standard deviation of 7.76 (Table 4). Approximately 2.4\% $(n=6)$ did not report their years on the job. The average age of Bus Drivers was 49.19, Bus Aides, 50, Mechanics, 49.6 and Clerical Workers, 49.6 (Table 5). Table 4 Summary of Means of Age and Years on the Job

\begin{tabular}{lcc}
\hline Variable & $n$ & $M$ \\
Age & 246 & $(S D)$ \\
& & 49.6 \\
Years on the job & 247 & $(9.25)$ \\
& & 15.32 \\
\end{tabular}


Table 5

Cross Tabulation of Means and Standard Deviations of Job Title by Age and Years on the Job

\begin{tabular}{|c|c|c|c|c|c|c|c|c|}
\hline \multirow[b]{3}{*}{ Variable } & \multicolumn{8}{|c|}{ Job Title } \\
\hline & \multicolumn{2}{|c|}{ Bus Driver } & \multicolumn{2}{|c|}{ Bus Aide } & \multicolumn{2}{|c|}{ Mechanic } & \multicolumn{2}{|c|}{ Clerical Worker } \\
\hline & $n$ & $\begin{array}{c}M \\
(S D)\end{array}$ & $n$ & $\begin{array}{c}M \\
(S D)\end{array}$ & $n$ & $\begin{array}{c}M \\
(S D)\end{array}$ & $n$ & $\begin{array}{c}M \\
(S D)\end{array}$ \\
\hline Age & 130 & $\begin{array}{l}49.19 \\
(8.59)\end{array}$ & 51 & $\begin{array}{c}50 \\
(9.84)\end{array}$ & 31 & $\begin{array}{c}49.6 \\
(12.2)\end{array}$ & 34 & $\begin{array}{l}49.6 \\
(7.8)\end{array}$ \\
\hline $\begin{array}{l}\text { Years on the } \\
\text { Job }\end{array}$ & 132 & $\begin{array}{l}14.58 \\
(7.22)\end{array}$ & 51 & $\begin{array}{c}17.5 \\
(7.44)\end{array}$ & 31 & $\begin{array}{c}15 \\
(9.76)\end{array}$ & 33 & $\begin{array}{l}15.32 \\
(8.16)\end{array}$ \\
\hline
\end{tabular}

\section{Examination of Hypotheses}

Job structure was used in this study to describe the characterization of a job based on Karasek's (1998) model which includes job demands and job control. In the analysis that follows job structure was operationalized through job titles of respondents, specifically Bus Aides, Bus Drivers, Clerical Workers, and Mechanics. Karasek's job strain model is conceptualized as having three related components: physical demands, psychological demands, and decision latitude.

Ordinary least squares (OLS) regression analyses were used to test each of the first three hypotheses to establish how different occupational categories in the same workplace have different levels of physical and psychological demands, as well as different levels of job control. Additionally, OLS regression analyses were used to test the second set of hypotheses exploring the relationship between occupations and different dimensions of physical and psychological demands, and burnout. Hypothesis 3 was examined by conducting an OLS 
analysis to examine if individual ways of coping act as a moderator between job structure and individual employee burnout.

Hypotheses 1a, 1b, 1c

The physical demands 5-item subscale from the Job Content Questionnaire (JCQ) used for this study (Karasek et al., 1998) had a Cronbach's $\alpha=.825(n=250)$. A reliability statistic Cronbach's alpha between .7 and .8 indicates an acceptable value for a reliable scale (Field, 2009). A simple means analysis of physical demands among the four occupational categories shows the Mechanics had the highest mean of 13.78 with a standard deviation of 3.95 (see Table 6). Although the means provide an overall summary of scores, the simultaneous regression analysis was used to formally test each hypothesis. 
Table 6

Summary of Means and Standard Deviations of Job Content Questionnaire (JCQ) Scale Scores by Job Title

JCQ Scales

\begin{tabular}{lccc}
\hline & \multicolumn{2}{c}{ JCQ Scales } \\
\cline { 2 - 4 } Job Title & Physical & Psychological & Decision \\
& Demands & Demands & Latitude \\
& $M$ & $M$ & $M$ \\
& $(S D)$ & $(S D)$ & $(S D)$ \\
\cline { 2 - 4 } Bus Driver & & & \\
& 11.73 & 29.35 & 61.75 \\
Bus Aide & $(3.27)$ & $(5.99)$ & $(10.11)$ \\
& & & \\
Mechanic & 12.29 & 28.84 & $(9.21)$ \\
& $(3.49)$ & $(5.93)$ & 63.13 \\
Clerical Worker & 13.78 & 29.64 & $(10.12)$ \\
& $(3.95)$ & $(6.77)$ & 70.97 \\
& 10.09 & 31.44 & $(24.35)$ \\
\hline
\end{tabular}

( $n$ = range from 256 - 251 due to missing data)

Simultaneous regression analysis for testing $\mathrm{H}_{1 \mathrm{a}}$. Hypothesis 1 a stated that different occupational categories of employees in the same workplace have different levels of physical demands. Table 7 presents the multivariate simultaneous regression analysis of physical job demands. In Model 1a, physical job demands are regressed on three control variables - work site, gender and marital status. In the case of work site, two dummy variables, North and Southwest, were created to represent the North and Southwest depots, respectively. These are compared to the South Depot that is represented in the base of the equation. As is evident in Table 7, Model 1a, model has poor fit $\left(R^{2}{ }_{a d j}=-.017, F=.209\right)$ and there is no statistically significant relationship 
between the perceived physical demands of work and the work site, gender, and married status of respondents at the $p<.05$-level. Model $1 \mathrm{~b}$ includes the control variables in Model 1a and Years on the Job as an additional control variable. Model $1 \mathrm{~b}$, as well, has poor fit $\left(R^{2}{ }_{a d j}=-.020, F=.263\right)$, indicating no statistically significant relationships at the $p<.05$-level.

Model $1 \mathrm{c}$ includes the control variables of Models $1 \mathrm{a}$ and $1 \mathrm{~b}$ and adds the job title variables to represent the construct of job structure. Three job title dummy variables are used in Model 1c: Bus Aide, Bus Driver, and Clerical Worker to represent workers in these job titles. They are compared to Mechanics who are in the base of the equation. The results of Model 1c indicate support for Hypothesis $1_{\mathrm{a}}$ that postulated a relationship between job title and physical demands $\left(R_{\text {adj }}^{2}=.116, F=4.091, p<.001\right)$. Specifically, when compared to Mechanics (in the base of the model), Bus Aides, Bus Drivers, and Clerical Workers have significantly lower perceptions of physical job demands $(p .<$ .001). Also noteworthy in Model $1 \mathrm{c}$ is that after the inclusion of the job title variables, the control variable of gender becomes statistically significant $(p<.01)$. This suggests that controlling for job title, male respondents report lower levels of perceived physical job demands. 
Table 7

Summary of Simultaneous Regression Analysis of Physical Job Demands

\begin{tabular}{lccc}
\hline & \multicolumn{3}{c}{ Physical Job Demands } \\
\cline { 2 - 4 } Variable & Model 1a & Model 1b & Model 1c \\
\cline { 2 - 4 } North & -.039 & -.022 & .009 \\
Southwest & -.047 & -.018 & .012 \\
Male & -.006 & -.006 & $-.254^{* *}$ \\
Single & & -.065 & -.022 \\
Years on Job & & .043 & -.021 \\
Bus Aide & & & $-.439^{* * *}$ \\
Bus Driver & & & $-.625^{\star * *}$ \\
Clerical Worker & 193 & 189 & $-.575^{\star * *}$ \\
$N$ & -.017 & -.020 & 189 \\
$R_{\text {adj }}^{2}$ & .209 & .263 & .116 \\
$F$ Statistic & & & $4.091^{* * *}$ \\
\hline
\end{tabular}

Note: Standardized $\beta$ coefficients used. ${ }^{*} p<.05,{ }^{* *} p<.01,{ }^{* * *} p<.001$

Simultaneous regression analysis for testing $\mathbf{H}_{1 \mathrm{~b}}$. Hypothesis $1 \mathrm{~b}$ stated that different occupational categories of employees in the same workplace have different levels of psychological demands. Table 8 presents the multivariate simultaneous regression analysis of psychological job demands. In Model 2a, psychological job demands are regressed on three control variables - work site, gender, and marital status. In the case of work site, two dummy variables, North and Southwest, were created to represent the North and Southwest depots, respectively. The South depot is used in the base of the equation. Model 2a shows a poor fit $\left(R_{a d j}^{2}=.006, F=1.317\right)$ with no statistically significant 
relationship between the perceived psychological demands of work and work site, gender, or married status of respondents.

Model $2 \mathrm{~b}$ adds an additional control variable, Years on the Job, to Model 2a. Once this variable was added, results show a statistically significant relationship between bus depot location and psychological job demands $\left(R^{2}{ }_{a d j}=\right.$ $.010, F=1.404)$ with respondents at the Southwest depot perceiving lower levels of psychological demands than respondents at North and South Depots $(p<.05)$.

Model $2 c$ includes the control variables of Models $2 a$ and $2 b$ and adds the job title variables to represent the construct of job structure. Three job title dummy variables are used in Model 2c: Bus Driver, Clerical Worker, and Mechanic to represent workers in these job titles. These are compared to Bus Aides who are in the base of the equation. Although the results of Model $2 \mathrm{c}$ do not indicate support for Hypothesis $1 \mathrm{~b}$ that posited a relationship between occupational category and psychological demands $(p>.05)$, there was still a statistically significant relationship between the bus depot location and psychological job demands in the fully specified model $(p<.05)$. However, the overall poor fit of this fully specified model and low F-Statistic indicates the low of statistical validity of Model $2 \mathrm{c}\left(R_{\text {adj }}^{2}=-.004, F=.914\right)$. 
Table 8

Summary of Simultaneous Regression Analysis of Psychological Job Demands

\begin{tabular}{lccc}
\hline & \multicolumn{3}{c}{ Psychological Job Demands } \\
\cline { 2 - 4 } Variable & Model 2a & Model 2b & Model 2c \\
\cline { 2 - 4 } North & .141 & $.164^{*}$ & $.166^{*}$ \\
Southwest & .150 & $-.174^{*}$ & $.165^{*}$ \\
Male & .031 & .042 & .012 \\
Single & .009 & .004 & .006 \\
Years on Job & & .001 & -.007 \\
Bus Driver & & & -.008 \\
Clerical Worker & & & .024 \\
Mechanic & 195 & 191 & .048 \\
$N$ & .006 & .010 & 191 \\
$R^{2}{ }_{\text {adj }}$ & 1.317 & 1.404 & -.004 \\
$F$ Statistic & & & .914 \\
\hline
\end{tabular}

Note: Standardized $\beta$ coefficients used. ${ }^{*} p<.05,{ }^{* *} p<.01,{ }^{* * *} p<.001$

Simultaneous regression analysis for testing $\mathbf{H}_{1 \mathrm{c}}$. Hypothesis $1 \mathrm{c}$ stated that different occupational categories of employees in the same workplace have different levels of decision latitude. Table 9 presents the multivariate simultaneous regression analysis of decision latitude. In Model 3a, decision latitude is regressed on three control variables - work site, gender, and married status. Again, two dummy variables, North and Southwest, were created to represent the North and Southwest depots, respectively. The South depot is used in the base of the equation. Model 1a shows a poor fit $\left(R^{2}{ }_{a d j}=.011, F=\right.$ 1.543) with no statistically significant relationship between respondents' 
perceived decision latitude and work site, gender, or married status. Model 2b also shows no significant relationships after adding Years on the Job as a control variable $\left(R^{2}{ }_{a d j}=.038, F=2.495\right)$.

Model $3 c$ includes the control variables of Models $1 a$ and $1 b$ and adds the job title variables to represent the construct of job structure. Three job title dummy variables are used in Model 3c: Bus Driver, Bus Aide, and Mechanic to represent workers in these job titles. These are compared to the Clerical Workers who are in the base of the equation. Results of Model $3 c$ indicate support for Hypothesis 1c that proposed a relationship between occupational category and decision latitude $\left(R_{\text {adj }}^{2}=.048, F=2.173, p<.05\right)$. More specifically, Clerical Workers perceive greater decision latitude, or job control, as compared to Bus Aides $(p<.05)$. In addition, after including job title variables, work site becomes statistically significant; with respondents at the Southwest depot perceiving higher levels of job latitude $(p<.05)$. 
Table 9

Summary of Simultaneous Regression Analysis of Decision Latitude

\begin{tabular}{lccc}
\hline & \multicolumn{3}{c}{ Decision Latitude } \\
\cline { 2 - 4 } Variable & Model 3a & Model 3b & Model 3c \\
\hline North & -.098 & -.047 & -.052 \\
Southwest & .104 & .221 & $.191^{*}$ \\
Male & .046 & .077 & .103 \\
Single & .069 & .019 & .010 \\
Years on Job & & -.017 & -.008 \\
Bus Driver & & & -.204 \\
Bus Aide & & & $-.222^{*}$ \\
Mechanic & 191 & 187 & -.183 \\
$N$ & .011 & .038 & 187 \\
$R_{\text {adj }}^{2}$ & 1.543 & 2.495 & .048 \\
$F$ Statistic & & & 2.173 \\
\hline
\end{tabular}

Note: Standardized $\beta$ coefficients used. ${ }^{*} p<.05,{ }^{* *} p<.01,{ }^{* * *} p<.001$

\section{Hypotheses 2a, 2b}

The second set of hypotheses was tested using the Maslach Burnout Inventory $(\mathrm{MBI})$ to measure burnout. The $\mathrm{MBI}$ includes three subscales: emotional exhaustion, depersonalization, and personal accomplishment, each used to measure a different dimension of burnout (Maslach et al., 1996). Analysis of responses $(n=242)$ on the nine-item emotional exhaustion subscale indicated it was reliable (Cronbach's $\alpha=.874)$. Analysis of the 5 -item depersonalization subscale indicated that it was also reliable (Cronbach's $\alpha=$ $.688, n=235$ ) as was the eight-item personal accomplishment (Cronbach's $\alpha=$ $.760, n=239)$. 
Higher mean scores on the emotional exhaustion and depersonalization scales correlate with higher degrees of burnout. The personal accomplishment scale measures the feeling of reduced personal accomplishment, another indicator of burnout (Maslach \& Jackson, 1981). Higher means on this scale indicate lower levels of burnout. For clearer presentations of results, the final results of this scale were reverse scored; therefore, lower means on the personal accomplishment scale results used in this study indicate lower levels of burnout. Table 10 provides a summary of the mean scores for each of the MBI subscales by Job Title. 
Table 10

Summary of Means and Standard Deviations of Maslach Burnout Inventory (MBI) Scale Scores by Job Title

\begin{tabular}{|c|c|c|c|}
\hline \multirow[b]{2}{*}{ Job Title } & \multicolumn{3}{|c|}{ MBI Scales } \\
\hline & Emotional Exhaustion & Depersonalization & $\begin{array}{c}\text { Personal } \\
\text { Accomplishment }\end{array}$ \\
\hline & $\begin{array}{c}M \\
(S D) \\
\end{array}$ & $\begin{array}{c}M \\
(S D) \\
\end{array}$ & $\begin{array}{c}M \\
(S D) \\
\end{array}$ \\
\hline \multicolumn{4}{|l|}{ Bus Driver } \\
\hline & $\begin{array}{c}15.77 \\
(11.76)\end{array}$ & $\begin{array}{c}4.44 \\
(4.78)\end{array}$ & $\begin{array}{c}-23.78 \\
(9.45)\end{array}$ \\
\hline \multirow[t]{2}{*}{ Bus Aide } & 17.70 & 7.44 & -24.30 \\
\hline & $(11.95)$ & $(6.72)$ & $(11.24)$ \\
\hline Mechanic & $\begin{array}{c}20.93 \\
(14.38)\end{array}$ & $\begin{array}{c}9.27 \\
(7.75)\end{array}$ & $\begin{array}{c}-29.31 \\
(9.37)\end{array}$ \\
\hline \multirow[t]{2}{*}{ Clerical Worker } & 16.33 & 5.09 & -30.73 \\
\hline & (11.99) & $(5.73)$ & $(9.87)$ \\
\hline
\end{tabular}

The following section presents multivariate simultaneous regression analyses that were conducted on each of the subscales of the MBI (emotional exhaustion, depersonalization, and personal accomplishment). Next, these results, along with results from Hypotheses $1 \mathrm{a}, 1 \mathrm{~b}$, and 1c, were interpreted to test Hypotheses 2a and 2b.

Table 11 presents the multivariate simultaneous regression analysis of emotional exhaustion. In Model 4a, emotional exhaustion is regressed on three control variables - work site, gender and married status. In the case of work site, 
two dummy variables, North and Southwest, were created to represent the North and Southwest depots, respectively. These are compared to the South Depot that is represented in the base of the equation. Model 4a has poor fit $\left(R^{2}{ }_{a d j}=\right.$ $.024, F=1.123)$ and there is no statistically significant relationship between reported emotional exhaustion and work site, gender, and marital status of respondents at the $p<.05$ level.

Model $4 b$ adds Years in Job as an additional control variable. Results show a statistically significant relationship between bus depot location and emotional exhaustion $\left(R_{a d j}^{2}=.173, F=1.542\right)$ with participants at the North depot expressing more emotional exhaustion than those at the South depot at the $p<.05$-level.

Model $4 c$ includes the control variables of Models $4 a$ and $4 b$ and adds the job title variables to represent the construct of job structure. Three job title dummy variables are used in Model 4c: Bus Driver, Bus Aide, and Clerical Worker to represent workers in these job titles. Mechanics are in the base of the equation. The results of Model $4 \mathrm{c}$ indicate that Mechanics, when compared to Bus Drivers, Bus Aides, and Clerical Workers have higher levels of emotional exhaustion $\left(R_{\text {adj }}^{2}=.062, F=2.519, p<.05\right)$. There was also a statistically significant relationship between bus depot location with participants at the North depot showing higher levels of emotional exhaustion than those at the South depot at the $p<.05$-level. 
Table 11

Summary of Simultaneous Regression Analysis of Emotional Exhaustion

\begin{tabular}{lccc}
\hline & & Emotional Exhaustion \\
Variable & Model 4a & Model 4b & Model 4c \\
\cline { 2 - 4 } North & .159 & $.173^{*}$ & $.186^{*}$ \\
Southwest & .015 & .025 & .007 \\
Male & .009 & .034 & -.152 \\
Single & -.007 & .005 & .026 \\
Years on the & & .123 & .061 \\
Job & & & $-.495^{* *}$ \\
Bus Driver & & & $-.328^{*}$ \\
Bus Aide & & & $-.313^{* *}$ \\
Clerical Worker & 187 & 183 & 183 \\
$N$ & .024 & .015 & .062 \\
$R_{\text {adj }}^{2}$ & 1.123 & 1.542 & $2.519^{*}$ \\
$F$ Statistic & & & \\
\hline$N$
\end{tabular}

Note: Standardized coefficients used. ${ }^{*} p<.05,{ }^{\star *} p<.01,{ }^{\star \star *} p<.001$

A multivariate regression analysis of depersonalization is presented in

Table 12. Model 5a shows depersonalization regressed on three control variables - work site, gender and married status. Two dummy variables, North and Southwest, were created to represent the North and Southwest depot locations respectively. These are compared to the South Depot that is represented in the base of the equation. Model 5 a has poor fit $\left(R^{2}{ }_{\text {adj }}=.006\right.$, $F=1.275)$ and there is no statistically significant relationship between reported depersonalization and work site, gender, and married status of respondents at the $p<.05$ level. Model $5 \mathrm{~b}$ adds Years in Job as an additional control variable 
and also shows poor fit $\left(R^{2}{ }_{a d j}=.032, F=2.166\right)$ with no statistically significant relationship at the $p>.05$ level.

Model $5 c$ includes the control variables of Models $5 a$ and $5 b$ and adds the job title variables to represent the construct of job structure. Three job title dummy variables are used in Model 5c: Bus Driver, Mechanic, and Clerical Worker to represent workers in these job titles. Bus Aides are in the base of the equation. The results of Model $5 \mathrm{c}$ indicate that Bus Aides, when compared to Bus Drivers, have higher levels of depersonalization $\left(R^{2}{ }_{a d j}=.109, F=3.712, p\right.$ $<.01)$.

Table 12

Summary of Simultaneous Regression Analysis of Depersonalization

\begin{tabular}{lccc}
\hline & & & \\
& & & \\
\cline { 2 - 3 } Variable & Model 5a & Model 5b & Model 5c \\
\hline & & & \\
North & .094 & .097 & .115 \\
Southwest & -.052 & -.052 & -.091 \\
Male & .093 & .121 & -.043 \\
Single & -.010 & .016 & .026 \\
Years on the & & .177 & .108 \\
Job & & & $-.242^{* *}$ \\
Bus Driver & & & .177 \\
Mechanic & & & -.091 \\
Clerical Worker & 181 & 177 & 177 \\
$N$ & .006 & .032 & .109 \\
$R^{2}{ }_{\text {adj }}$ & 1.275 & 2.166 & $3.712^{* *}$ \\
$F$ Statistic & & &
\end{tabular}

Note: Standardized coefficients used. ${ }^{*} p<.05,{ }^{* *} p<.01,{ }^{* * *} p<.001$ 
Table 13 presents the summary of the multivariate simultaneous regression of personal accomplishment. For clearer presentations of results, the final results of this scale were reverse scored; therefore, lower means on the personal accomplishment scale results used in this study indicate lower levels of burnout and higher levels indicate higher levels of burnout. In Model 6a, personal accomplishment is regressed on three control variables - work site, gender and marital status. Again, two dummy variables, North and Southwest, were created to represent the North and Southwest depot locations respectively to be compared to the South Depot that is represented in the base of the equation. Model 6a has poor fit $\left(R^{2}{ }_{a d j}=.016, F=1.770\right)$ and there is no statistically significant relationship between reported personal accomplishment and work site, gender, and married status of respondents at the $p<.05$ level. Model $6 b$ adds Years in Job as an additional control variable and also shows poor fit $\left(R^{2}{ }_{a d j}=.013, F=1.476\right)$ with no statistically significant relationship at the $p<.05$ level.

However, after adding the job title variables as control variables to Models $6 a$ and $6 b$, Model $6 c$ shows that Bus Drivers and Bus Aides have a lower sense of personal accomplishment than Clerical Workers (in the base of the equation) and Mechanics $\left(R_{\text {adj }}^{2}=.066, F=2.596, p<.01\right)$. 
Table 13

Summary of Simultaneous Regression Analysis of Personal Accomplishment

\begin{tabular}{lccc}
\hline & \multicolumn{3}{c}{ Personal Accomplishment } \\
\cline { 2 - 4 } Variable & Model 6a & Model 6b & Model 6c \\
\hline North & .054 & .052 & .050 \\
Southwest & -.116 & -.122 & -.055 \\
Male & -.142 & -.143 & -.078 \\
Single & -.035 & -.032 & -.031 \\
Years on the Job & & -.048 & -.031 \\
Bus Driver & & & $.411^{* *}$ \\
Mechanic & & & .138 \\
Bus Aide & 186 & 182 & $.314^{* *}$ \\
$N$ & .016 & .013 & 182 \\
$R_{\text {adj }}^{2}$ & 1.770 & 1.476 & .066 \\
$F$ Statistic & & & $2.596^{*}$ \\
\hline
\end{tabular}

Note: Standardized coefficients used. ${ }^{*} p<.05,{ }^{* *} p<.01,{ }^{* * *} p<.001$

Hypothesis 2a interpretation. Hypothesis 2a stated that occupations

that show greater levels of physical demands and lower levels of job control have greater levels of individual employee burnout. Regression results from Model 3c show that Clerical workers have greater decision latitude and lower sense of personal accomplishment than Bus Aides. Regression results from Model 1c show Mechanics have the greatest physical demands on the job. Results from the multivariate regression analyses in Model $4 c$ and Model $6 c$ used to test $\mathrm{H}_{2 a}$ show Mechanics have greater levels of emotional exhaustion, a key indicator of burnout Therefore, the data provide evidence that partially supports $\mathrm{H}_{2 a}$. 
Hypothesis $\mathbf{2 b}$ interpretation. Hypothesis $2 b$ stated that occupations that are characterized by greater levels of psychological demands and lower levels of job control have greater levels of individual employee burnout. Regression results from Model 2c indicated Bus Aides had lower decision latitude, or job control and results of Model $5 c$ showed that Bus Aides, when compared to Bus Drivers, have higher levels of depersonalization, an indicator of burnout. Therefore, $\mathrm{H} 2 \mathrm{~b}$ is partially supported. Table 14 provides a summary of these results. 
Table 14

Summary of Simultaneous Linear Regression Analysis of Relationship between Maslach Burnout Inventory (MBI) Scales, Job Content Questionnaire (JCQ) Scales and Job Title, Bus Depot Location, Gender, and Marital Status

\begin{tabular}{|c|c|c|c|c|c|c|}
\hline \multirow[b]{2}{*}{ Job Title } & \multicolumn{3}{|c|}{ JCQ Scales } & \multicolumn{3}{|c|}{ MBI Scales } \\
\hline & $\begin{array}{l}\text { Physical Job } \\
\text { Demands } \\
\text { (Model 1c) } \\
\end{array}$ & $\begin{array}{c}\text { Psychological Job } \\
\text { Demands } \\
\text { (Model 2c) } \\
\end{array}$ & $\begin{array}{c}\text { Decision } \\
\text { Latitude } \\
\text { (Model 3c) }\end{array}$ & $\begin{array}{l}\text { Emotional } \\
\text { Exhaustion } \\
\text { (Model 4c) } \\
\end{array}$ & $\begin{array}{c}\text { Depersonalization } \\
\text { (Model 5c) } \\
\end{array}$ & $\begin{array}{c}\text { Personal } \\
\text { Accomplishment } \\
\text { (Model 6c) }\end{array}$ \\
\hline Bus Driver & $-.625^{\star \star \star}$ & -.008 & -.204 & $-.495^{\star \star \star}$ & $-.242^{\star \star}$ & $.411^{* *}$ \\
\hline Bus Aide & $-.439^{\star * *}$ & - & $-.222^{*}$ & $-.328^{\star}$ & - & $.314^{\star *}$ \\
\hline Mechanic & - & .198 & -.183 & - & .177 & .138 \\
\hline $\begin{array}{l}\text { Clerical } \\
\text { Worker }\end{array}$ & $-.575^{\star \star \star}$ & .024 & - & $-.313^{* *}$ & -.091 & - \\
\hline North & -.009 & $.166^{\star}$ & -.052 & $.186^{*}$ & .115 & .050 \\
\hline South & - & - & - & - & - & - \\
\hline Southwest & .012 & $.165^{\star}$ & $.191^{*}$ & .007 & -.091 & -.055 \\
\hline Single & -.022 & .006 & .010 & .026 & .026 & -.031 \\
\hline $\begin{array}{l}\text { Years on the } \\
\text { Job }\end{array}$ & -.021 & -.007 & -.008 & .061 & .108 & -.031 \\
\hline Male & $-.254^{\star *}$ & .012 & .103 & -.152 & -.043 & -.078 \\
\hline$N$ & 189 & 191 & 187 & 183 & 177 & 182 \\
\hline$R_{a d j}^{2}$ & .116 & -.004 & .048 & .062 & .109 & .066 \\
\hline F Statistic & $4.091^{* * *}$ & .914 & $2.653^{*}$ & $2.519^{*}$ & $3.712^{\star *}$ & $2.596^{*}$ \\
\hline
\end{tabular}

Note: Standardized $\beta$ coefficients used. ${ }^{*} p<.05,{ }^{* *} p<.01,{ }^{* * *} p<.001$ 


\section{Hypothesis 3}

The Brief COPE Survey (Carver, 1997) was used to establish different individual ways of coping. The 28 -items of the survey represent 14 different ways of coping using two items per scale. Table 15 delineates each way of coping scale and the two items under each with the corresponding Cronbach's alpha reliability. The three scales, Acceptance $(\alpha=.488, n=250)$, Venting $(\alpha=$ $.476, n=248)$, and Self-distraction $(\alpha=.432, n=251)$ each had an alpha level

under .60 indicating a relatively low reliability score. These scales were dropped. Furthermore, a principal component analysis with varimax rotation confirmed poor factor loadings of these three scales as discussed in the following section. 


\section{Table 15}

Cronbach's Alpha Reliability for Brief COPE Inventory Scales

\section{Brief COPE scale name and questions}

Religion

I try to find comfort in my religion or spiritual beliefs.

I pray or meditate.

Humor

I make jokes about it.

I make fun of the situation.

Denial

I say to myself this isn't real.

I refuse to believe that it has happened.

Use of instrumental support

I get help and advice from other people.

I try to get advice or help from other people about what to do.

Self-blame

I criticize myself.

I blame myself for things that happen.

Planning

I try to come up with a strategy about what to do.

I think hard about what steps to take.

Positive reframing

I try to see it in a different light to make it more positive.

I look for something good in what is happening.

Substance Use

I use alcohol or other drugs to make myself feel better.

I use alcohol or other drugs to get through it.

Behavioral disengagement

I give up trying to deal with it.

I give up the attempt to cope.

Use of emotional support

I get emotional support from others.

I get comfort and understanding from someone.

Active Coping

I concentrate my efforts on doing something about the situation.

I take action to try to make the situation better.

Acceptance

I accept the reality of the fact that it has happened.

I learn to live with it.

Venting

I say things to let my unpleasant feelings escape.

I express my negative feelings.

Self-distraction

I turn to work or to other activities.

I do something to think about it less such as going to the movies, watching $t v$, reading, daydreaming, sleeping, or shopping.
252

.764

251

.720

251

.670

251

.663

249

.662

250

.650

253

.645

252

.644

251

.617

252

.617

247

.609

250

.488

248

.476

251

Note: Scales listed in order from high to low Cronbach's a values. 
A principal component analysis with a varimax rotation was conducted. A varimax rotation maximizes the distribution of loadings within factors to simplify interpretation (Field, 2009). A study by Guadagnoli and Velicer (1988) found that the most significant factors are component saturation (the absolute magnitude of the loadings) and the absolute sample size (p. 333). Therefore, components with four or more loadings above .60 in absolute value are reliable regardless of the sample size; components with about 10 or more low loadings (.40 or below) are reliable when the sample size is greater than 150 (Guadagnoli \& Velicer, 1988). Stevens (2012) recommended loadings above .512 for sample sizes of about 100 , and loadings above .364 for sample sizes of about 200 to be reliable.

Results from the principal component analysis with varimax rotation (see Table 16) show that Factor 1 had six loadings ranging from .534 to $.785, \alpha=.82$, showing high reliability according to both Guadagnoli (1988) and Stevens (2012). Factor 2 had four loadings ranging from .615 to $.849, \alpha=.79$, and Factor 3 had four loadings ranging from .569 to $.790, \alpha=.72$ showing high reliability.

In a study to examine stress appraisals, ways of coping, social support, and burnout at work between social workers, psychologists and nurses, Ben-Zur and Michael (2007) showed a structure of two factors. Two scales were formed: a problem-focused scale, loaded on active coping, planning, suppression of competing activities, instrumental and emotional support, and positive reinterpretation $(\alpha=.70)$; and an emotion-focused scale, loaded on mental and behavioral disengagement, denial, ventilation, acceptance, alcohol use, and humor $(\alpha=.67)($ Ben-Zur \& Michael, 2007, p. 70). Because restraint and religion 
each loaded less than .40 these were not included. Similarly, after a principal component analysis with varimax rotation, the Acceptance $(\alpha=.488, n=250)$, Venting ( $\alpha=.476, n=248)$, and Self-distraction scales $(\alpha=.432, n=251)$ in the present study loaded less than .40 , except for one item under the Self-distraction scale, (Acceptance, .331 and .227; Venting, .190 and .044; and Self-Distraction, .492 and .122; see Table 16). 


\section{Table 16}

\section{Results of Principal Component Analysis with Varimax Rotation of Brief COPE Scale}

\begin{tabular}{|c|c|c|c|}
\hline \multirow[b]{2}{*}{ Scale items } & \multicolumn{3}{|c|}{ Factors } \\
\hline & 1 & 2 & 3 \\
\hline I take action to try to make the situation better. & .785 & .218 & .039 \\
\hline I try to come up with a strategy about what to do. & .742 & .114 & .002 \\
\hline I look for something good in what is happening. & .694 & .243 & .010 \\
\hline I think hard about what steps to take. & .595 & .063 & .114 \\
\hline $\begin{array}{l}\text { I concentrate my efforts on doing something about the } \\
\text { situation. }\end{array}$ & .584 & .188 & -.036 \\
\hline $\begin{array}{l}\text { I try to see it in a different light to make it more } \\
\text { positive. }\end{array}$ & .534 & .142 & -.016 \\
\hline I turn to work or other activities. & .492 & .022 & .235 \\
\hline I accept the reality of the fact that it has happened. & .331 & .186 & -.154 \\
\hline I learn to live with it. & .227 & .078 & .141 \\
\hline I get comfort and understanding from someone. & .220 & .801 & .061 \\
\hline I try to find comfort in my religion or spiritual beliefs. & .193 & .155 & .036 \\
\hline I say things to let my unpleasant feelings escape. & .190 & .029 & .399 \\
\hline $\begin{array}{l}\text { I try to get advice or help from other people about what } \\
\text { to do. }\end{array}$ & .182 & .670 & .076 \\
\hline I refuse to believe that it has happened. & .152 & .085 & .790 \\
\hline I get emotional support from others. & .148 & .615 & .064 \\
\hline I pray or meditate. & .147 & .149 & -.046 \\
\hline I say to myself this isn't real. & .134 & .017 & .757 \\
\hline I get help and advice from other people. & .135 & .849 & .007 \\
\hline I do something to think about it less. & .122 & .259 & .226 \\
\hline I make jokes about it. & .118 & .076 & .042 \\
\hline I use alcohol or other drugs to make myself feel better. & .080 & .009 & .051 \\
\hline I make fun of the situation. & .060 & .103 & .092 \\
\hline I blame myself for things that happen. & .066 & -.010 & .328 \\
\hline I express my negative feelings. & .044 & .173 & .109 \\
\hline I criticize myself. & -.004 & .044 & .169 \\
\hline I use alcohol or other drugs to get through it. & -.037 & .054 & .129 \\
\hline I give up trying to deal with it. & -.053 & -.023 & .667 \\
\hline I give up the attempt to cope. & -.266 & .177 & .569 \\
\hline Eigenvalue & 3.41 & 2.61 & 2.49 \\
\hline$\%$ of Variance & 12.18 & 9.34 & 8.87 \\
\hline$\alpha$ & .82 & .79 & .72 \\
\hline
\end{tabular}


Ways of coping describe recognizable action types (Lazarus, 1996) which should be organized into higher order categories consistent with their adaptive function (Skinner et al., 2003). The six items that significantly loaded on Factor 1 make up three of the original Brief COPE scales, Active Coping, Planning, and Positive Reframing, all rational indicators of a problem solving approach to coping; therefore Factor 1 was labeled as Problem-solving Coping. To further substantiate this label, a meta-analysis of 100 coping assessments and factor loadings by Skinner et al. (2003) found that Problem-solving was used as a label in 40 of the assessments and included instrumental action, direct action, decision making and planning.

The four items that significantly loaded on Factor 2 make up two of the Brief COPE scales, Use of Instrumental support and Use of Emotional Support; this factor was labeled as Support-Seeking Coping. Support-Seeking was used as a label in 34 of 100 coping assessments and included comfort seeking, help seeking, and spiritual support after a meta-analysis of 100 coping assessments and factor loadings (Skinner et al., 2003).

Factor 3 had four significant loadings made up of two of the Brief COPE scales, Behavioral Disengagement and Denial. This factor was labeled as Escape Coping for this study. According to Skinner et al. (2003), Escape Coping was used in 13 out of 100 coping assessments and included avoidance, disengagement and denial.

Simultaneous Regression Analysis for testing $\mathrm{H}_{3}$. Hypothesis 3 stated that individual differences in coping act as a moderator between job structure, 
operationalized by job title, and individual employee burnout. To test if individual ways of coping have a moderator effect between job structure, operationalized by job title, and individual employee burnout, a simultaneous regression analysis of ways of coping (using the three new coping factors, Problem-solving, SupportSeeking, and Escape) by Job Title, and the MBI scales was conducted. As a result of the regression analysis, $6.4 \%$ of the variance in personal accomplishment was accounted for by the linear relationship with Bus Drivers' Problem-solving Coping, $R_{\text {adj }}^{2}=.064, p<.01$. Bus Drivers who used Escape Coping show a significant positive correlation with emotional exhaustion, $R_{\text {adj }}^{2}=$ $.025, p<.05$ and with personal accomplishment, $R_{\text {adj }}^{2}=.048, p<.05$.

The personal accomplishment scale was negatively and significantly correlated with Bus Aides' Problem-solving Coping, $R_{\text {adj }}^{2}=.023, p<.01$ and Support-Seeking Coping, $R_{\text {adj }}^{2}=.022, p<.05$, while the depersonalization scale was positively and significantly correlated with Bus Aides' Escape Coping, $R^{2}{ }_{\text {adj }}=$ $.037, p<.01$.

Results from the linear regression show for Mechanics: a significant and negative relationship between Problem-solving Coping and emotional exhaustion, $R_{\text {adj }}^{2}=.045, p<.01$, Problem-solving Coping and depersonalization, $R_{\text {adj }}^{2}=.140, p<.001$, and Problem-solving Coping and personal accomplishment, $R_{\text {adj }}^{2}=.047, p<.01$; and a significant and positive correlation between Support-Seeking Coping and depersonalization, $R_{\text {adj }}^{2}=.128, p<.05$, and Escape Coping and depersonalization $R_{\text {adj }}^{2}=.262, p<.001$. Therefore, the research evidence supports Hypothesis 3, which stated that individual 
differences in coping act as a moderator between job structure and individual employee burnout. Table 17 provides a summary of these results. 
Table 17

Summary of Linear Regression Analysis of Relationship between Maslach Burnout Inventory Scales (MBI) and New Coping Factors (Problem-solving Coping, Support-Seeking Coping, Escape Coping) by Job Title

\begin{tabular}{|c|c|c|c|c|c|c|c|c|c|}
\hline \multirow{3}{*}{ Variable } & \multicolumn{9}{|c|}{ MBI Scales } \\
\hline & \multicolumn{3}{|c|}{ Emotional Exhaustion } & \multicolumn{3}{|c|}{ Depersonalization } & \multicolumn{3}{|c|}{ Personal Accomplishment } \\
\hline & $\beta$ & $R_{\text {adj }}^{2}$ & $\begin{array}{l}\text { Sig. F } \\
\text { change }\end{array}$ & $\beta$ & $R_{\text {adj }}^{2}$ & $\begin{array}{l}\text { Sig. } F \\
\text { change }\end{array}$ & $\beta$ & $R_{\text {adj }}^{2}$ & $\begin{array}{l}\text { Sig. F } \\
\text { change }\end{array}$ \\
\hline \multicolumn{10}{|l|}{$\underline{\text { Bus Driver }}$} \\
\hline Problem-solving Coping & -.056 & .003 & .393 & -.053 & .044 & .420 & -.198 & .064 & $.002^{* *}$ \\
\hline Support-Seeking Coping & -.079 & .006 & .229 & .034 & .042 & .600 & -.031 & .026 & .638 \\
\hline Escape Coping & .158 & .025 & $.016^{*}$ & .118 & .055 & .069 & .152 & .048 & $.019 *$ \\
\hline \multicolumn{10}{|l|}{ Bus Aide } \\
\hline Problem-solving Coping & .020 & -.007 & .764 & .031 & .008 & .645 & -.171 & .023 & $.009 * *$ \\
\hline Support-Seeking Coping & .078 & -.001 & .227 & .017 & .007 & .792 & -.166 & .022 & $.011^{*}$ \\
\hline Escape Coping & .065 & -.003 & .326 & .178 & .037 & $.008^{* *}$ & .053 & -.003 & .430 \\
\hline \multicolumn{10}{|l|}{$\underline{\text { Mechanic }}$} \\
\hline Problem-solving Coping & -.179 & .045 & $.005^{\star *}$ & -.299 & .140 & $.000^{* * *}$ & -.189 & .047 & $.003^{* *}$ \\
\hline Support-Seeking Coping & .091 & .021 & .162 & .128 & .067 & $.048 *$ & -.062 & .014 & .347 \\
\hline Escape Coping & .115 & .026 & .073 & .262 & .120 & $.000 * * *$ & .052 & .013 & .422 \\
\hline \multicolumn{10}{|l|}{ Clerical Worker } \\
\hline Problem-solving Coping & -.045 & -.006 & .530 & -.033 & -.006 & .667 & -.084 & .039 & .270 \\
\hline Support-Seeking Coping & -.075 & -.002 & .247 & .030 & -.005 & .652 & -.067 & .038 & .294 \\
\hline Escape Coping & .136 & .008 & .053 & .121 & .007 & .082 & .113 & .045 & .099 \\
\hline
\end{tabular}




\section{Summary}

Several instruments were used to test the hypotheses based on an extensive review of the literature. Results supported Hypothesis 1a that stated there was a relationship between occupational category and physical job demands. Bus Aides, Bus Drivers, and Clerical Workers, when compared to Mechanics, had significantly lower perceptions of physical job demands. There was no evidence to support a relationship between occupational category and psychological demands. Results showed support for Hypothesis 1c with Clerical Workers perceiving greater decision latitude, or job control, as compared to Bus Aides.

Furthermore, Mechanics, who perceived the greatest physical demands, also had greater levels of emotional exhaustion, a key indicator of burnout. Therefore, the data provide evidence that partially supports $\mathrm{H}_{2 \mathrm{a}}$. Results indicated Bus Aides had lower decision latitude, or job control, and that when compared to Bus Drivers, had higher levels of depersonalization, an indicator of burnout. Therefore, $\mathrm{H}_{2 b}$ is partially supported.

The data analysis supported Hypothesis 3 with results finding significant correlations between individual ways of coping as a moderator between job structure, operationalized by job title, and individual employee burnout. The results and implications for theory, research and practice are discussed in Chapter 5. 


\section{CHAPTER V}

\section{DISCUSSION}

This final chapter presents a summary of the study followed by a discussion of the results. The first two sections relate to the first two sets of hypotheses and the overarching question of how job demands and control were related to burnout among four groups of workers in the transportation department of the same school district. The final section relates to the last hypothesis and overarching question about ways of coping as a moderator between job structure and burnout. Next, implications for theory, research and practice are discussed. The final section provides limitations of the study.

\section{Summary of the Study}

There is a noteworthy connection between job structure, work environment, and individual perceptions of control, demands, rewards and coping within the work environment. Previous studies demonstrated that occupations with high levels of demands and low levels of control lead to higher levels of burnout (Maslach, 2001; Schaufeli \& Bakker, 2004; Schaufeli et al., 2009).

Burnout in these studies was measured by using the three subscales of emotional exhaustion, depersonalization and personal accomplishment of the MBI (Maslach et al., 1996). Burnout had many negative outcomes in terms of employee health and impact on the work organization.

The purpose of this study was to examine the relationship between the structure of jobs, operationalized by job title, and burnout and to assess to what extent, if any, this relationship is moderated by individual ways of coping. Two 
overall overarching questions framed this study: (a) what is the relationship between job control and demands, and burnout across different occupations in support services within the same large municipal school district? and (b) To what extent do individual differences in coping methods moderate these relationships? Specifically, the following hypotheses were tested:

$H_{1 a}$ : Different occupational categories of employees in the same workplace have different levels of physical demands.

$H_{1 b}$ : Different occupational categories of employees in the same workplace have different levels of psychological demands.

$H_{1 c}$ : Different occupational categories of employees in the same workplace have different levels of job control.

$H_{2 a}$ : Occupations characterized by greater levels of physical demands and lower levels of job control have greater levels of individual employee burnout.

$H_{2 b}$ : Occupations characterized by greater levels of psychological demands and lower levels of job control have greater levels of individual employee burnout.

$H_{3}$ : Individual differences in coping act as a moderator between job structure, operationalized by job title, and individual employee burnout.

\section{Discussion of the Results}

Guided by theory and research, the following two sections interpret the results of the study as they relate to each hypothesis. The data analysis indicates that there were statistically significant and relevant relationships among the variables of interest; job demands, job control, burnout, and ways of coping. 


\section{Hypotheses 1a, 1b, 1c - Job Structure, Demands and Control}

The initial hypothesis was used to examine if different job titles, more specifically, Bus Drivers, Bus Aides, Mechanics, and Clerical Workers within the same organization perceived different levels of physical job demands. Results indicated that Mechanics perceived higher levels of physical demands than the three other job titles in this sample.

However, results did not show a significant difference of psychological demands among the four occupational categories of employees in the same workplace. One possible explanation for the low variability across the occupations groups was that there appeared to a relatively high level of disaffection across all employees in the workplace. Successive years of budget cuts have led to stagnant wages and little investment in the worksites that were rundown. During data collection at the worksites, the researcher observed an overall sense of apathy and helplessness among all of the employees. A constant and consistent remark from individuals in all four job titles was related to low salary and no raises in the past seven years within the public school transportation department. This may have translated into indiscernible effects among the employees on the psychological demands scale. Although there were no statistical differences among the groups, the mean values and standard deviations were similar to those reported by de Araujo and Karasek (2008) for informal jobs in transportation.

With regards to the hypothesis $1_{\mathrm{c}}$, among the four groups in this study, Clerical Workers did show greater job control based on the decision latitude 
scale scores than the other three occupational categories. At the same time, it would be incorrect to suggest that Clerical Workers have a lot of job control. Rather, this result may only reflect the very low job control of the other three occupational categories. During data collection, Bus Drivers and Bus Aides consistently shared with the researcher how little control they have over their job. For example, a Bus Driver's job is dictated by strict time schedules. In addition, Bus Drivers have little control over who rides their bus and many times are subjected to aggressive and discourteous behavior. Bus Aides, although their main job is to aid the driver with the riders, also complained that they felt there was little they could do in cases of disruptive riders.

These three initial hypotheses were used to establish the job structure of each of the four job titles in terms of Karasek's model. Hence, Mechanics had higher physical demands and lower sense of job control, whereas the Clerical Workers experienced greater job control. There were some differences across the locations, with respondents from the North depot showed greater levels of psychological demands than those at the South depot.

\section{Hypotheses 2a and 2b-Job Structure and Burnout}

Mechanics had greater physical demands and showed greater levels of emotional exhaustion when compared to the Bus Aides. Job structure for Mechanics in this study can thus be defined as one with high physical demands and lower job control, placing this occupational group in the high strain quadrant of Karasek's model of occupational stress. Furthermore, among the four job titles, Mechanics showed the greatest levels of emotional exhaustion. Mean 
scores were also the highest for mechanics for emotional exhaustion and depersonalization.

Consistent with findings from previous research studies, Clerical Workers with greater decision latitude experienced greater levels of personal accomplishment; therefore suggesting lower levels of burnout. Studies have shown a significant correlation between job control and personal accomplishment (Halbesleben \& Buckley, 2004; Landsbergis, 1988).

Therefore, these findings partially support $\mathrm{H}_{2 \mathrm{a}}$ by showing that occupations, specifically Mechanics, with greater levels of physical demands and have greater levels of individual employee burnout as evidenced by their higher levels of emotional exhaustion. There was no statistical significance for Mechanics and job control. A previous research study presented similar results with emotional exhaustion being more strongly associated with higher job demands than lower control (Rafferty et al., 2001) while other studies showed workers who perceived high job demands and low control on the job tended to experience symptoms of burnout (Landsbergis, 1988; Maslach \& Schaufeli, 1993; Schaufeli \& Bakker, 2004; Schaufeli et al., 2009). In a study of 1,482 nurses, results high job demands and low skill discretion, one of the subscales for job control, were the best predictors of occupational stress (Pisanti et al., 2011).

Results partially supported Hypothesis $2 \mathrm{~b}$ which postulated that occupations characterized by greater levels of psychological demands and lower levels of job control have greater levels of individual employee burnout. There 
were no statistically significant findings of difference among the four occupational groups based on psychological demands as noted in the discussion of $\mathrm{H}_{1 \mathrm{~b}}$ above, but Bus Aides did show lower decision latitude, or control, and higher levels of depersonalization. In a study specifically looking at the Karasek's model and burnout, results also showed depersonalization and reduced personal accomplishment were more strongly associated with lower control than with higher demands (Rafferty et al., 2001). Furthermore, reduced personal accomplishment was also related to lower control in a study by Landsbergis (1988).

It is interesting to note, that the North depot results indicated a significantly overall higher level of psychological demands as well as higher levels of emotional exhaustion suggesting that Karasek's model may not only be applicable for characterization of individual occupations, but also may be useful to assess demands and control within organizations as a whole. Based on researcher observations, many factors may have played a role in these findings at the North Depot. The lounge was small and mostly dimmed. Bus Drivers and Bus Aides expressed clear concerns about the danger of some of the routes with regards to the children being transported. The Mechanics were the most vocal about their distrust of the central administration. The lot is not properly secured so that buses are vandalized on the weekends- so an overall sense of negativity was constant. 


\section{Hypothesis 3}

Hypothesis 3 postulates that individual differences in coping act as a moderator between job structure, operationalized by job title, and individual employee burnout. Problem-solving, Support-seeking and Escape coping strategies were used to describe individual differences in coping after a factor analysis on the Brief COPE by Carver. Each of these was regressed with each of the MBI subscales by Job Title.

Problem-solving coping. Three out of the four job titles, Bus Drivers, Bus Aides, and Mechanics showed a negative correlation between Problemsolving Coping and personal accomplishment. Problem-solving coping attributes a sense of control (Greenglass \& Burke, 2000; Lazarus, 2006) and was negatively associated with a sense of personal accomplishment (reverse scored). However, it is possible that in stressful situations, problem-solving coping may lead to confusion and helplessness (Skinner et al., 2003, p. 231), and therefore, a diminished sense of personal accomplishment. In addition, for the Mechanics, Problem-solving Coping was negatively and significantly correlated to emotional exhaustion and depersonalization.

Researchers have found problem-focused coping strategies to be significantly negatively correlated to emotional exhaustion even suggesting the use of problem focused coping to alleviate detrimental effects of emotional exhaustion (Lewin \& Sager, 2009; Sand \& Miyazaki, 2000). In a study of 1,363 nurses, use of problem-solving coping or control coping lead to less likelihood of cynicism or depersonalization (Greenglass \& Burke, 2000). 
Support-seeking coping. There was a negative correlation between Support-seeking Coping and personal accomplishment for Bus Aides consistent with studies that have shown support-seeking coping moderated sense of personal accomplishment, (Cordes et al., 1997). There is also the possibility that Bus Aides who had a greater sense of personal accomplishment sought to cope through support seeking. It is important to note, that although in this study the results were consistent with previous research, it is possible that when comfort and emotional support from others is not found through support-seeking coping, it may actually lead to isolation and depersonalization (Skinner et al., 2003; Skinner \& Zimmer-Gembeck, 2007).

There was a positive correlation between Support-seeking Coping and depersonalization for Mechanics. Depersonalization refers to an insensitive reaction toward people who are recipients of one's services (Schaufeli \& Greenglass, 2001). Gender may have played an indirect role as masculinity has normally been associated with strength and autonomy (Greenglass, 1991) and depersonalization may reflect men's repressed emotionality (Schaufeli \& Greenglass, 2001). A meta-analysis of the relationship between gender and burnout using 409 effect sizes from 183 studies indicated that men were more depersonalized than women regardless of the occupation (Purvanova \& Muros, 2010).

Escape coping. There was a significant and positive correlation between Escape Coping and emotional exhaustion for Bus Drivers. Studies have been inconsistent with findings showing how escape and disengaging ways 
of coping are related to emotional exhaustion. There is support for both positive (Greenglass \& Burke, 2000; Boyd et al., 2009) and negative correlations between escape coping and emotional exhaustion (Riolli \& Savicki, 2003; Lewin \& Sager, 2009). Greenglass and Burke (2000) found that escape coping was associated with greater psychological distress in the nurses studied while Riolli and Savicki (2003) showed that escapist strategies used by computer analysts were significantly and negatively correlated with emotional exhaustion.

There was also a significant and positive correlation between Escape Coping and personal accomplishment (reverse scored) for Bus Drivers. Individuals who have a lower sense of self-esteem tended to use escape coping strategies (Folkman et al., 1986) as well as those experiencing prolonged frustration (Perrewé \& Zellars, 1999). Lazarus and Folkman (1984) also posited that when individuals are faced with stressful situations perceived as unsolvable, escapist strategies may lessen the degree of stress felt; hence there is a possibility of a greater sense of personal accomplishment. However, Lazarus (2006) stated the importance of seeing and describing individuals within their environment when considering ways of coping. Although this dissertation was a quantitative study, the researcher made observations of the work environments as well as witnessed the interactions among individuals in all four job titles over a period of three weeks. Specifically, Bus Drivers and Bus Aides were mostly observed playing cards in between their work shifts. It is plausible these types of activities provide an element of escape, and therefore may serve to strengthen their sense of personal accomplishment. 
Additionally, there was a positive correlation between Escape Coping and depersonalization for both Bus Aides and Mechanics. Although Greenglass and Burke (2000) reported that escape coping was correlated with depersonalization, gender may again have played a role in the positive correlation for the Mechanics. Furthermore, as compared to the other job titles in this study, Mechanics have the least amount of direct responsibility for others.

In summary, it is important that these results showed coping plays a moderating role. The literature substantiates that there is no wrong or right way of coping (Skinner et al., 2003); it may be that certain occupations are presented with similar stressful situations, and therefore may use similar ways of coping. If workers can be educated as to the possibility that coping may help in the way they see things, then this a valuable tool for organizations as well as employees, not only to help reduce stress levels among employees, but also to help the organization in terms of costs related to absenteeism, health insurance, turnover, and job productivity.

\section{Implications for Theory}

This study was conducted within the framework of Karasek's Job Demand Control Support model of occupational stress, Maslach's theoretical basis of burnout, and integrates Lazarus' theory of the role of individual differences through ways of coping. Findings from this study partially supported all of the hypotheses, providing further empirical evidence to the related to occupational stress, burnout and ways of coping. Furthermore, the integration of ways of coping as a moderator between job structure was valuable in helping to assess 
the role of individual differences. This section will discuss the implications for each of these theoretical frameworks.

Job Control and Demands

Mechanics indicated a greater level of physical job demands and a lower sense of job control. These results fit the model well as hypothesized for job structure, where different occupations have different levels of job demands and control. Using these results, Mechanics were then placed into the high strain quadrant. Karasek and Theorell (1990) identified four quadrants within the model: high strain, low strain, active, and passive jobs. High strain occupations experienced high demands, low control, and low social support (Dollard, 2003). Low strain jobs have low demands, but high decision latitude. High-level executives and professionals, who experience high demands and high decision latitude, are classified as having active jobs. Passive jobs have low demands and low control.

Therefore, if supervisors want to create a job structure that is more balanced in terms of demands and control in organizations, there should be an effort to minimize job demands in relation to job control, or to offer more job control where job demands are high. For example, grounded in the job demands and control theory, administrators may use results of the JCQ in addition to questionnaires geared to each job title to help identify specific work stressors that can then be addressed. 


\section{Job Structure and Burnout}

Findings from this study revealed that Mechanics, with a job structure of greater physical job demands and lower sense of control, showed greater levels of emotional exhaustion and a lower sense of personal accomplishment pointing to symptoms of burnout. In addition to using Karasek's model to establish job structure among the four job titles, this study examined if high strain jobs lead to symptoms of burnout using Maslach's theoretical framework of burnout.

Research from this study supported Karasek's (1998) four quadrant model and provided further empirical evidence to the findings from the meta-analysis of 63 studies which showed strong support for the strain hypothesis, which states that the most negative psychological well being is found in employees working in high demands and low control jobs (Van der Doef \& Maes, 1999). Additionally, research evidence from this study supported Karasek's (1990) model and extends Maslach and Schaufeli's (1993) theory that burnout describes the feeling of emotional exhaustion, depersonalization (cynicism), and ineffectiveness or feeling a lack of personal accomplishment attributable to work stressors (Halbesleben \& Buckley, 2004).

The job structure of Mechanics, one of high demands and low control, accounted for $6.2 \%$ of the variance in predicting emotional exhaustion and for $6.6 \%$ of perceived level of depersonalization adding to empirical evidence in the burnout literature. High demands and low control lead to burnout as evidenced by prior research studies (Day et al., 2009; Johnson et al., 1989; Pisanti et al., 2011; Van der Doef \& Maes, 1999). Furthermore, no known research study has 
included a population of county public school bus drivers, bus aides, mechanics and clerical workers within these frameworks making these findings of unique significance for the theoretical construct of burnout.

Lastly, findings supported and extended Karasek's (1990) model by providing empirical evidence that not only characteristics of jobs can help define job structure, but also characteristics of organizations as a whole may help define organizational demands and control. It can be suggested that organizations can then be placed within a quadrant as substantiated by the North depot results showing a significantly overall higher level of psychological demands, as well as higher levels of emotional exhaustion._Human resource professionals along with administrators may use these results to assess job structure to help prevent symptoms of burnout both among individual job structures and organizations as well.

\section{Role of Individual Differences through Coping}

Findings of simultaneous regression analyses provided empirical evidence that ways of coping act as a moderator between job structure and burnout for three of the four job titles (Bus Drivers, Bus Aides, Mechanics), and support and extend Lazarus' (1984) emphasis on the role of individual differences through coping. Moreover, when groups are studied, individual differences along with the contexts of where the individual variation occurred should be considered.

Findings from this study showed that job structure is also useful in determining work stressors. Results for this study extended the theoretical framework where interpretation of objective stressors, discussed in terms of coping methods, plays 
an important role in predicting employee strain (Lazarus, 2006; Perrewé \& Zellars, 1999); and therefore, supported the proposed model that a combination of worker and work environment is key in occupational stress theory, not job structure exclusively but rather a dynamic model involving individual differences in ways of coping and burnout in addition to job structure.

According to the transactional model, the response to an environmental stressor is either problem-focused or emotion-focused coping (Lazarus, 1995). However, the findings of this study showed that coping responses could not be defined exclusively as one or the other, supporting previous research studies that showed there are up to 400 ways of coping and higher order categories that may be described differently according to stressors (Skinner et al., 2003). For example, Mechanics, with a job structure defined by this study as one with high physical demands and low control showed higher levels of burnout.

Furthermore, once coping styles were added, Problem-solving coping, Supportseeking coping and Escape coping all indicated a moderating effect on personal accomplishment, emotional exhaustion, and depersonalization for this job title. The transactional model could benefit from more inclusiveness of the demands control theory as well as burnout theory to better address work stressors, response to work stressors and outcomes.

\section{Implications for Research}

The field of occupational stress researchwould benefit from replication and extension of this study by examining not only work environment stressors such as job demands and control, but also researching the outcomes associated with 
these (such as burnout) as well as examining the roles individual coping differences. This parallels the recent interest and investment by NIOSH (2012) to seek out the many issues involving employee health, safety, and stress related to the work environment. Researchers have pointed out the need to explore the relationship between environmental triggers, such as high physical job demands, and emotions, as well as between emotions and coping in organizations (Lazarus, 1996; Perrewé \& Zellars, 1999) citing the importance of understanding how people respond to objective conditions rather than simply correlating stressors to strains (Perrewé \& Zellars, 1999, p. 749).

Replication to further test the proposed model may include the same job titles, specifically county public school transportation employees, and a larger sample across counties and states may better generalize the findings. No prior research study found has studied work stressors, burnout, and coping methods among public school county bus drivers, bus aides, mechanics and clerical workers as the sample population. Future studies might include a mixed method design (Creswell, 2009) to build on the findings of this study. A qualitative approach may give better insight or add more meaningfulness to the quantitative results (Greiner et al., 2004); as in this study the researcher observed and heard about many specific issues that did not surface in the quantitative analyses, such as the overall sense of apathy and helplessness among individuals in all four of the job titles. In addition, structured interviews would provide depth of individuals' perceptions and give a more definite contextual representation (Rubin \& Rubin, 2005) of the experienced stressors and ways of coping. Hence, a mixed 
methods approach using a larger sample may help improve the external validity of the findings of this study.

Experimental designs may also prove useful in adding to the occupational stress research literature to help assess the effects of interventions to enhance coping methods and balance job structure. In turn, the effects of interventions on the outcomes of job structure, such as burnout, could also be examined. An example may be to test an intervention such as a wellness program, which in theory provides an element of control for participants and an escape way of coping. Results of pre and post intervention data, including a measure of burnout, could validate an organizational investment.

Longitudinal studies could enhance the understanding of ways people cope over a period of time and how these moderate perceptions of job structure and burnout, providing a pool of evidence that may be translated into practice. A longitudinal design would help to discover psychological structures such as personality traits, while allowing for the examination of changes in psychological responses over time and varied circumstance (Lazarus, 2000, p. 668).

Researchers could examine county public school transportation employees at a specific number of bus depots over a one year period, which would include the down time of the summer months. It would also be noteworthy to compare the changes in perceived job structure, ways of coping and burnout, over the course of one year for new hires to those of more seasoned workers. Findings of a longitudinal study may yield essential patterns of how employees choose to cope and the effect of these patterns on perceived job structure, giving HRD 
professional tools to better not only the work environment, but also encourage more useful individual ways of coping.

Moreover, the inclusion of significant biometric data would enhance future studies and aid in providing a clinical premise in addition to job structure for interventions. Future researchers can build on the existing literature and studies on urban transit drivers (Chen \& Cunradi, 2008; Greiner et al., 2004; Tse et al., 2006) by replicating the present study with public school bus drivers and including employee facts such as height, weight, hypertension, and evidence of cardiovascular disease. This new data would help interpret relationships between job structure, ways of coping and personal attributes and outcomes. Results would encourage HRD professionals to carve out specific programs in relation to these associations.

\section{Implications for Practice}

Work related strains and emotional exhaustion have been shown to have an annual cost of $\$ 300$ billion to organizations (Chapman, 2005). It has been established that job demands and control are key in the process that leads to burnout, health problems, and other outcomes such as turnover and absenteeism (Schaufeli \& Bakker, 2004). Many organizations have seen the need to modify job structure through job redesign, adjustment to work schedules and goal setting (Schaufeli \& Bakker, 2004).

This study provides support to this idea and also provides evidence that in addition to job structure, individual differences also play an important role in the process that leads to burnout. Previous studies have found that ways of coping 
correlated with urban transit operators' poor health, further sustaining the value of a person-directed intervention (Chen \& Cunradi, 2008). Therefore, HRD professionals can use the results of this study to create targeted individual oriented interventions, such as wellness programs and coaching in coping strategies, as well as organization oriented interventions such as work environment and job redesign.

Research has shown that worksite wellness programs are an effective approach to prevent the major shared risk factors for cardiovascular disease and stroke, including cigarette smoking, obesity, hypertension, physical inactivity, and diabetes, (Carnethon et al., 2009) which in turn have been shown to be related to burnout (Hurrell et al., 1998; Johnson et al., 1989; Landsbergis et al., 2003). A practical plan may include a 12 week comprehensive wellness program, with a two week hiatus from fixed workouts and meetings after the first six weeks, and then completion of the program. The two week hiatus would allow for wellness program participants to evaluate their actions or inactions during this unsupervised time to help identify problems for sustainability once the program ends. The program would incorporate daily, individualized workout schedules, as well as nutrition education and one-on-one counseling. A wellness program cohort could begin every three months with new participants. Pre and post analysis of biometric data would provide evidence of the positive effects of the program.

Sessions on how to cope with stressors may also be a valuable tool in helping to change negatively perceived job structure. As observed by the 
researcher, there is a significant amount of down time in between shifts where bus drivers and bus aides could strongly benefit from specific training in coping with stress. Results from the present study can help guide HRD professionals in promoting and making participants understand how different ways of coping can affect the stress outcome. The program may consist of voluntary small groups of 8-10 for one hour, once a week for six weeks with a financial reward upon completion. The sessions would include common work stressors, the different possibilities and consequences of possible reactions to those stressors, and how perceptions can vary from one incident to another. Studies have shown that stress management programs that incorporate a cognitive-behavioral approach have been linked to reduced burnout (Van der Klink et al., 2001). Undoubtedly, individual- based programs should be complemented by organization oriented programs in order to prove useful over the long term (Schaufeli \& Bakker, 2004).

Organizational oriented interventions need to have an "individually tailored focus" (Van der Klink et al., 2001, p. 275) to be successful. For example, a planned intervention to help better the work environment would have to include feedback from all employees, not just administrators or union leaders. This would require greater communication between the administration and employees. Possible ideas to better the work environment, based on researcher observations from this study, would be to enhance the lounge areas where workers spend hours of break time. For the Mechanics, it may prove useful to provide a better work environment to help alleviate physical demands. Researcher observations revealed that at times the ignition needs to be turned 
on to diagnose or evaluate repairs, while the Mechanics are underneath the bus inhaling harmful fumes. As far as job redesign interventions, findings from this study revealed that job structure, based on perceived demands and control, plays a role in burnout.

Therefore, HRD professionals would be wise to group employees by job title to hear specific issues of each. Each of the job titles would be targeted over a three week period with interviews, anonymous surveys, and observation to build a comprehensive basis from which to launch effective changes that each job title would relate to; as often organizational job redesign are too general for the employee to feel an applicable change (Van der Klink et al., 2001).

\section{Limitations of the Study}

Recent budget cuts to the county transportation department where the study was performed posed the first limitation of this study. There have been current budget cuts affecting government workers, specifically those in transportation. It may be that workers were feeling particularly stressed due to the lack of monetary raises over the last seven years. Thus, it is possible for these factors to have negatively affected stress levels among the population studied.

Another limitation was the use of self-report measures. Self-reports can be tainted by common method variance (CVM). To reduce the likelihood of CVM, participant anonymity was ensured, clear instructions were given verbally and in writing (Reio, 2010). This study was based on perceptions of workers 
which can only be based on self-report measures; therefore an inescapable limitation of the study of burnout (Cordes et al., 1997).

Survey questions asked respondents about the personal use of alcohol and drugs. Social desirability bias has the potential to guide answers that comply with acceptable behavior (Fisher, 1993); however, participants were granted anonymity in order to reduce the likelihood of social desirability bias.

Generalizability of results posed another limitation. In order to improve generalization of results, future studies need to use a sample that includes greater numbers of each job title. In the present study, the majority of participants were bus drivers. In addition, approximately $79 \%$ of all participants were Black; and although representative of the population in this study, it would be interesting to examine other populations with more diverse ethnicity/race. Although analyses did not reveal any significance among ethnicity, generalization beyond the current study should be speculative.

Lastly, the cross-sectional design allowed for a snapshot of workers' perceptions and outcomes; not allowing for causal inferences or order of events with regards to burnout and coping. However, this study focused on examining the associations between variables, not the cause and effects of one variable in relation to the other. Selection bias could have occurred if the respondents in the present study were atypical with regard to their perceptions about their job demands and control but the means showed strong similarity to those of previous studies. 


\section{REFERENCES}

Ahmad, K. Z. (2010). Person-environment fit: A critical review of the previous studies and a proposal for future research. International Journal of Psychological Studies, 2(1), 71-78.

Albright, C., Winkleby, M., Ragland, D., Fisher, J., \& Syme, S. (1992). Job strain and prevalence of hypertension in a biracial population of urban bus drivers. American Journal of Public Health, 82(7), 984-989.

Ashforth, B. E., \& Mael, F. (1989). Social identity theory and the organization. Academy of Management Review, 14(1), 20-39.

Bakker, A. B., Killmer, C. H., Siegrist, J., \& Schaufeli, W. B. (2000). Effort-reward imbalance and burnout among nurses. Journal of Advanced Nursing, 31(4 ), 884-891.

Barak, M. E., Nissly, J., \& Levin, A. (2001). Antecedents to retention and turnover among child welfare, social work, and other human service employees: What can we learn from past research? A review and metanalysis. Social Service Review, 75(4), 625-661.

Baron, R., \& Kenny, D. (1986). The moderator-mediator variable distinction in social psychological research: Conceptual, strategic, and statistical considerations. Journal of Personality and Social Psychology, 51(6), 11731182.

Bartlett II, J. E., Kotrlik, J. W., \& Higgins, C. C. (2001). Organizational research: Determining appropriate sample size in survey research. Informational Technology, Learning, and Peformance Journal, 19(1), 43-50.

Bartone, P. T. (1989). Predictors of stress-related illness in city bus drivers. Journal of Occupational Medicine, 31(8), 657-663.

Beehr, T. A., Glaser, K. M., Canali, K. G., \& Wallwey, D. A. (2001). Back to basics: Re-examination of demand-control theory of occupational stress. Work \& Stress, 15(2), 115-130.

Ben-Zur, H., \& Michael, K. (2007). Burnout, social support, and coping at work among social workers, psychologists, and nurses: the role of dchallenge/control appraisals. Social Work and Health Care, 45(4), 63-82. doi: 10.1300/J010v45n04_04

Berkman, L. F., \& Kawachi, I. (2000). A historical framework for socialepidemiology. In L. F. Berkman \& I. Kawachi (Eds.), Social Epidemiology (pp. 3-12). New York, NY: Oxford Press. 
Biron, M., \& Bamberger, P. (2012). Aversive workplace conditions and absenteeism: taking referent group norms and supervisor support into account. Journal of Appied Psychology, 97(4), 901-912. doi: 10.1037/a0027437

Bogdan, R. C., \& Biklen, S. K. (2007). Qualitative research for education: An introduction to theories and methods (5th ed.). New York, NY: Allyn \& Bacon.

Bond, M. A., Punnett, L., Pyle, J. L., Cazeca, D., \& Cooperman, M. (2004). Gendered Work Conditions, Health, and Work Outcomes. Journal of Occupational Health Psychology; Journal of Occupational Health Psychology, 9(1), 28-45. doi: 10.1037/1076-8998.9.1.28

Boyd, N. G., Lewin, J. E., \& Sager, J. K. (2009). A model of stress and coping and their influence on individual and organizational outcomes. Journal of Vocational Behavior, 75(2), 197-211. doi: 10.1016/j.jvb.2009.03.010

Brief, A., \& George, J. M. (1995). Psychological stress and the workplace: A brief comment on Lazarus' outlook. In R. Crandall \& L. P. Perrewe (Eds.), Occupational stress: A handbook (pp. 15-20). Washington, DC: Taylor \& Francis.

Bureau of Labor Statistics. (2011). Women at work, 2011. Washington, DC: U.S. Department of Labor. Retrieved from http://www.bls.gov/spotlight/2011/women/.

Bureau of Labor Statistics. (2012). Job openings and labor turnover, November 2011. Washington, DC: U.S. Department of Labor. Retrieved from http://www.bls.gov/news.release/pdf/jolts.pdf

Burisch, M. (1993). In search of a theory: Some ruminations on the nature and etiology of burnout. In W. B. Schaufeli, C. Maslach \& T. Marek (Eds.), Professional burnout: Recent developments in theory and research (pp. 75-93). Washington, DC: Taylor \& Francis.

Cable, D. M., \& Edwards, J. R. (2004). Complementary and supplementary fit: a theoretical and empirical integration. Journal of Appied Psychology, 89(5), 822-834. doi: 10.1037/0021-9010.89.5.822

Campbell, J. Q., Nelson, D. L., \& Quick, J. D. (2001). Occupational stress and self-reliance: Developmental and research issues. In J. Dunham (Ed.), Stress in the workplace: Past, present and future (pp. 19-32). London: Philadelphia Whurr Publishing.

Cannon, W. B. (1932). The wsidom of the body (2nd ed.). New York, NY: Norton. 
Caplan, R. D. (1987). Person-Environment fit in organizations: Theories, facts and values. In A. W. Riley \& S. J. Zaccarao (Eds.), Occupational Stress and Organizational Effectiveness (pp. 103-140). New York, NY: Praeger.

Carnethon, M., Whitsel, L. P., Franklin, B. A., Kris-Etherton, P., Milani, R., Pratt, C. A., \& Wagner, G. R. (2009). Worksite wellness programs for cardiovascular disease prevention: A policy statement from the American Heart Association. Circulation, 120(17), 1725-1741. doi: 10.1161/CIRCULATIONAHA.109.192653

Carver, C. S. (1997). You want to measure coping but your protocol's too long: consider the Brief COPE. International Journal of Behavioural Medicine, 4(1), 92-100.

Carver, C. S., Scheier, M. F., \& Weintraub, J. K. (1989). Assessing coping strategies: A theoretically based approach. Journal of Personality and Social Psychology, 56(2), 267-283.

Commerce Clearing House. (2007). Unscheduled absence survey. Retrieved from http://www.cch.com/absenteeism2007/Images/Reasons20062007.pdf.

Chadwick-Jones, J. K., Nicholson, N., \& Brown, C. (1982). Social psychology of absenteeism. New York, NY: Praeger.

Chang, C., \& Spector, P. E. (2011). Cross-cutlural occuaptional health psychology. In J. C. Quick \& L. E. Tetrick (Eds.), Occupational health psychology (pp. 119-137). Washington, DC: American Psychological Association.

Chapman, K. (2005). Are you working too hard? Harvard Business Review, 83, 53-58.

Chen, M.-J., \& Cunradi, C. (2008). Job stress, burnout and substance use among urban transit operators: The potential mediating role of coping behaviour. Work \& Stress, 22(4), 327-340. doi: 10.1080/02678370802573992

Cherniss, C. (1980). Professional burnout in human service organziations. New York, NY: Praeger.

Connor-Smith, J. K., \& Flachsbart, C. (2007). Relations between personality and coping: A meta-analysis. Journal of Personality and Social Psychology, 93(6), 1080-1107. doi: 10.1037/0022-3514.93.6.1080.supp 
Cooper, C. L., Dewe, P. J., \& O'Driscoll, M. P. (2001). Organizational stress: A review and critique of theory, research and applications. Thousand Oak, CA: Sage.

Cooper, C. L., Dewe, P. J., \& O'Driscoll, M. P. (2011). Employee assistance programs: Strengths, challenges, and future roles. In J. C. Quick \& L. E. Tetrick (Eds.), Handbook of occupational health psychology (2nd ed.). Washington, DC American Psychological Association.

Cordes, C. L., Dougherty, T. W., \& Blum, M. (1997). Patterns of Burnout among Managers and Professionals: A Comparison of Models. Journal of Organizational Behavior, 18(6), 685-701.

Cox, T., \& Ferguson, E. (1991). Individual differences, stress and coping. In C. L. Cooper \& R. Payne (Eds.), Personality and stress: Individual differences in the stress process (pp. 7-30). New York: NY: John Wiley \& Sons.

Creswell, J. W. (2009). Research design: Qualitative, quantitative, and mixed methods approaches (3rd ed.). Los Angeles, CA: Sage.

Darr, W., \& Johns, G. (2008). Work strain, health, and absenteeism: a metaanalysis. Journal of Occupational Health Psychology, 13(4), 293-318. doi: $10.1037 / \mathrm{a} 0012639$

David, D., Melman, T., Mendoza, L., Kulick-Bell, R., Ironson, G., \& Schneiderman, N. (1996). Psychiatric morbidity following Hurricane Andrew. Journal of Traumatic Stress, 9(3), 607-612.

Day, A. L., Sibley, A., Scott, N., Tallon, J. M., \& Ackroyd-Stolarz, S. (2009). Workplace risks and stressors as predictors of burnout: The Moderating Impact of Job Control and Team Efficacy. Canadian Journal of Administrative Sciences, 26(1), 7-22.

de Araujo, T. M., \& Karasek, R. (2008). Validity and reliability of the job content questionnaire in formal and informal jobs in Brazil. Scandinavian Journal of Work, Environemnt, and Health, 34(6), 52-59.

De Jonge, J., Bosma, H., Peter, R., \& Siegrist, J. (2000). Jop strain, effort-reward imbalance and employee well-being: a large scale cross-sectional study. Social Science \& Medicine, 50, 1317-1327.

De Jonge, J., \& Kompier, M. A. J. (1997). A critical examination of the demandcontrol-support model from a work psychological perspective. International Journal of Stress Management, 4(4), 235-258.

De Jonge, J., van Vegchel, N., Shimazu, A., Schaufeli, W. B., \& Dormann, C. (2010). A longitudinal test of the demand-control model using specific job 
demands and specific job control. International Journal of Behavior Medicine, 17(2), 125-133. doi: 10.1007/s12529-010-9081-1

de Lange, A. H., Taris, T. W., Kompier, M. A., Houtman, I. L., \& Bongers, P. M. (2003). "The very best of the millennium": Longitudinal research and the demand-control-(support) model. Journal of Occupational Health Psychology, 8(4), 282-305. doi: 10.1037/1076-8998.8.4.282

Demerouti, E., Nachreiner, F., Bakker, A. B., \& Schaufeli, W. B. (2001). The job demands-resources model of burnout. Journal of Applied Psychology, 86(3), 499-512.

Dewe, P. (1997). The Transactional Model of Stress: Some Implications for Stress Management Programs. Asia Pacific Journal of Human Resources, 35(2), 41-51. doi: 10.1177/103841119703500205

Dollard, M. F. (2003). Introduction: Context, Theories and Intervention. In M. F. Dollard, A. H. Winefield \& H. R. Winefield (Eds.), Occupational stress in the service professions (pp. 1-42). London: Taylor \& Francis.

Edwards, J. R., \& Cooper, C. L. (1990). The peron-environment fit approach to stress: recurring problems and some suggested solutions. Journal of Organizational Behavior, 11, 293-307.

Evans, G. W., \& Carrère, S. (1991). Traffic congestion, perceived control, and psychophysiological stress among urban bus drivers. Journal of Applied Psychology, 76(5), 658-663.

Farrow, A., \& Reynolds, F. (2012). Health and safety of the older worker. Occupational Medicine, 62(1), 4-11. doi: 10.1093/occmed/kqr148

Field, A. (2009). Discovering statistics using SPSS (3rd ed.). Los Angeles, CA: Sage.

Fisher, R. J. (1993). Social desirability bias and the validity of indirect questioning. Journal of Consumer Research, 20(2), 303-315.

Folkman, S., \& Lazarus, R. S. (1980). An analysis of coping in a middle-aged community sample. Journal of Health and Social Behavior, 21(3), 219239.

Folkman, S., \& Lazarus, R. S. (1985). If it changes it must be a process: A study of emotion and coping during three stages of a college examination. Journal of Personality and Social Psychology(48), 150-170.

Folkman, S., \& Lazarus, R. S. (1988). Manual for the ways of coping scale. Palo Alto, CA: Consulting Psychology Press. 
Folkman, S., Lazarus, R. S., Gruen, R. J., \& DeLongis, A. (1986). Appraisal, coping, health status, and psychological symptoms. Journal of Personality and Social Psychology, 50(3), 571-579.

Folkman, S., \& Moskowitz, J. T. (2000). Positive affect and the other side of coping. American Psychologist, 55(6), 647-654. doi: 10.1037//0003066x.55.6.647

Freudenberger, J. H. (1977). Burn-out: Occupational hazard of the child care worker. Child and Youth Care Forum, 6(2), 90-99. doi: doi:10.1007/BF01554695

Ganster, C. D., \& Perrewé, P. L. (2011). Theories of occupational stress. In J. Q. Campbell \& L. E. Tetrick (Eds.), Handbook of occupational health psychology (2nd ed., pp. 37-54). Washington, DC: American Psychological Association.

Gay, L. R., \& Airasian, P. (2000). Educational research: Competencies for analysis and application (6th ed.). Englewood Cliffs, NJ: Prentice-Hall.

Geller, E. S. (2001). Behavior-based safety in industry: Realizing the large-scale potential of psychology to promote human welfare. Applied and Preventive Psychology, 10(2), 87-105. doi: 10.1017/s0962-1849(02)01002-8

Gerhart, B. (1987). How important are dispositional factors as determinants of job satisfaction. Journal of Applied Psychology, 72(3), 366-373.

Goh, Y. W., Sawang, S., \& Oei, T. P. S. (2012). The revised transactional model (RTM) of occupational stress and coping: An improved process approach. The Australian and New Zealand Journal of Organisational Psychology, 3, 13-20. doi: 10.1375/ajop.3.1.13

González-Morales, M. G., Rodríguez, I., \& Peiró, J. M. (2010). A longitudinal study of coping and gender in a female-dominated occupation: Predicting teachers' burnout. Journal of Occupational Health Psychology, 15(1), 2944. doi: $10.1037 / \mathrm{a} 0018232$

Greenglass, E. R. (1991). Burnout and gender: Theoretical and organizational implications. Canadian Psychology/Psychologie Canadienne, 32(4), 562574.

Greenglass, E. R., \& Burke, R. J. (2000). Hospital downsizing, individual resources, and occupational stressors in nurses. Anxiety, Stress, and Coping: An International Journal for Nurses in Staff Development, 13(4), 371-390. 
Greiner, B. A., Krause, N., Ragland, D., \& Fisher, J. (1998). Objective stress factors, accidents, and absenteesim in transit operators: A theoretical framework and empirical evidence. Journal of Occupational Health Psychology, 3(2), 130-146.

Greiner, B. A., Krause, N., Ragland, D., \& Fisher, J. M. (2004). Occupational stressors and hypertension: a multi-method study using observer-based job analysis and self-reports in urban transit operators. Social Science \& Medicine, 59(5), 1081-1094. doi: 10.1016/j.socscimed.2003.12.006

Guadagnoli, E., \& Velicer, W. F. (1988). Relation of sample size to the stability of component patterns. Psychological Bulletin, 103(2), 265-275.

Halbesleben, J. R. B., \& Buckley, R. M. (2004). Burnout in Organizational Life. Journal of Management, 30(6), 859-879.

Harris, J. R. (1995). An examination of the transaction approach in occupational stress research. In R. Crandall \& L. P. Perrewe (Eds.), Occupational stress: A handbook (pp. 21-28). Washington, DC: Taylor \& Francis.

Hausser, J. A., Mojzischa, A., Niesela, M., \& Schulz-Hardta, S. (2010). Ten years on: A review of recent research on the Job Demand-Control -(Support) model and psychological well-being. Work \& Stress: An International Journal of Work, Health \& Organisations, 24(1), 1-35. doi: 10.1080/02678371003683747

Hinkle, D. E., Wiersma, W., \& Jurs, S. G. (2003). Applied statistics for the behavioral sciences (5th ed.). New York, NY: Houghton Mifflin.

Hofstede, G. (1980). Motivation, leadership, and organization: Do American theories apply aborad? Organizational Dynamics, 9(1), 42-63.

House, J. S. (1981). Work stress and social support. Reading, MA: AddisonWesley.

Hurrell, J. J., Jr., Nelson, D. L., \& Simmons, B. L. (1998). Measuring job stressors and strains: Where we have been, where we are, and where we need to go. Journal of Occupational Health Psychology, 3(4), 368-389. doi: 10.1037/1076-8998.3.4.368

Ironson, G., Wynings, C., Schneiderman, N., Baum, A., Rodriguez, M. T. V., Greenwood, D., . . . Fletcher, M. A. (1997). Post-traumatic stress sympotms, instrusive thoughts, loss, and immune function after Hurricane Andrew. Psychosomatic Medicine, 59(2), 128-141.

Jauregui, M., \& Schnall, P. L. (2009). Work, psychosocial stressors, and the bottom line. In P. L. Schnall, M. Dobson \& E. Rosskam (Eds.), Unhealthy 
work: Causes, consequences and cures (pp. 153-167). Amityville, NY: Baywood.

Johns, G. (2008). Absenteeism or presenteeism? Attendance dynamics and employee well-being. In S. Cartwright \& C. L. Cooper (Eds.), The Oxford handbook of organizational well-being. Oxford: Oxford University Press.

Johnson, J. V., \& Hall, E. M. (1988). Job strain, work place social support, and cardiovascular disease: A cross-sectional study of a random sample of the Swedish working population. American Journal of Public Health, 78(10), 1336-1342.

Johnson, J. V., Hall, E. M., \& Theorell, T. (1989). Combined effects of job strain and social isolation on cardiovascular disease morbidity and mortality in a random sample of Swedish male working population. Scandinavian Journal of Work, Environment, and Health, 15, 271-279.

Karasek, R. A. (1979). Job demands, job decision latitude, and mental strain: Implications for job redesign. Administrative Science Quarterly, 24(2), 285308.

Karasek, R. A., Kawakami, N., Brisson, C., Houtman, I., Bongers, P., \& Amick, B. (1998). The job content questionnaire (JCQ): An instrument for internationally comparative assessments of psychosocial job characteristics. Journal of Occupational Health Psychology, 3(4), 322-355.

Karasek, R. A., \& Theorell, T. (1990). Heathy work: Stress, productivity, and the reconstruction of working life. New York, NY: Basic Books.

Kawakami, N., Kobayashi, F., Araki, S., Haratini, T., \& Furui, H. (1995). Assessment of job stress dimensions based on Job Demands-Control Model of employees of telecommunications and electric power companies in Japan. International Journal of Behavioural Medicine, 2, 358-375.

Kim, H., \& Stoner, M. (2008). Burnout and turnover intention among social workers: Effects of role stress, job autonomy and social support. Administration in Social Work, 32(3), 5-25. doi: 10.1080/03643100801922357

Kivimäki, M., Virtanen, M., Elovainio, M., Kouvonen, A., Väänänen, A., \& Vahtera, J. (2006). Work stress in the etiology of coronary heart diseasea meta-analysis. Scandinavian Journal of Work, Environment \& Health, 32(6), 431-442. doi: 10.5271/sjweh.1049

Kompier, M. A., \& di Martino, V. (1995). Review of bus drivers' occupational stress and stress prevention. Stress Medicine, 11(1), 253-262. 
Kornitzer, M., deSmet, P., Sans, S., Dramaix, M., Boulenguez, C., DeBacker, G., ... Wilhelmsen, L. (2006). Job stress and major coronary events: Results from the job stress, absenteeism and coronary heart disease in Europe study. Euroupean Journal of Cardiovascular Prevention \& Rehabilitation, 13(5), 695-704. doi: 10.1097/01.hjr.0000221865.19415.e9

Koukoulaki, T. (2010). New trends in work environment. Safety Science, 48(8), 936-942. doi: 10.1016/j.ssci.2009.04.003

Kristof-Brown, A. L., Zimmerman, R. D., \& Johnson, E. C. (2005). Consequences of individuals' fit at work: A meta-analysis of person-job, personorganization, person-group, and person-supervisor fit. Personnel Psychology, 58(2), 281-342.

Kristof, A. L. (1996). Person-organization fit: An integrative review of its conceptualizations, measurement, and implications. Personnel Psychology, 49(1), 1-49. doi: 10.1111/j.1744-6570.1996.tb01790.x

Kuhlmann, T. M. (1990). Coping with occupational stress among urban bus and tram drivers. Journal of Occupational Psychology, 63, 89-96.

Kuper, H., Singh-Manoux, A., Siegrist, J., \& Marmot, M. (2002). When reciprocity fails: effort-reward imbalance in relation to coronary heart disease and health functioning within the Whitehall II study. Occupational and Environmental Medicine, 59(11), 777-784. doi: 10.1136/oem.59.11.777

Landsbergis, P. A. (1988). Occupational stress among health care workers: A test of job demands-control model. Journal of Organizational Behavior, 9, 217-239.

Landsbergis, P. A., Schnall, P. L., Belkic, K. L., Baker, D., Schwartz, J. E., \& Pickering, T. G. (2011). Workplace and cardiovascular disease:

Relevance and potential role for occupational health psychology. In J. C. Quick \& L. E. Tetrick (Eds.), Handbook of occupational health psychology (2nd ed., pp. 243-264). Washington, DC: American Psychological Association.

Landsbergis, P. A., Schnall, P. L., Pickering, T. G., Warren, K., \& Schwartz, J. E. (2003). Life-course exposure to job strain and ambulatory blood pressure in men. American Journal of Epidemiology, 157(11), 998-1006. doi: 10.1093/aje/kwg095

Lazarus, R. S. (1984). On the primacy of cognition. American Psychologist, 39(2), 124-129. 
Lazarus, R. S. (1993). Coping theory and research: Past, present, and future. Psychosomatic Medicine, 55, 234-247.

Lazarus, R. S. (1995). Psychological stress in the workplace. In R. Crandall \& P. L. Perrewe (Eds.), Occupational stress: A handbook (pp. 3-14). Washington, DC: Taylor \& Francis.

Lazarus, R. S. (1996). The role of coping in the emotions and how coping changes over the life course. In C. Maletesta-Magni \& S. H. McFadden (Eds.), Handbook of emotion, adult development, and aging. New York, NY: Academic Press.

Lazarus, R. S. (1999). Stress and emotion. New York: NY: Springer.

Lazarus, R. S. (2000). Toward better research on stress and coping. American Psychologist, 55(6), 665-673. doi: DOI: 10.1037//0003-066X.55.6.665

Lazarus, R. S. (2006). Emotions and interpersonal relationships: toward a person-centered conceptualization of emotions and coping. Journal of Personality, 74(1), 9-46. doi: 10.1111/j.1467-6494.2005.00368.x

Lazarus, R. S., \& Folkman, S. (1984). Stress, appraisal, and coping. New York, NY: Springer.

LeCroy, C., \& Rank, M. (1987). Factors associated with burnout in the social services: An exploratory study. In D. F. Gillespie (Ed.), Burnout among social workers (pp. 23-39). New York, NY: Hawthorne Press.

Lee, R. T., \& Ashforth, B. E. (1996). A meta-analytic examination of the correlates of the three dimensions of job burnout. Journal of Applied Psychology, 81(2), 123-133. doi: 10.1037/0021-9010.81.2.123

Leiter, M. P. (1993). Burnout as a developmental process: Consideration of models. In W. B. Schaufeli, C. Maslach \& T. Marek (Eds.), Professional burnout: Recent developments in theory and research (pp. 237-250). Washington, DC: Taylor \& Francis.

Leiter, M. P., \& Durup, J. (1994). The discriminant validity of burnout and depression: A confirmatory factor analytic study. Anxiety, Stress \& Coping, 7, 357-373.

Leiter, M. P., \& Maslach, C. (1988). The impact of interpersonal environment on burnout and organizational commitment. Journal of Organizational Behavior, 9(4), 297-308. 
Leiter, M. P., \& Maslach, C. (1999). Six areas of worklife: A model of the organziational context of burnout. Journal of Health and Human Science Administration, 21, 472-489.

Lewin, J. E., \& Sager, J. K. (2009). An investigation of the influence of coping resources in salespersons' emotional exhaustion. Industrial Marketing Management, 38(7), 798-805. doi: 10.1016/j.indmarman.2008.02.013

Liu, C., Spector, P. E., \& Shi, L. (2007). Cross-national job stress: a quantitative and qualitative study. Journal of Organizational Behavior, 28(2), 209-239. doi: 10.1002/job.435

Liu, C., Spector, P. E., \& Shi, L. (2008). Use of both qualitative and quantitative approaches to study job stress in different gender and occupational groups. Journal of Occupational Health Psychology; Journal of Occupational Health Psychology, 13(4), 357-370. doi: 10.1037/10768998.13.4.357

Lonne, R. L. (2003). Social workers and human service practitioners. In M. F. Dollard, A. H. Winefield \& H. R. Winefield (Eds.), Occupational stress in the service professions (pp. 281-309). London: Taylor \& Francis.

Losa Iglesias, M. E., Vallejo, R. B. d. B., \& Fuentes, P. S. (2010). The relationship between experiential avoidance and burnout syndrome in critical care nurses: A cross-sectional questionnaire survey. International Journal of Nursing Studies, 47(1), 30-37.

Maslach, C. (2001). What have we learned about burnout and health? Psychology \& Health, 16(5), 607-611. doi: 10.1080/08870440108405530

Maslach, C., \& Jackson, S. E. (1981). The measurement of experienced burnout. Journal of Occupational Behavior, 2, 99-113.

Maslach, C., \& Jackson, S. E. (1984b). Patterns of burnout among a national sample of public contact workers. Journal of Health and Human Resources Administration, 7, 189-212.

Maslach, C., Jackson, S. E., \& Leiter, M. P. (1996). The Maslach Burnout Inventory (3rd ed.). Palo Alto, CA: Consulting Psychologists Press.

Maslach, C., \& Leiter, M. P. (1997). The truth about burnout: How organizations cause personal stress and what to do about it. San Francisco: JosseyBass.

Maslach, C., \& Schaufeli, W. B. (1993). Historical and conceptual development of burnout. In W. B. Schaufeli, C. Maslach \& T. Marek (Eds.), Professional 
burnout: Recent developments in theory and research. Washington, D.C.: Taylor \& Francis.

Mayer, J. D., Salovey, P., \& Caruso, D. (2000). Models of emotional intelligence. In R. J. Sterberg (Ed.), The handbook of intelligence (pp. 396-420). New York: NY: University Press.

Mazzola, J. J., Schonfeld, I. S., \& Spector, P. E. (2011). What qualitative research has taught us about occupational stress. Stress and Health, 27(2), 93-110. doi: 10.1002/smi.1386

Melchior, M., Krieger, N., Kawachi, I., Berkman, L. F., Niedhammer, I., \& Goldberg, M. (2005). Work factors and occupational class disparities in sickness absence: findings from the GAZEL cohort study. American Journal of Public Health, 95(7), 1206-1212. doi: 10.2105/AJPH.2004.048835

Meurs, J. A., \& Perrewé, P. L. (2011). Cognitive Activation Theory of Stress: An Integrative Theoretical Approach to Work Stress. Journal of Management, 37(4), 1043-1068. doi: 10.1177/0149206310387303

Morash, M., Kwak, D.-H., \& Haarr, R. (2006). Gender differences in the predictors of police stress. Policing: An International Journal of Police Strategies \& Management, 29(3), 541-563. doi: $10.1108 / 13639510610684755$

Muchinsky, P. M., \& Monahan, C. J. (1987). What is person-environment congruence? Supplementary versus complementary models of fit. Journal of Vocational Behavior, 31(3), 268-277. doi: 10.1016/00018791(87)90043-1

Murphy, R. L. (2002). Job Stress Research at NIOSH: 1972-2002. In L. P. Perrewe \& C. D. Ganster (Eds.), Historical and Current Perspectives on Stress and Health (Vol. 2, pp. 1-55). Oxford: Elsevier Science.

Nelson, D. L., \& Simmons, B. L. (2011). Savoring eustress while coping with distress: The holistic model of stress. In J. C. Quick \& L. E. Tetrick (Eds.), Handbook of occupational health psychology (2nd ed., pp. 55-74). Washington, DC: American Psychological Association.

Nelson, D. L., \& Sutton, C. (1990). Chronic work stress and coping: A longitudinal study and suggested new directions. Academy of Management Review, 33(4), 859-869. 
Newell, J., \& MacNeil, G. A. (2011). A comparative analysis of burnout and professional quality of life in clinical mental health providers and health care administrators. Journal of Workplace Behavioral Health, 26(1), 25-43.

Nyberg, S. T., Heikkila, K., Fransson, E. I., Alfredsson, L., De Bacquer, D., Bjorner, J. B., . . Kivimaki, M. (2012). Job strain in relation to body mass index: pooled analysis of 160000 adults from 13 cohort studies. Journal of Internal Medicine, 272(1), 65-73. doi: 10.1111/j.1365-2796.2011.02482.x

O'Reilly III, C. A., Chatman, J., \& Caldwell, D. F. (1991). People and organizational culture: A profile comparison approach to assessing person-organization fit. Academy of Management Journal, 34(3), 487-516.

Papadopoulos, G., Georgiadou, P., Papazoglou, C., \& Michaliou, K. (2010). Occupational and public health and safety in a changing work environment: An integrated approach for risk assessment and prevention. Safety Science, 48(8), 943-949. doi: 10.1016/j.ssci.2009.11.002

Pasca, R., \& Wagner, S. L. (2011). Occupational stress in the multicultural workplace. Journal of Immigrant and Minority Health 13(4), 697-705. doi: $10.1007 / \mathrm{s} 10903-011-9457-6$

Pasca, R., \& Wagner, S. L. (2012). Occupational Stress, Mental Health and Satisfaction in the Canadian Multicultural Workplace. Social Indicators Research 109(3), 377-393. doi: 10.1007/s11205-011-9907-5

Pelfrene, E., Vlerick, R. P., Mak, R. P., De Smets, P., Kornitzer, M., \& De Backer, G. (2001). Scale reliability and validity of the Karasek 'Job DemandControl-Support' model in the Belstress study. Work \& Stress, 15(4), 297313.

Perrewé, P. L., \& Zellars, K. L. (1999). An examination of attributions and emotions in the transactional approach to the organizational stress process. Journal of Organizational Behavior, 20(5), 739-752.

Peter, R., Alfredsson, L., Hammar, N., Siegrist, J., Theorell, T., \& Westerholm, P. (1998). High effort, low reward, and cardiovascular risk factors in employed Swedish men and women: baseline results from the WOLF Study. Journal of Epidemiology and Community Health, 52, 540-547.

Pines, A. M. (1993). Burnout: An existential perspective. In W. B. Schaufeli, C. Maslach \& T. Marek (Eds.), Professional burnout (pp. 33-51). Washington, D.C.: Taylor \& Francis.

Pines, A. M., \& Aronson, E. (1988). Career burnout: Causes and cures. New York, NY: Free Press. 
Pisanti, R., van der Doef, M., Maes, S., Lazzari, D., \& Bertini, M. (2011). Job characteristics, organizational conditions, and distress/well-being among Italian and Dutch nurses: A cross-national comparison. International Journal of Nursing Studies. doi: 10.1016/j.ijnurstu.2010.12.006

Purvanova, R. K., \& Muros, J. P. (2010). Gender differences in burnout: A metaanalysis. Journal of Vocational Behavior, 77(2), 168-185. doi: http://dx.doi.org/10.1016/j.jvb.2010.04.006

Rafferty, Y., Friend, R., \& Landsbergis, P. A. (2001). The association between job skill discretion, decision authority and burnout. Work \& Stress, 15(1), 73-85. doi: 10.1080/02678370110064627

Ragland, D., Winkleby, M., Schwalbe, J., Holman, B., Morse, L., Syme, S., \& Fisher, J. (1987). Prevalence of hypertension in bus drivers. International Journal of Epidemiology, 16(2), 208-214.

Reio, T. G. (2010). The threat of common method variance bias to theory building. Human Resource Development Review, 9(4), 405-411. doi: $10.1177 / 1534484310380331$

Reisenzein, R. (1983). The Schachter theory of emotion: Two decades later. Psychological Bulletin, 94(2), 239-264.

Riolli, L., \& Savicki, V. (2003). Optimism and coping as moderators of the relationship between chronic stress and burnout. Psychological Reports, 92(3c), 1215-1226. doi: doi: 10.2466/pr0.2003.92.3c.1215

Rosengren, A., Anderson, K., \& Wilhelmsen, L. (1991). Risk of coronary heart disease in middle-aged male bus and tram drivers compared to men in other occupations: A prospective study. International Journal of Epidemiology, 20(1), 82-87.

Rubin, H. J., \& Rubin, I. S. (2005). Qualitative interviewing: The art of hearing data (2nd ed.). Thousand Oaks, CA: Sage.

Rydstedt, L., Johansson, G., \& Evans, G. W. (1988). A longitudinal study of wokrload, health and well-being among male and female urban bus drivers. Journal of Occupational and Organizational Psychology, 71(1), 35-45.

Sand, G., \& Miyazaki, A. D. (2000). The impact of social support on salesperson burnout and burnout components. Psychology and Marketing, 17(1), 1326.

Sauter, S. L., Murphy, L. R., \& Jurrell, J. J. (1990). Prevention of work-related psychological disorders. American Psychologist, 45, 1146-1158. 
Schachter, S., \& Singer, J. (1962). Cognitive, social and physiological determinants of emotional state. Psychological Review, 69, 379-399.

Schaubroeck, J. (1999). Should the subjective be the objective? On studying mental processes, coping behavior, and actual exposures in organizational stress research. Journal of Organizational Behavior, 20, 753-760.

Schaufeli, W. B., \& Bakker, A. B. (2004). Job demands, job resources, and their relationship with burnout and engagement: a multi-sample study. Journal of Organizational Behavior, 25(3), 293-315.

Schaufeli, W. B., Bakker, A. B., Hoogduin, K., Schaap, C., \& Kladler, A. (2001). On the clinical validity of the Maslach Burnout Inventory and the Burnout Measure. Psychology and Health, 16(5), 565-582.

Schaufeli, W. B., \& Greenglass, E. R. (2001). Introduction to special issue on burnout and health. Psychology \& Health, 16(5), 501-510. doi: 10.1080/08870440108405523

Schaufeli, W. B., Leiter, M. P., \& Maslach, C. (2009). Burnout: 35 years of research and practice. Career Development International, 14(3), 204-220. doi: 10.1108/13620430910966406

Schnall, P. L., \& Landsbergis, P. A. (1994). Job strain and cardiovascular disease. Annual Review of Public Health, 15(381-411).

Schneider, B. (1987). The people make the place. Personnel Psychology, 40, 437-453.

Schwartz, S. H. (1992). Universals in the content and structure of values: Theory and empirical tests in 20 countries. In M. Zanna (Ed.), Advances in experimental social psychology (Vol. 25, pp. 1-65). New York, NY: Academic Press.

Schwartz, S. H., \& Boehnke, K. (2004). Evaluating the structure of human values with confirmatory factor analysis. Journal of Research in Personality, 38(3), 230-255. doi: 10.1016/s0092-6566(03)00069-2

Seyle, H. (1975). Confusion and controversy in the stress field. Journal of Human Stress, 1, 37-44.

Siegrist, J. (1996). Adverse health effects of high-effort/low-reward conditions. Journal of Occupational Health Psychology, 1(1), 27-41. 
Siegrist, J. (2001). A theory of occupational stress. In J. Dunham (Ed.), Stress in the workplace: Past, present and future (pp. 52-66). London: Whurr Publishers.

Siegrist, J. (2002). Effort-Reward imbalance at work and health. In L. P. Perrewe \& C. D. Ganster (Eds.), Historical and current perspectives in stress and health (Vol. 2, pp. 261-291). Oxford: Elsevier Science.

Siegrist, J., \& Peter, R. (1996). Measuring effort-reward imbalance at work: Guidelines. Dusseldorf: Heinrich Heine University.

Siegrist, J., Shackelton, R., Link, C., Marceau, L., von dem Knesebeck, O., \& McKinlay, J. (2010). Work stress of primary care physicians in the US, UK and German health care systems. Social Science \& Medicine, 71(2), 298304. doi: 10.1016/j.socscimed.2010.03.043

Siegrist, J., Siegrist, K., \& Weber, I. (1986). Sociological concepts in the etiology of chronic disease: The case of ischemic heart disease. Social Science \& Medicine, 22(2), 247-253.

Siegrist, J., Starke, D., Chandola, T., Godin, I., Marmot, M., Niedhammer, I., \& Peter, R. (2004). The measurement of effort-reward imbalance at work: European comparisons. Social Science \& Medicine, 58(8), 1483-1499. doi: 10.1016/s0277-9536(03)00351-4

Skinner, E. A., Edge, K., Altman, J., \& Sherwood, H. (2003). Searching for the structure of coping: A review and critique of category systems for classifying ways of coping. Psychological Bulletin, 129(2), 216-269. doi: 10.1037/0033-2909.129.2.216

Skinner, E. A., \& Zimmer-Gembeck, M. J. (2007). The development of coping. Annual Review of Psychology, 58, 119-144. doi: 10.1146/annurev.psych.58.110405.085705

Stansfeld, S. A., Fuhrer, R., Shipley, M. J., \& Marmot, M. G. (1999). Work characteristics predict psychiatric disorder: prospective results form the Whitewall II study. Occupational and Environmental Medicine, 56, 302307.

Stansfeld, S. A., Rasul, F. R., Head, J., \& Singleton, N. (2011). Occupation and mental health in a national UK survey. Social Psychiatry and Psychiatric Epidemiology, 46(2), 101-110. doi: 10.1007/s00127-009-0173-7

Stevens, J. P. (2012). Applied multivariate statistics for the social sciences (5th ed.). New York, NY: Routledge. 
Stewart, W. F., Ricci, J. A., Chee, E., Hahn, S. R., \& Morganstein, D. (2003). Cost of lost productive work time among US workers with depression. Journal of American Medical Association, 289(3), 3135-3144.

Susser, M. (1973). Causal thinking in the health sciences: concepts and strategies in epidemiology. New York: Oxford Press.

Taris, T. W. (2006). Bricks without clay: On urban myths in occupational health psychology. Work \& Stress, 20(2), 99-104. doi:

$10.1080 / 02678370600893410$

Tetrick, L. E., \& Quick, J. C. (2011). Overview of Occupational health psychology: Public health in occupational settings. In J. C. Quick \& L. E. tetrick (Eds.), Handbook of occupational health psychology (2nd ed., pp. 3-20). Washington, DC: American Psychological Association.

The National Academies Press. (2011). The future of nursing: Leading change, advancing health. Washington, DC: The National Academies Press. Retrieved from http://www.nap.edu/openbook.php?record_id=12956\&page

Theorell, T. (1999). How to deal with stress in organizations? A health perspective on theory and practice. Scandinavian Journal of Work, Environment, and Health, 25(6,special issue), 616-624.

Toppinen-Tanner, S., Ojajarvi, A., Vaananen, A., Kalimo, R., \& Jappinen, P. (2005). Burnout as a predictor of medically certified sick-leave absences and their diagnosed causes. Behavioral Medicine, 31(1), 18-32.

Triandis, H. C. (1989). The self and social behavior is differing cultural contexts. Psychological Review, 96(3), 506-520.

Trochim, W. M. K., \& Donnelly, J. P. (2008). The research methods knowledge base (3rd ed.). Mason, OH: Atomic Dog.

Tse, J. L. M., Flin, R., \& Mearns, K. (2006). Bus driver well-being review: 50 years of research. Transportation Research Part F: Traffic Psychology and Behaviour, 9(2), 89-114. doi: 10.1016/j.trf.2005.10.002

Um, M., \& Harrison, D. F. (1998). Role stressors, burnout,mediators, and job satisfaction: A stress-strain-outcome model and an empirical test. Social Work Research, 22, 100-115.

Van der Doef, M., \& Maes, S. (1999). The job demand-control-support model and psychological well-being: A review of 20 years of empirical research. Work \& Stress: An International Journal of Work, Health \& Organisations, 13(2), 87-114. doi: 10.1080/026783799296084 
Van der Klink, J. L., Blonk, R. W. B., Schene, A. H., \& Van Dijk, F. J. H. (2001). The benefits of interventions for work-related stress. American Journal of Public Health, 91(2), 270-276.

van Vegchel, N., de Jonge, J., Bosma, H., \& Schaufeli, W. B. (2005). Reviewing the effort-reward imbalance model: Drawing up the balance of 45 empirical studies. [Research Support, Non-U.S. Gov't]. Social Science \& Medicine, 60(5), 1117-1131. doi: 10.1016/j.socscimed.2004.06.043

Vandenberg, R. J., Kyoung-Ok, P., DeJoy, D. M., Wilson, M. G., \& Griffin-Blake, C. S. (2002). The healthy work organization model: Expanding the view of individual health and well being in the workplace. In L. P. Perrewe \& C. D. Ganster (Eds.), Historical and Current Perspectives on Stress and Health (Vol. 2, pp. 57-115). Oxford: Elsevier Science.

Vasan, R. S., Larson, M. G., Leip, E. P., Evans, J. C., O'Donnel, C. J., Kannel, W. B., \& Levy, D. (2001). Impact of high-normal blood pressure on the risk of cardiovascular disease. The New England Journal of Medicine, 346(18), 1291-1297.

Waldman, J. D., Kelly, F., Aurora, S., \& Smith, H. L. (2004). The Shocking Cost of Turnover in Health Care. Health Care Management Review, 29(1), 2-7.

Webster, J. R., Beehr, T. A., \& Love, K. (2011). Extending the challengehindrance model of occupational stress: The role of appraisal. Journal of Vocational Behavior, 79(2), 505-516. doi: 10.1016/j.jvb.2011.02.001

Winnubst, J. (1993). Organizational structure, social support, and burnout. In W. B. Schaufeli, C. Maslach \& T. Marek (Eds.), Professional burnout: Recent developments in theory and research (pp. 151-162). Washington, D.C.: Taylor \& Francis.

Wofford, J. C., \& Daly, P. S. (1997). A cognitive-affective approach to understanding individual differences in stress propensity and resultant strain. Journal of Occupational Health Psychology, 2(2), 134-147.

Wu, H., Chi, T. S., Chen, L., Wang, L., \& Jin, Y. P. (2010). Occupational stress among hospital nurses: cross-sectional survey. Journal of Advanced Nursing, 66(3), 627-634. doi: 10.1111/j.1365-2648.2009.05203.x

Zajonc, R. B. (1980). Feeling and thinking: Prefernces need no inferences. American Psychologist, 35(2), 151-175. 


\section{APPENDIX}

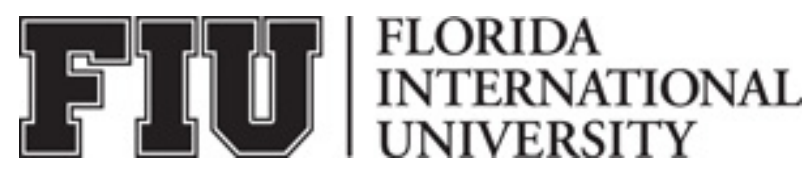

ADULT VERBAL CONSENT TO PARTICIPATE IN A RESEARCH STUDY

The Relationship between Job Structure, Burnout, and Coping Methods among County Bus Drivers, Aides, Mechanics, and Clerical Workers

Hello, my name is Monica Restrepo. You have been chosen at random to be in a research study about stress at work. The purpose of this study is to measure your stress at work and see how each person copes with this stress. If you decide to be in this study, you will be one of about 1,140 people in this research study. Participation in this study will take about 25-30 minutes of your time. If you agree to be in the study, I will ask you to do the following things:

You will be asked to fill out a questionnaire. There are no foreseeable risks or benefits to you for participating in this study. It is expected that this study will benefit society by showing how changes in the way jobs are set up within the county transportation system, in addition to the ways workers cope with stress can help alleviate stress at work.

There is no cost to you.

You will remain anonymous. In any sort of report we might publish, we will not include any information that will make it possible to identify you as a subject. Research records will be stored securely and only the researcher team will have access to the records.

If you have questions for one of the researchers conducting this study, you may contact Me, Monica Restrepo. If you would like to talk with someone about your rights of being a subject in this research study or about ethical issues with this research study, you may contact the FIU Office of Research Integrity by phone at 305-348-2494 or by email at ori@fiu.edu.

Your participation in this research is voluntary, and you will not be penalized or lose benefits if you refuse to participate or decide to stop. If you consent to participate, please continue with this survey. Thank you. 
Please check off the answer each question with the best answer available. If there is a space next to the question, please write in your answer.

1. What is your job title?

O Bus Driver O Bus Driver Aide OMechanic OClerical worker

2. How long have you been in this job title?

3. What is your shift?

4. Do you work full time or part time? O Full time OPart time

5. What is your race? OBlack O Hispanic OWhite OOther

6. What is your age?

7. Sex OMale OFemale

8. What is your marital status?

OSingle OMarried ODivorced/Separated OWidowed

9. What is your education? (highest grade completed)

- Elementary School

- Junior High School

- High School

- Junior College (1-2 years of college)

- College graduate

- Graduate school

10. What is your weight?

11. What is your height?

12. Do you have diabetes Type $2 ?$

OYes O No

13. Do you have high cholesterol?

OYes O No

14. Do you have high blood pressure? O Yes O No 
Please answer every item. There are no "right" or "wrong" answers. Please answer what is most accurate for YOU.

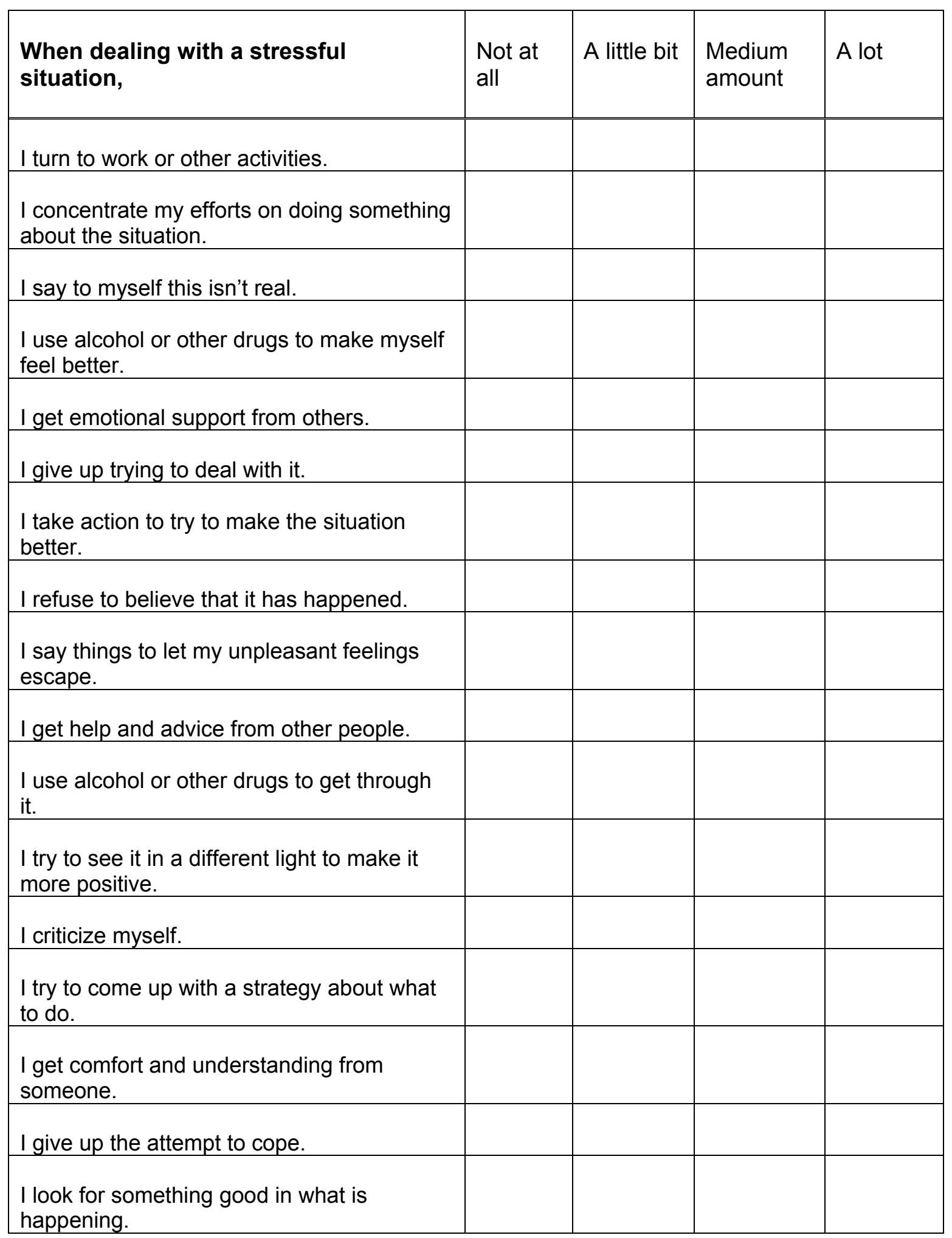


Please answer every item. There are no "right" or "wrong" answers. Please answer what is most accurate for YOU.

\begin{tabular}{|l|l|l|l|l|}
\hline When dealing with a stressful situation, & $\begin{array}{l}\text { Not at } \\
\text { all }\end{array}$ & $\begin{array}{l}\text { A little } \\
\text { bit }\end{array}$ & $\begin{array}{l}\text { Medium } \\
\text { amount }\end{array}$ & A lot \\
\hline I make jokes about it. & & & & \\
\hline $\begin{array}{l}\text { I do something to think about it less such going } \\
\text { to the movies, watching TV., reading, } \\
\text { daydreaming, sleeping, or shopping. }\end{array}$ & & & & \\
\hline $\begin{array}{l}\text { I accept the reality of the fact that it has } \\
\text { happened. }\end{array}$ & & & & \\
\hline I express my negative feelings. & & & & \\
\hline $\begin{array}{l}\text { I try to find comfort in my religion or spiritual } \\
\text { beliefs. }\end{array}$ & & & & \\
\hline $\begin{array}{l}\text { I try to get advice or help from other people } \\
\text { about what to do. }\end{array}$ & & & & \\
\hline I learn to live with it. & & & & \\
\hline I think hard about what steps to take. & & & & \\
\hline I blame myself for things that happen. & & & & \\
\hline I pray or meditate. & & & & \\
\hline I make fun of the situation. & & & & \\
\hline
\end{tabular}


Please read each statement carefully and please state if you ever feel this way about your job.

\begin{tabular}{|c|c|c|c|c|c|c|c|}
\hline $\begin{array}{l}\text { Check the box that best } \\
\text { describes how often you } \\
\text { feel this way. }\end{array}$ & Never & $\begin{array}{l}\text { A few } \\
\text { times a } \\
\text { year }\end{array}$ & $\begin{array}{l}\text { Once } \\
\text { a } \\
\text { month }\end{array}$ & $\begin{array}{l}\text { A few } \\
\text { times } \\
\text { a } \\
\text { month }\end{array}$ & $\begin{array}{l}\text { Once } \\
\text { a } \\
\text { week }\end{array}$ & $\begin{array}{l}\text { A few } \\
\text { times } \\
\text { a } \\
\text { week }\end{array}$ & $\begin{array}{l}\text { Every } \\
\text { Day }\end{array}$ \\
\hline I feel emotionally drained. & & & & & & & \\
\hline $\begin{array}{l}\text { I feel used up at the end of } \\
\text { the workday. }\end{array}$ & & & & & & & \\
\hline $\begin{array}{l}\text { I feel tired when I get up in } \\
\text { the morning and I have to } \\
\text { face another day at the job. }\end{array}$ & & & & & & & \\
\hline $\begin{array}{l}\text { I can easily understand } \\
\text { how the people I interact } \\
\text { with at work feel about } \\
\text { things. }\end{array}$ & & & & & & & \\
\hline $\begin{array}{l}\text { I feel I treat the people I } \\
\text { interact with at work as if } \\
\text { they were impersonal } \\
\text { objects. }\end{array}$ & & & & & & & \\
\hline $\begin{array}{l}\text { Working with people all day } \\
\text { is really a strain for me. }\end{array}$ & & & & & & & \\
\hline $\begin{array}{l}\text { I deal very effectively with } \\
\text { the problems of the people } \\
\text { I interact with at work. }\end{array}$ & & & & & & & \\
\hline $\begin{array}{l}\text { I feel burned out from my } \\
\text { work. }\end{array}$ & & & & & & & \\
\hline $\begin{array}{l}\text { I feel I'm positively } \\
\text { influencing other people's } \\
\text { lives through my work. }\end{array}$ & & & & & & & \\
\hline $\begin{array}{l}\text { I've become more } \\
\text { insensitive toward people } \\
\text { since I took this job. }\end{array}$ & & & & & & & \\
\hline $\begin{array}{l}\text { I worry that this job is } \\
\text { hardening me emotionally. }\end{array}$ & & & & & & & \\
\hline I feel very energetic & & & & & & & \\
\hline
\end{tabular}


Please read each statement carefully and please state if you ever feel this way about your job.

\begin{tabular}{|c|c|c|c|c|c|c|c|}
\hline $\begin{array}{l}\text { Check the box that best } \\
\text { describes how often you } \\
\text { feel this way. }\end{array}$ & Never & $\begin{array}{l}\text { A few } \\
\text { times } \\
\text { a year }\end{array}$ & $\begin{array}{l}\text { Once } \\
\text { a } \\
\text { month }\end{array}$ & $\begin{array}{l}\text { A few } \\
\text { times } \\
\text { a } \\
\text { month }\end{array}$ & $\begin{array}{l}\text { Once } \\
\text { a } \\
\text { week }\end{array}$ & $\begin{array}{l}\text { A few } \\
\text { times } \\
\text { a } \\
\text { week }\end{array}$ & $\begin{array}{l}\text { Every } \\
\text { Day }\end{array}$ \\
\hline I feel frustrated by my job. & & & & & & & \\
\hline $\begin{array}{l}\text { I feel I'm working too hard } \\
\text { on my job. }\end{array}$ & & & & & & & \\
\hline $\begin{array}{l}\text { I don't really care what } \\
\text { happens to the people I } \\
\text { interact with at work. }\end{array}$ & & & & & & & \\
\hline $\begin{array}{l}\text { Working with people } \\
\text { directly puts too much } \\
\text { stress on me. }\end{array}$ & & & & & & & \\
\hline $\begin{array}{l}\text { I can easily create a } \\
\text { relaxed atmosphere with } \\
\text { others at work. }\end{array}$ & & & & & & & \\
\hline $\begin{array}{l}\text { I feel joyful after working } \\
\text { closely with others at work. }\end{array}$ & & & & & & & \\
\hline $\begin{array}{l}\text { I have accomplished many } \\
\text { worthwhile things in this } \\
\text { job. }\end{array}$ & & & & & & & \\
\hline $\begin{array}{l}\text { I feel like I'm at the end of } \\
\text { my rope. }\end{array}$ & & & & & & & \\
\hline $\begin{array}{l}\text { In my work, I deal with } \\
\text { emotional problems very } \\
\text { calmly. }\end{array}$ & & & & & & & \\
\hline $\begin{array}{l}\text { I feel the people I interact } \\
\text { with at work blame me for } \\
\text { some of their problems. }\end{array}$ & & & & & & & \\
\hline
\end{tabular}


Please check the answer that comes closest to answering the question.

\begin{tabular}{|c|c|c|c|c|}
\hline $\begin{array}{l}\text { Check the box that describes how much } \\
\text { you agree or disagree with each statement. }\end{array}$ & $\begin{array}{l}\text { Strongly } \\
\text { disagree }\end{array}$ & Disagree & Agree & $\begin{array}{l}\text { Strongly } \\
\text { agree }\end{array}$ \\
\hline My job requires that I learn new things. & & & & \\
\hline My job involves a lot of repetitive work. & & & & \\
\hline My job requires me to be creative. & & & & \\
\hline My job requires a high level of skill. & & & & \\
\hline $\begin{array}{l}\text { I get to do a variety of different things on my } \\
\text { job. }\end{array}$ & & & & \\
\hline $\begin{array}{l}\text { I have an opportunity to develop my own } \\
\text { special abilities. }\end{array}$ & & & & \\
\hline $\begin{array}{l}\text { My job allows me to make a lot of decisions on } \\
\text { my own. }\end{array}$ & & & & \\
\hline $\begin{array}{l}\text { On my job, I have very little freedom to decide } \\
\text { how I do my work. }\end{array}$ & & & & \\
\hline $\begin{array}{l}\text { I have a lot of say about what happens on my } \\
\text { job. }\end{array}$ & & & & \\
\hline $\begin{array}{l}\text { I have a significant influence over decisions in } \\
\text { my work group or unit. }\end{array}$ & & & & \\
\hline $\begin{array}{l}\text { My work group makes decisions } \\
\text { democratically. }\end{array}$ & & & & \\
\hline $\begin{array}{l}\text { I have at least some chance that my ideas will } \\
\text { be considered about company policy (such as } \\
\text { hiring, firing, wage levels, depot closings). }\end{array}$ & & & & \\
\hline My job requires working very fast. & & & & \\
\hline My job requires me working very hard. & & & & \\
\hline $\begin{array}{l}\text { I am not asked to do an excessive amount of } \\
\text { work. }\end{array}$ & & & & \\
\hline I have enough time to get the job done. & & & & \\
\hline $\begin{array}{l}\text { I am free from conflicting demands that others } \\
\text { make. }\end{array}$ & & & & \\
\hline
\end{tabular}


Please check the answer that comes closest to answering the question.

\begin{tabular}{|c|c|c|c|c|}
\hline $\begin{array}{l}\text { Check the box that describes how much } \\
\text { you agree or disagree with each statement. }\end{array}$ & $\begin{array}{l}\text { Strongly } \\
\text { disagree }\end{array}$ & Disagree & Agree & $\begin{array}{l}\text { Strongly } \\
\text { agree }\end{array}$ \\
\hline $\begin{array}{l}\text { My job requires long periods of intense } \\
\text { concentration on the task. }\end{array}$ & & & & \\
\hline $\begin{array}{l}\text { My tasks are often interrupted before they can } \\
\text { be completed, requiring extra attention at a } \\
\text { later time. }\end{array}$ & & & & \\
\hline My job is very hectic. & & & & \\
\hline $\begin{array}{l}\text { Waiting on work from other people or } \\
\text { departments often slows me down on my job. }\end{array}$ & & & & \\
\hline My job requires a lot of physical effort. & & & & \\
\hline $\begin{array}{l}\text { I am often required to move or lift heavy loads } \\
\text { on my job. }\end{array}$ & & & & \\
\hline $\begin{array}{l}\text { My work requires fast and continuous physical } \\
\text { activity. }\end{array}$ & & & & \\
\hline $\begin{array}{l}\text { I am often required to work for long periods } \\
\text { with my body in physically awkward positions. }\end{array}$ & & & & \\
\hline $\begin{array}{l}\text { I am required to work for long periods of time } \\
\text { with my head in arms in physically awkward } \\
\text { positions. }\end{array}$ & & & & \\
\hline My job security is good. & & & & \\
\hline $\begin{array}{l}\text { My prediction for career development and } \\
\text { promotions are good. }\end{array}$ & & & & \\
\hline $\begin{array}{l}\text { My supervisor is concerned about the welfare } \\
\text { of those under him. }\end{array}$ & & & & \\
\hline In five years, my skills will still be valuable. & & & & \\
\hline $\begin{array}{l}\text { My supervisor pays attention to what I am } \\
\text { saying. }\end{array}$ & & & & \\
\hline $\begin{array}{l}\text { I am exposed to hostility or conflict from my } \\
\text { supervisor. }\end{array}$ & & & & \\
\hline
\end{tabular}


Please check the answer that comes closest to answering the question.

\begin{tabular}{|l|l|l|l|l|}
\hline $\begin{array}{l}\text { Check the box that describes how much } \\
\text { you agree or disagree with each statement. }\end{array}$ & $\begin{array}{l}\text { Strongly } \\
\text { disagree }\end{array}$ & Disagree & Agree & $\begin{array}{l}\text { Strongly } \\
\text { agree }\end{array}$ \\
\hline $\begin{array}{l}\text { My supervisor is helpful in getting the job } \\
\text { done. }\end{array}$ & & & & \\
\hline $\begin{array}{l}\text { My supervisor is successful in getting people } \\
\text { to work together. }\end{array}$ & & & & \\
\hline $\begin{array}{l}\text { People I work with are competent in doing } \\
\text { their jobs. }\end{array}$ & & & & \\
\hline $\begin{array}{l}\text { People I work with take a personal interest in } \\
\text { me. }\end{array}$ & & & & \\
\hline $\begin{array}{l}\text { I am exposed to hostility or conflict from the } \\
\text { people I work with. }\end{array}$ & & & & \\
\hline $\begin{array}{l}\text { People I work with are friendly. } \\
\text { People I work with encourage each other to } \\
\text { work together. }\end{array}$ & & & & \\
\hline $\begin{array}{l}\text { People I work with are helpful in getting the } \\
\text { job done. }\end{array}$ & & & & \\
\hline
\end{tabular}




\begin{tabular}{|l|l|l|l|l|}
\hline $\begin{array}{l}\text { Check the box that best answers the } \\
\text { question. }\end{array}$ & $\begin{array}{l}\text { Regular } \\
\text { and } \\
\text { steady }\end{array}$ & Seasonal & $\begin{array}{l}\text { Both } \\
\text { seasonal } \\
\text { and } \\
\text { frequent } \\
\text { lay-offs }\end{array}$ & Other \\
\hline How steady is your work? & & & & \\
\hline
\end{tabular}

\begin{tabular}{|l|l|l|l|l|}
\hline $\begin{array}{l}\text { Check the box that best answers the } \\
\text { question. }\end{array}$ & Never & $\begin{array}{l}\text { Faced the } \\
\text { possibility } \\
\text { once }\end{array}$ & $\begin{array}{l}\text { Faced the } \\
\text { possibility } \\
\text { more than } \\
\text { once }\end{array}$ & Constantly \\
\hline $\begin{array}{l}\text { During the past year, how often were you } \\
\text { in a situation where you faced job loss or } \\
\text { layoff? }\end{array}$ & & & & \\
\hline
\end{tabular}

\begin{tabular}{|l|l|l|l|l|}
\hline $\begin{array}{l}\text { Check the box that best answers the } \\
\text { question. }\end{array}$ & $\begin{array}{l}\text { Not } \\
\text { likely }\end{array}$ & $\begin{array}{l}\text { Not too } \\
\text { likely }\end{array}$ & $\begin{array}{l}\text { Somewhat } \\
\text { likely }\end{array}$ & Very likely \\
\hline $\begin{array}{l}\text { Sometimes people permanently lose jobs } \\
\text { they want to keep. How likely is it that } \\
\text { during the next couple of years you will } \\
\text { lose your present job with your employer? }\end{array}$ & & & & \\
\hline
\end{tabular}


VITA

\section{MONICA RESTREPO}

Born, New York, New York

$1986-1990$

B.S., Criminal Justice

Minor in French

Florida International University

Miami, Florida

1987-1994

Acting District Manager, Store Manager

Southeast Region of Florida

1996-1999

Owner, Piccolini Fashion for Children

Coral Gables, Florida

2000-2001

Teaching Assistant, Research Assistant

College of Education, Florida International University Miami, Florida

2001-2003

Editor in Chief, InFocus Journal

Florida International University

Miami, Florida

2002

Master of Science, International Development

Education

Florida International University

Miami, Florida

Certification in Conflict Resolution and Mediation

Florida International University

Miami, Florida

2003-2013

Vice President, Design Consultant Group

Miami, Florida

$2009-2010$

Director, 21st Century Grant

St. Thomas University

Miami Gardens, Florida

2013

Doctoral Candidate

Florida International University

Miami, Florida 


\section{PUBLICATIONS AND PRESENTATIONS}

Restrepo, M., \& Pilgrim, S. (2011). Caring for the caregiver: Emotional challenges of pediatric palliative care nurses. In M. S. Plakhotnik, S. M. Nielsen, \& D. M. Pane (Eds.), Proceedings of the Tenth Annual College of Education \& GSN Research Conference (pp. 192-199). Miami: Florida International University. http://coeweb.fiu.edu/research_conference/

Ohlrich, N., Restrepo, M., AIGrain, O. (2011). [Review of the book Transformative learning practice: Insights form community, workplace and higher education, by J. Mezirow \& E.W. Taylor \& Associates]. Studies in the Education of Adults, 43(1), 106-108. 